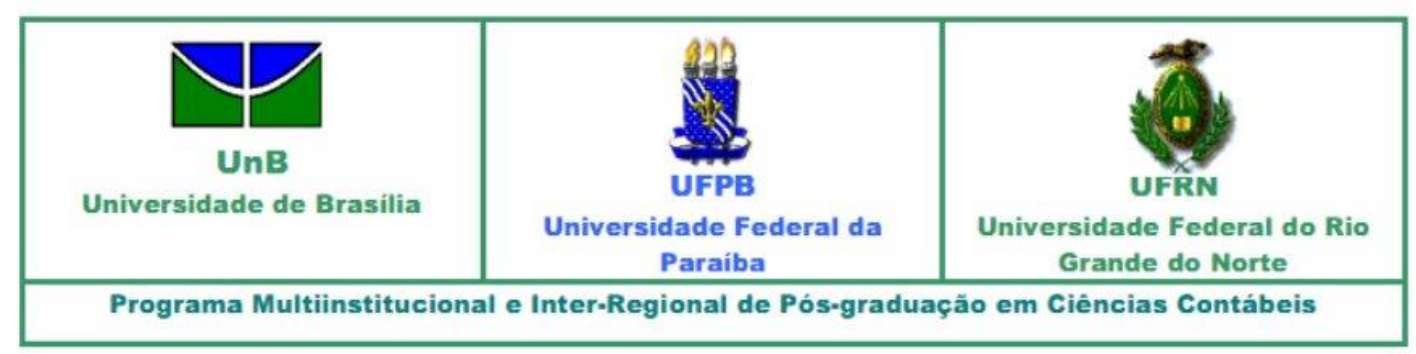

PROGRAMA MULTIINSTITUCIONAL E INTER REGIONAL DE PÓSGRADUAÇÃO EM CIÊNCIAS CONTÁBEIS - UnB/ UFPB/ UFRN

A INFLUÊNCIA DO CONSELHO DE ADMINISTRAÇÃO NA LUCRATIVIDADE DAS EMPRESAS LISTADAS NA BM\&FBOVESPA

Carlos André Marinho Vieira

João Pessoa 
CARLOS ANDRÉ MARINHO VIEIRA

\section{A INFLUÊNCIA DO CONSELHO DE ADMINISTRAÇÃO NA LUCRATIVIDADE DAS EMPRESAS LISTADAS NA BM\&FBOVESPA}

Dissertação de mestrado apresentado ao Programa Multi-institucional e Inter-Regional de PósGraduação em Ciências Contábeis da Universidade de Brasília, Universidade Federal da Paraíba e Universidade Federal do Rio Grande do Norte.

Orientador: Dr. Paulo Aguiar do Monte

Linha de Pesquisa: Contabilidade e Mercado Financeiro 
V658i Vieira, Carlos André Marinho.

A influência do Conselho de Administração na lucratividade das empresas listadas na BM\&FBOVESPA / Carlos André Marinho Vieira.- João Pessoa, 2016.

$75 f$.

Orientador: Paulo Aguiar do Monte

Dissertação (Mestrado) - UnB-UFPB-UFRN

1. Contabilidade. 2. Mercado financeiro. 3. Conselho de Administração. 4. Diretores independentes. 5. Dualidade do CEO. 6. Lucratividade. 


\section{A INFLUÊNCIA DO CONSELHO DE ADMINISTRAÇÃO NA LUCRATIVIDADE DAS EMPRESAS LISTADAS NA BM\&FBOVESPA}

Dissertação apresentada ao Programa Multiinstitucional e Inter-regional de Pós-graduação em Ciências Contábeis da Universidade de Brasília, Universidade Federal da Paraíba e Universidade Federal do Rio Grande do Norte, como requisito à obtenção do título de Mestre em Ciências Contábeis.

Data da aprovação: 04/04/2016

No da Dissertação: 308

BANCA EXAMINADORA:

Prof. Dr. Paulo Aguiar do Monte

Orientador - UnB/UFPB/UFRN

Prof. Dr. Aldo Leonardo Cunha Callado

Membro Examinador Interno - UnB/UFPB/UFRN

Prof. Dr. Cássio da Nóbrega Bessaria

Membro Examinador Externo - UFPB 


\section{AOS MEUS PAIS}

Dedico este trabalho àqueles que me aturam desde o meu nascimento, que apoiaram minha entrada nessa louca vida de acadêmico. 


\section{AGRADECIMENTOS}

Acho que essa parte me deu mais trabalho para fazer que a própria pesquisa em si. São muitos os motivos que tenho para agradecer aos que estiveram comigo durante esta dura jornada. Durante o curso surgiram diversas dúvidas sobre se era realmente isso que eu queria fazer, se teria fôlego para terminar, se não seria melhor ter tomado outro rumo para a minha vida. Diante de tantas dúvidas, não sei se teria conseguido terminar este curso sem a ajuda de tantas pessoas.

(Sempre) em primeiro lugar, gostaria de agradecer aos meus pais, Aparecido e Valdilene, por todo o apoio que tive durante estes dois anos de curso (e desde o nascimento). Estes que nunca deixaram de acreditar em mim, pois mais árdua que fosse a caminhada, que vibraram comigo a cada conquista e que compartilharam cada fracasso. Não poderia ter pedido pais melhores e sei que tudo que consegui até aqui foi graças ao apoio que obtive deles.

Agradeço também ao resto da minha família, de igual importância, começando pelos meus irmãos, Luiz Eduardo, Ana Beatriz e Ana Maria. Cada um destes deu sua contribuição na minha caminhada, seja com um conselho, um abraço (ou até mesmo uma xícara de café). A minha tia Isabel, que sempre foi como uma segunda mãe para mim. Ao xodó da família, Pandora. Ela que esteve comigo desde a minha preparação para a seleção de mestrado. Obrigado por ter devorado metade do meu livro de contabilidade (estava desatualizado mesmo...). São muitas vezes que precisamos de alguém para nos tirar da solidão dos livros e ela nunca saiu de perto de mim.

Por todos os ensinamentos, obrigado a todos os meus professores de curso: Edilson, Wenner, Márcia, Aneide, Paulo Amilton, Adriano, Adilson, Aldo, Paulo Roberto, Orleans e, em especial, ao meu orientador, Paulo Aguiar, pelos ensinamentos, por todo o apoio que tive quando mais precisei e pela boa vontade sempre demonstrada.

Não poderia esquecer de todos meus colegas de curso (aos efetivos e aos adotados) Marcelo, Roberto, Agamenon, Victor Godeiro, Leandro, Victor Araújo, Ana Karla, Inajá, Polyandra, Camila, Fabiana, João Marcelo, Nyalle, Gilberto e José Célio (este último, apesar de não ter comparecido às aulas, nos livrou de ter que apresentar mais seminários, por este motivo, muito obrigado). Todos deixarão uma saudade enorme por todos os momentos compartilhados, seja pelos roncos quando dividimos quartos, pelos cochilos durante as aulas e principalmente pelas sagradas segundas-feiras dedicadas exclusivamente a estudos noturnos aqui em João Pessoa, que tenho certeza serão lembrados para sempre por todos os participantes.

Agradeço ao meu mentor Felipe Pontes por toda a ajuda dada para o meu ingresso no mundo acadêmico. Ao meu amigo Thiago, por ter me introduzido a todos os benefícios que a entrada no mestrado me proporcionaria (ele esqueceu de me falar da parte ruim, mas obrigado assim mesmo). Ao meu amigo Leonard, por uma amizade que já dura décadas.

Poderia fazer menção a várias outras pessoas que foram importantes durante minha vida, mas infelizmente pretendo terminar meus agradecimentos em apenas uma página. A todos os citados e aos não citados nos meus agradecimentos, MUITO OBRIGADO! 
"Valar morghulis"

Arya Stark 


\section{RESUMO}

Os estudos acerca do Conselho de Administração focam principalmente em três de suas características: o tamanho do órgão, sua independência e a dualidade do CEO. O presente estudo teve por objetivo analisar a influência destas três características no desempenho empresarial. Para isso foi utilizada uma amostra composta por 182 empresas abertas nãofinanceiras listadas na BM\&FBOVESPA no período de 2010 a 2014. A metodologia utilizada consistiu no uso de modelos de dados em painel de efeitos fixos (FE) e aleatórios (RE) e regressões quantílicas para verificar a influência de cada característica do Conselho de Administração na lucratividade empresarial. Os modelos de painel indicaram que o tamanho do Conselho de Administração está positivamente relacionado com o desempenho, onde esta variável mostra uma relação forte com algumas das as proxies utilizadas para medir a lucratividade. A dualidade do CEO também apresentou uma relação positiva com o desempenho, porém fraca, visto que esta relação foi observada em apenas uma medida de lucratividade. Já a independência do Conselho de Administração, medida pelo percentual de conselheiros independentes e pelo percentual de conselheiros externos, não mostrou relação com o desempenho. Os resultados para os modelos de regressão quantílica indicaram que o tamanho do Conselho de Administração se relaciona positivamente com a lucratividade, onde esta relação é mais forte apenas quando consideradas as empresas mais lucrativas da amostra.

Palavras-chave: Conselho de Administração; Tamanho; Diretores Independentes, Dualidade do CEO; Lucratividade. 


\begin{abstract}
Research on Board of Directors focuses mainly in three characteristics: board's size, board independence and CEO duality. This study investigates the relation between the three main board characteristics and firm profitability. We analyzed a sample of 182 non-financial firms listed on BM\&FBOVESPA from 2010 to 2014. Using fixed effects and random effects panel data models to assess the relation between board's size, board independence and CEO duality on firm profitability. We also employed quantile regression models to examine this relation. Through panel data models we show that board's size has a positive impact on firm profitability. This relation is strong considering our measures of profitability. CEO duality also showed a positive impact on firm profitability, but this relation is weaker than that which we found assessing board's size. Board independence, measured as the ratio of independent/outside directors over all board members was not correlated with profitability. Quantile regression models indicate that board's size is positively correlated with firm profitability. This relation is strong only when we consider the most profitable firms in our sample.
\end{abstract}

Keywords: Board of directors; Board Size; Independent Directors; CEO duality; Profitability. 


\section{LISTA DE QUADROS}

Quadro 1 - Atribuições do Conselho de Administração.......................................................... Quadro 2 - Influência das características do Conselho de Administração no desempenho e valor de mercado das empresas: Principais resultados obtidos.

Quadro 3 - Resumo das variáveis dependentes e independentes utilizadas na pesquisa, sua forma de mensuração, os trabalhos semelhantes que utilizaram esta variável e o sinal esperado para seu coeficiente angular. 


\section{LISTA DE TABELAS}

Tabela 1 - Estatísticas descritivas da amostra composta por 182 empresas não-financeiras listadas na BM\&FBOVESPA 2010-2014.

Tabela 2 - Empresas que apresentaram os 5 valores máximos e mínimos para as variáveis do estudo 2010-2014..

Tabela 3 - Resultado dos testes de especificação de Sargan-Hansen para a escolha do método de estimação de dados em painel 2010-2014..........................................................................32

Tabela 4 - Resultado das estimações dos modelos de dados em painel para a variável dependente ROA. 2010-2014.

Tabela 5 - Resultado das estimações dos modelos de dados em painel para a variável dependente ROA ajustado. 2010-2014.

Tabela 6 - Resultado das estimações dos modelos de dados em painel para a variável dependente ROE. 2010-2014.

Tabela 7 - Resultado das estimações dos modelos de dados em painel para a variável dependente ROE ajustado. 2010-2014.

Tabela 8 - Resumo dos resultados obtidos quando analisado o reflexo das características do Conselho de Administração na lucratividade empresarial.

Tabela 9 - Resultado das estimações dos modelos de regressão quantílica para a variável dependente ROA. 2014

Tabela 10 - Resultado das estimações dos modelos de regressão quantílica para a variável dependente ROA ajustado. 2014.

Tabela 11 - Resultado das estimações dos modelos de regressão quantílica para a variável dependente ROE. 2014.

Tabela 12 - Resultado das estimações dos modelos de regressão quantílica para a variável dependente ROE ajustado. 2014.

Tabela 13 - Resultado das estimações dos modelos de regressão quantílica para a variável dependente ROA. 2013. .54

Tabela 14 - Resultado das estimações dos modelos de regressão quantílica para a variável dependente ROA ajustado. 2013.

Tabela 15 - Resultado das estimações dos modelos de regressão quantílica para a variável dependente ROE. 2013.

Tabela 16 - Resultado das estimações dos modelos de regressão quantílica para a variável dependente ROE ajustado. 2013.

Tabela 17 - Resultado das estimações dos modelos de regressão quantílica para a variável dependente ROA. 2012

Tabela 18 - Resultado das estimações dos modelos de regressão quantílica para a variável dependente ROA ajustado. 2012.

Tabela 19 - Resultado das estimações dos modelos de regressão quantílica para a variável dependente ROE. 2012. 
Tabela 20 - Resultado das estimações dos modelos de regressão quantílica para a variável

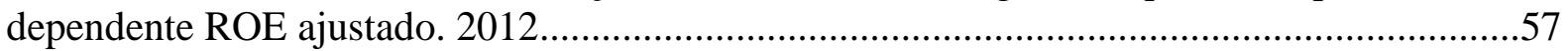

Tabela 21 - Resultado das estimações dos modelos de regressão quantílica para a variável

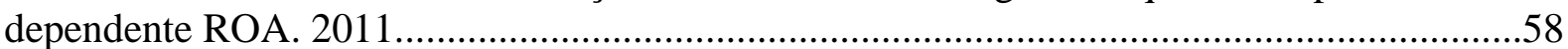

Tabela 22 - Resultado das estimações dos modelos de regressão quantílica para a variável

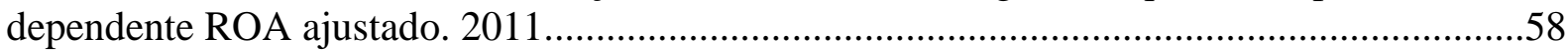

Tabela 23 - Resultado das estimações dos modelos de regressão quantílica para a variável

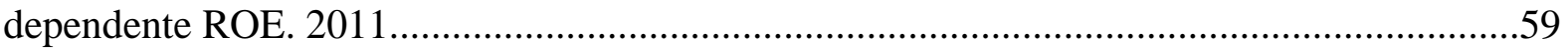

Tabela 24 - Resultado das estimações dos modelos de regressão quantílica para a variável dependente ROE ajustado. 2011.

Tabela 25 - Resultado das estimações dos modelos de regressão quantílica para a variável dependente ROA. 2010

Tabela 26 - Resultado das estimações dos modelos de regressão quantílica para a variável dependente ROA ajustado. 2010 ..60

Tabela 27 - Resultado das estimações dos modelos de regressão quantílica para a variável dependente ROE. 2010 61

Tabela 28 - Resultado das estimações dos modelos de regressão quantílica para a variável dependente ROE ajustado. 2010. 


\section{LISTA DE ABREVIATURAS E SIGLAS}

BM\&FBOVESPA Bolsa de Valores, Mercadorias e Futuros de São Paulo

CA

CEO

CVM

FE

IBGC

LogAtivos

LSDV

PIB

$\mathrm{RE}$

ROA

ROE
Conselho de Administração

Chief Executive Officer

Comissão de Valores Mobiliários

Fixed Effects Within-Group Model

Instituto Brasileiro de Governança Corporativa

Logaritmo dos Ativos Totais

Least Square Dummy Variables

Produto Interno Bruto

Random Effects

Return on Assets

Return on Equity 


\section{SUMÁRIO}

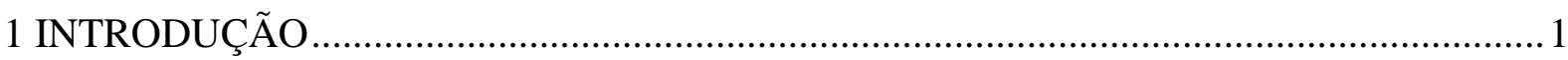

2 FUNDAMENTAÇÃO TEÓRICA: TEORIA DA AGÊNCIA E AS CARACTERÍSTICAS DO CONSELHO DE ADMINISTRAÇÃO ..................................................................... 4

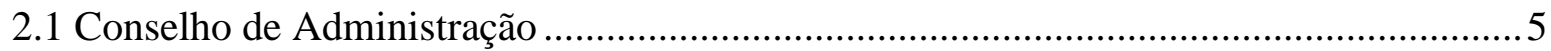

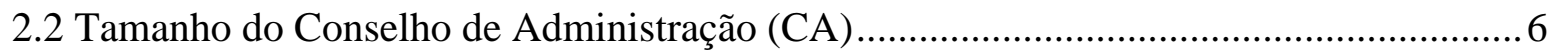

2.3 Independência do Conselho de Administração............................................................ 8

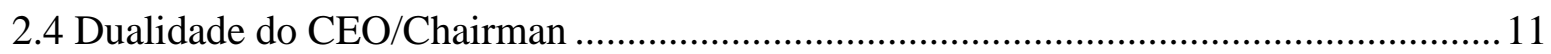

2.5 Literatura empírica sobre as características do Conselho de Administração................... 13

2.5.1 Tamanho do Conselho de Administração ................................................................ 13

2.5.2 Independência do Conselho de Administração ...................................................... 15

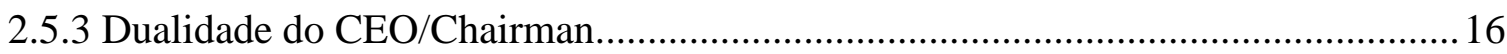

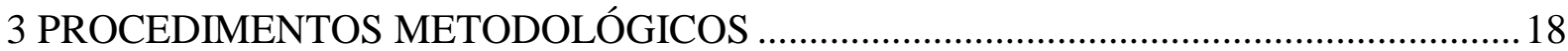

3.1 Especificação dos modelos e variáveis ................................................................... 18

3.2 Escolha dos Estimadores e Testes de Robustez......................................................... 24

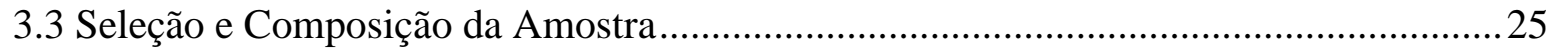

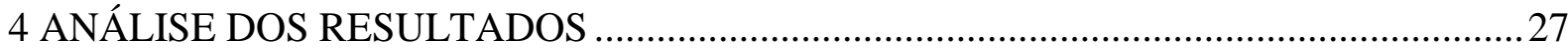

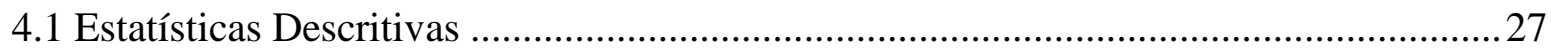

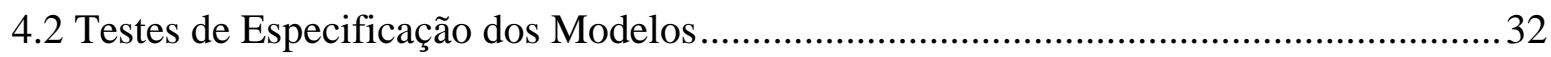

4.3 Resultados das Estimações dos Modelos de Dados em Painel .........................................33

4.4 Resultados das Estimações dos Modelos de Regressão Quantílica................................41

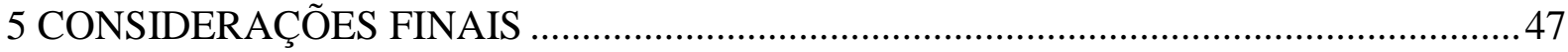

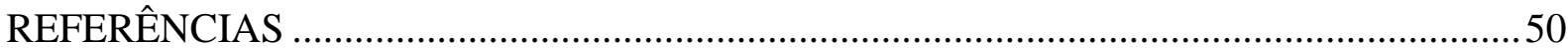

Apêndice I - Resultado das estimações dos modelos de regressão quantílica (2010-2013).....54 


\section{INTRODUÇÃO}

A crise de 2008 intensificou os estudos a respeito da responsabilidade de administradores e conselheiros sobre o resultado das empresas, tendo os estudos a respeito do Conselho de Administração e da monitoração das atividades dos executivos das empresas ganhado ampla importância na literatura mundial depois deste advento (CHOU et al., 2013; LIANG et al., 2013). Apesar do estado da arte encontrar-se bastante desenvolvido na literatura internacional, onde a maioria dos trabalhos se preocupou em estudar o tamanho do Conselho de Administração, sua independência e o nível de atividade (YERMACK, 1996; EISENBERG et al., 1998; VAFEAS, 1999; MAK; KUSNANDI, 2005; COLES et al., 2008; BRICK; CHIDAMBARAN, 2010; CHOU et al., 2013; LIANG et al., 2013), os estudos no Brasil ainda são escassos. Os poucos estudos que existem, dentre os quais os de Andrate et al. (2009) e Gondrige et al. (2012), apresentam resultados divergentes da literatura internacional, o que reforça a necessidade de novos estudos sobre o tema.

O Conselho de Administração (CA) é um órgão colegiado encarregado do monitoramento do comportamento da administração da empresa, sendo considerado o principal mecanismo de governança de uma empresa. Esse órgão tem por função representar o interesse dos acionistas e dos outros stakeholders frente às decisões tomadas pela equipe de gestão. Ao Conselho de Administração é delegado o poder de agir em prol do interesse dos acionistas, supervisionando o comportamento dos principais executivos da empresa de modo a coibir práticas que se mostrem prejudiciais à maximização do valor da empresa no longo prazo (IBGC, 2009). As principais características do Conselho de Administração estudadas são o seu tamanho, a independência de seus membros e a presença do Chief Executive Officer (CEO) como membro do conselho.

A maior parte da literatura internacional que prevê um melhor desempenho para conselhos de administração formados por uma menor quantidade de membros (YERMACK, 1996; EISENBERG et al., 1998). Yermack (1996) cita que a redução do tamanho dos Conselhos de Administração tem se tornado prioridade para alguns agentes de mercado como solução para empresas problemáticas, sendo uma prática utilizada também por grandes empresas no início da década de 1990. Este fato é justificado pela ocorrência de diversos problemas inerentes à formação de grandes grupos, tais como a difícil comunicação e coordenação e uma menor habilidade de grandes grupos controlarem a administração das empresas (EISENBERG et al., 1998). Já os estudos de Andrade et al. (2009) e Gondrige et al. (2012) no mercado brasileiro indicaram que o mercado acionário valoriza as empresas que possuem CAs com um número maior de membros. Porém, é admitido em Andrade et al. (2009) que este número se concentra em uma faixa ótima a partir da qual, com a inclusão de novos membros, o valor de mercado começa a decrescer.

Estes fatores relacionados por Yermack (1996) que afirma que um grupo volumoso teria menos probabilidade de coordenar suas atividades de maneira eficiente justificam a hipótese de que formar um Conselho de Administração com um número de membros elevado seria danoso ao desempenho empresarial. Outra corrente de pensamento considera que um maior número de membros no Conselho permitiria uma maior monitoração das atividades da alta administração (ANDRADE et al., 2009). Este maior nível de monitoração seria reflexo da divisão das tarefas inerentes ao conselho para um maior número de membros, o que evitaria conselheiros sobrecarregados e permitiria que estes desempenhassem suas atividades de maneira mais eficaz. Tomando isto como base, é esperada uma melhora no desempenho empresarial como reflexo do maior nível de monitoração exercido por um Conselho de Administração com maior número de membros (COLES et al., 2008). 
A independência dos membros do Conselho de Administração é vista como um fator que reflete positivamente no desempenho da empresa. Liang et al. (2013, p. 2956) citam que "a presença de diretores independentes nos conselhos tente a diminuir o conflito de interesses e tornar o órgão mais efetivo na redução dos custos de agência". A falta de autonomia dos membros internos do Conselho de Administração decorre do fato de que estes dificilmente seriam imparciais ao avaliar o desempenho da equipe de gestão da qual fazem parte. Ao mesmo tempo, estes profissionais estariam inclinados a não confrontar o CEO ao avaliarem seu desempenho à frente dos negócios, temendo sofrer represálias quando voltassem a executar as tarefas inerentes ao cargo de executivos da empresa (WEISBACH, 1988). Sendo assim, a inclusão de conselheiros independentes/externos aumenta a autonomia do CA e aprimora a realização de suas tarefas, pois muitas dessas demandam um órgão totalmente independente para serem executadas. Estas tarefas incluem vetar projetos que não atendam ao interesse dos acionistas de maximização da sua riqueza e a avaliação do desempenho da equipe de gestão (FAMA; JENSEN, 1983). Portanto, uma maior independência do CA estaria ligada a um melhor desempenho empresarial, em razão de uma maior eficiência do órgão em monitorar e avaliar as ações da administração da empresa.

Por outro lado, a baixa quantidade de membros internos no Conselho de Administração (CA) pode gerar uma maior assimetria entre este órgão e a diretoria executiva, visto que aumentarão os custos de transferência de informações e a qualidade destas entre os gestores e os membros do CA, uma vez que os conhecimentos específicos da equipe de administração sobre as operações da empresa poderiam auxiliar os outros membros na execução de suas tarefas (COLES et al., 2008). A ausência de informações relevantes e tempestivas proveniente da assimetria entre a gestão e o Conselho de Administração comprometeria o processo de tomada de decisão deste último, podendo levar à aprovação de ações danosas ao interesse dos acionistas ou ao veto de projetos de alta qualidade, deteriorando o desempenho empresarial. Estes fatos indicam que, apesar dos benefícios inerentes à adição de membros independentes/externos no Conselho de Administração, um órgão formado exclusivamente por este tipo de conselheiro pode se tornar prejudicial para a empresa.

As boas práticas de governança corporativa têm apontado que o fato de o CEO acumular também o cargo de Presidente do Conselho de Administração (Chairman) faz com que o poder de decisão esteja mais concentrado. Dotado de mais poder, o CEO/Chairman poderia utilizar sua influência para empreender projetos de interesse pessoal, sem se preocupar com a maximização do valor da empresa (FAMA; JENSEN, 1983). Ao mesmo tempo, este agente poderia utilizar seu poder para extrair rendas da empresa em forma de remuneração e outros benefícios que dificilmente lhe seriam concedidos caso este tivesse um menor domínio sobre o Conselho de Administração (BEBCHUK; FRIED, 2003). Ambos fatores contribuem para a deterioração do desempenho empresarial, dados os custos de agência associados a eles. Estes fatores são tomados como base nas recomendações de diversos órgãos quanto à nomeação de duas pessoas distintas para estes cargos.

Por outro lado, a separação de funções poderia trazer custos extras para a empresa. No caso da indicação de outro indivíduo para o cargo de Chairman, maior monitoração é demandada sobre o seu comportamento, pois este agente também estaria provido de poder e influência para extrair rendas extraordinárias da empresa. Um maior nível de monitoramento geraria mais custos de agência, diminuindo a lucratividade do empreendimento; assim como os custos de transferência de informações, visto que o Chairman necessita de informações específicas que estarão em poder do CEO, onde muitas vezes estas informações podem ser passadas de forma incompleta, prejudicando o desempenho empresarial (BRICKLEY et al., 1997). Apesar da maior parte dos estudos ligar a acumulação dos cargos de CEO/Chairman a 
um baixo desempenho, reflexo da tendência do CEO maximizar sua própria utilidade em detrimento da riqueza dos acionistas (FAMA; JENSEN, 1983; BEBCHUK; FRIED, 2003), a acumulação destes cargos pode reduzir outros custos de agência associados à monitoração de um CEO e Chairman distintos.

Partindo destes pressupostos discutidos com base na literatura sobre o tema, esta dissertação analisará a influência do Conselho de Administração (CA) no desempenho das empresas listadas na Bolsa de Valores, Mercadorias e Futuros de São Paulo (BM\&FBOVESPA). Para atingir este objetivo, fez-se uso de uma amostra composta pelas empresas listadas na bolsa brasileira durante o período de 2010 a 2014. O período foi escolhido em razão da disponibilidade das informações sobre a estrutura do CA de cada empresa de forma detalhada, informações exigidas a partir do ano de 2010 pela Instrução CVM n ${ }^{\circ} 480$, aprovada no ano de 2009. Foram coletadas informações acerca das das principais características do Conselho de Administração e seus possíveis impactos na lucratividade das empresas. A lucratividade empresarial foi mensurada a partir de quatro proxies: Retorno sobre os Ativos Totais (Return on Assets - ROA), ROA ajustado à mediana do setor, Retorno sobre o Patrimônio Líquido (Return on Equity - ROE) e o ROE ajustado à mediana do setor.

A metodologia econométrica adotada para a análise foi o método de regressão com dados em painel, que, dentre outras vantagens em relação aos modelos de regressão em cortes transversais, possui o fato de apresentar menos colinearidade entre as variáveis, mais graus de liberdade e mais eficiência (BALTAGI, 2005). Adicionalmente, também foi utilizado o método de regressão quantílica, que é mais robusto a valores extremos comparativamente aos modelos de painel, sendo seu uso crescente nas pesquisas no campo de contabilidade e administração.

Este trabalho procura se diferenciar dos demais (ANDRADE et al., 2009; GONDRIGE et al., 2012) por ter utilizado um período mais amplo, uma metodologia diferenciada e por utilizar variáveis representativas da lucratividade que consideram não apenas a lucratividade individual, mas a lucratividade ajustada à mediana do setor, estabelecendo um benchmark para avaliar a influência das características do Conselho de Administração no desempenho das empresas listadas em relação ao setor econômico em que atuam.

Sendo assim, esta dissertação buscou analisar empiricamente a influência do tamanho do Conselho de Administração, da sua independência e da dualidade do CEO/Chairman no desempenho das empresas. As principais evidências encontradas nos resulados deste trabalho parecem contradizer o esperado pela Teoria da Agência, de que uma maior concentração de poder resultado da dualidade do CEO/Chairman prejudicaria o desempenho das empresas (FAMA; JENSEN, 1983). Os resultados aqui alcançados indicam que uma estrutura de poder unitária, onde o CEO exerce também o cargo de Chairman, está ligada a uma maior lucratividade empresarial, assim como esperado por Donaldson e Davis (1991) e Brickley et al. (1997), indo de encontro às recomendações sobre governança corporativa dos principais órgãos brasileiros ligados ao tema, como mostrado ao decorrer do texto. Por outro lado, alguns achados estão em convergência com os trabalhos nacionais, sobretudo no referente ao tamanho do Conselho de Administração que se relaciona de forma positiva com o desempenho empresarial (ANDRADE et al., 2009).

Além desta introdução, esta dissertação contém mais 4 capítulos. O capítulo 2 refere-se à fundamentação teórica, que trata da Teoria da Agência, da importância do Conselho de Administração como ferramenta de governança corporativa e de suas principais características. O capítulo 3 expõe a metodologia e a amostra utilizada. No capítulo 4 são discutidos os resultados encontrados, enquanto, por fim, no capítulo 5 são apresentadas as considerações finais sobre a pesquisa desenvolvida. 


\section{FUNDAMENTAÇÃO TEÓRICA: TEORIA DA AGÊNCIA E AS CARACTERÍSTICAS DO CONSELHO DE ADMINISTRAÇÃO}

Os estudos acerca das características do Conselho de Administração têm por base a Teoria da Firma e o conflito de interesses entre os acionistas e a alta administração. Segundo a Teoria da Firma, as empresas representam uma ligação de contratos entre os possuidores dos fatores de produção e seus clientes, onde tais contratos especificam os direitos de cada agente dentro da organização. A empresa formada por esse emaranhado de contratos tem por objetivo entregar o resultado demandado por seus clientes ao menor preço possível, sob o risco de não conseguir sobreviver num mercado competitivo. A maioria dos riscos assumidos no negócio será suportada pelos proprietários, ou reclamantes residuais, os quais têm direito ao fluxo de caixa líquido, onde os contratos que melhor atendem aos interesses desses reclamantes aumentam o valor da empresa (FAMA; JENSEN, 1983).

Comparando-se as empresas abertas e fechadas (sendo estas últimas aquelas que não negociam seus valores mobiliários no mercado de capitais), a separação entre propriedade e controle torna-se mais clara, onde nas empresas fechadas predominam os acionistas internos à empresa, com participação muito maior sobre as decisões tomadas. Nas empresas abertas a figura do administrador profissional está muito mais difundida. Segundo Fama e Jensen (1983), o risco assumido por este tipo de profissional (administrador) em nome da empresa depende da estrutura dos contratos firmados entre o principal (proprietários) e os agentes (administradores) e suas políticas de remuneração e mensuração de desempenho.

Conforme Fama e Jensen (1983), o processo de decisão é dividido em quatro etapas e alocadas entre os agentes da empresa: a) iniciação (geração de propostas para a utilização dos recursos e estruturação de contratos); b) homologação (escolha das iniciativas a serem implantadas); c) implementação (execução das iniciativas implementadas); e d) monitoração (mensuração de desempenho e política de recompensas). A partir daí surge o chamado problema agente-principal, onde o agente (administrador) tenderá a agir em prol de seus próprios interesses, maximizando sua utilidade pessoal ao invés de agir em prol do interesse do principal (proprietários), maximizando a riqueza destes.

A relação de agência ocorre quando um serviço é executado por uma ou mais pessoas (agente(s)) em nome de outra (principal(is)) através de um contrato que delega autoridade a este agente, onde este nem sempre agirá de forma a tomar decisões ótimas sob o ponto de vista do principal. Tomando-se por base o problema do agente-principal, denominam-se de "custos de agência" os custos incorridos pelo principal para que o agente tenha maior probabilidade de agir em prol da maximização da sua riqueza. Os custos de agência são a soma das despesas de monitoração incorridas pelo principal, despesas referentes ao comprometimento do agente em tomar decisões ótimas sobre o ponto de vista do principal (bonding costs) e perdas residuais, sendo estas últimas toda a redução da riqueza do principal causada pela relação de divergência entre os interesses deste com os interesses do agente (JENSEN; MECKLING, 1976).

Para assegurar que o agente executará ações que visem a maximização da riqueza do principal e que este tomará decisões ótimas para este fim, o principal se utilizará de mecanismos que têm por objetivo a monitoração das atividades do agente. Estes mecanismos deverão limitar qualquer comportamento que seja considerado prejudicial aos acionistas, além de ferramentas e contratos que alinhem os interesses do agente aos seus, de modo a diminuir o conflito de interesses entre eles. 


\subsection{Conselho de Administração}

O Conselho de Administração (CA) é considerado por Silveira (2010) e Chou et al. (2013) como o principal órgão a posicionar-se sobre as questões estratégicas das empresas. A principal função do Conselho de Administração é monitorar o comportamento dos executivos, sendo seu papel principal a restrição de qualquer comportamento da administração considerado oportunista, protegendo o patrimônio dos acionistas de qualquer decisão que seja tomada e vá de encontro aos seus interesses.

Para Jensen (1993, p. 862), é papel do Conselho de Administração "contratar, destituir e recompensar o CEO, e provê-lo de orientação de alto nível". Este mesmo autor destaca ainda a cultura dos conselhos de administração em dar grande ênfase à cortesia e benevolência ao invés de pressionar os CEOs durante as reuniões, onde os conflitos são desencorajados. Tal comportamento estaria ligado às falhas ocorridas na monitoração e avaliação de desempenho da administração.

De acordo com Chou et al. (2013), o CA das empresas é considerado por muitos autores o principal mecanismo de monitoramento das atividades do agente, tendo três funções principais: a) monitoração das atividades, do desempenho e da remuneração recebida pelos administradores; b) assessoramento; e c) contratação. Chou et al. (2013) citam ainda que são as reuniões do conselho o principal veículo de disseminação e coleta de informações, tomada de decisão e monitoração da equipe de gestão.

O Conselho de Administração é considerado pelo Instituto Brasileiro de Governança Corporativa (IBGC) como o principal componente do sistema de governança de uma empresa, sendo o principal elo entre a administração da empresa e os acionistas e demais partes interessadas no negócio, tendo este o dever de monitorar a ação da administração e prestar contas aos sócios, além de agir em prol da maximização da riqueza das partes interessadas (shareholders e demais stakeholders). Conforme o Código das Melhores Práticas de Governança Corporativa do IBGC, as principais responsabilidades do Conselho de Administração estão listadas no Quadro 1.

Quadro 1 - Atribuições do Conselho de Administração

\section{Principais responsabilidades do Conselho de Administração}

Dentre as responsabilidades do Conselho de Administração, destacam-se a discussão, aprovação e monitoramento de decisões, envolvendo:

- Estratégia;

- Estrutura de capital;

- Apetite e tolerância ao risco;

- Fusões e aquisições;

- Contratação, dispensa, avaliação e remuneração do diretor-presidente e dos demais executivos, a partir da proposta apresentada pelo diretor-presidente;

- Escolha e avaliação da auditoria independente;

- Processo sucessório dos conselheiros e executivos;

- Práticas de Governança Corporativa;

- Relacionamento com partes interessadas;

- Sistemas de controles internos (incluindo políticas e limites de alçada);

- Práticas de gestão de pessoas;

- Código de Conduta.

Fonte: Adaptado de IBGC (2009, p. 30)

Além das melhores práticas sugeridas pelos diversos códigos de governança corporativa, é importante também observar as atribuições dadas ao Conselho de Administração pela 
legislação societária brasileira, a qual, dentre outros deveres, atribui as seguintes práticas a este órgão, de acordo com o art. 142 (Lei 6.404 /1976):

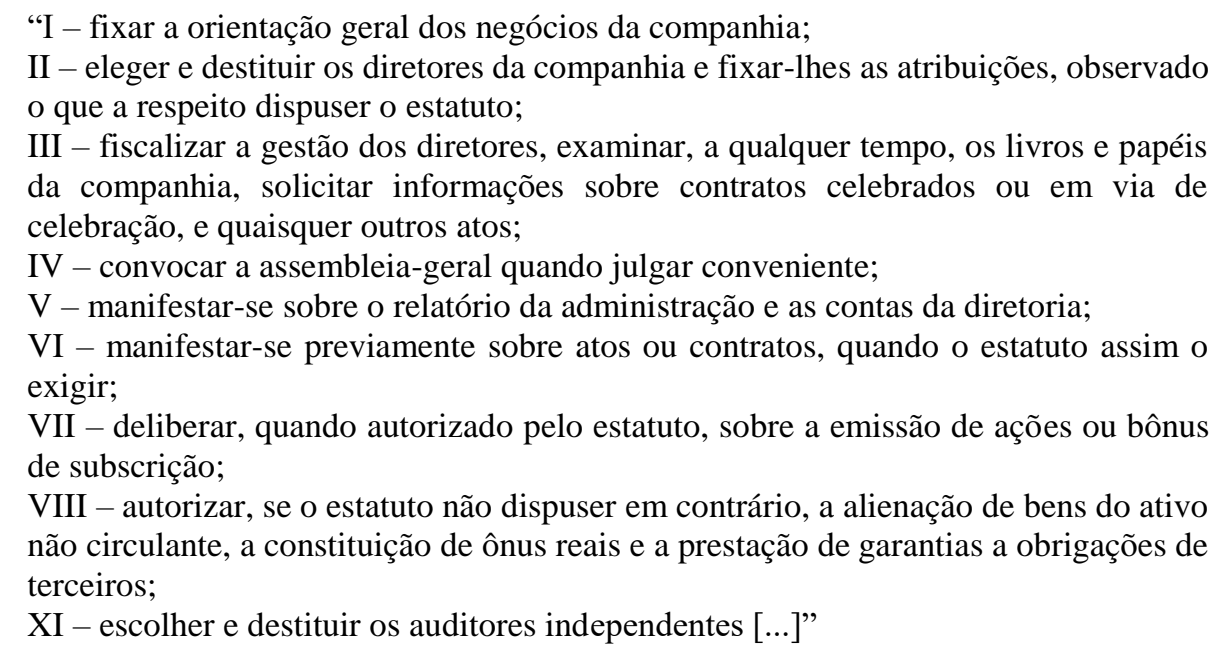

Por toda sua importância no contexto empresarial e pela sua função de assegurar que os administradores agirão em prol da maximização do interesse dos acionistas, diversos estudos acerca das características deste órgão focam na ligação entre o Conselho de Administração e o desempenho empresarial e valor de mercado (DONALDSON; DAVIS, 1991; YERMACK, 1996; BRICKLEY et al., 1997; EISENBERG et al., 1998; VAFEAS, 1999; MAK; KUSNADI, 2005; COLES et al., 2008; ANDRADE et al., 2009; BRICK; CHIDAMBARAN, 2010; GONDRIGE et al., 2012; CHOU et al., 2013; LIANG et al., 2013). As principais características estudadas o são o seu tamanho, independência dos membros, dualidade do CEO (o fato de o CEO ocupar a presidência do CA), frequência de reuniões do CA e a assiduidade dos membros do órgão nestas reuniões.

\subsection{Tamanho do Conselho de Administração (CA)}

O tamanho do CA é medido pelo número de membros que compõem o órgão. De acordo com Yermack (1996, p. 186) um Conselho de Administração com uma maior quantidade de membros pode significar para a empresa uma maior capacidade de monitoração das atividades dos gestores. Porém, os benefícios deste aumento do nível de monitoração vêm acompanhados de custos adicionais relativos a uma tomada de decisão mais lenta, discussões mais benevolentes sobre o desempenho empresarial e vieses quanto aos riscos assumidos nas operações da empresa.

Coles et al. (2008) argumentam que CAs com número de membros reduzido são mais coesos, mais produtivos e podem monitorar as atividades empresariais de maneira mais eficaz, enquanto que grupos maiores são menos eficazes por exigirem maiores custos para a coordenação de um número maior de conselheiros. Já Cheng (2008) associa os Conselhos de Administração maiores a uma menor variabilidade do desempenho, argumentando que quanto maior o tamanho do CA, menos este estará propenso a tomar decisões de negócios consideradas extremas. Ao mesmo tempo, um CA com maior número de membros demandaria mais esforços para se chegar a um consenso, sendo que a decisão final refletiria o compromisso dos membros com os interesses dos acionistas. Cheng (2008) cita ainda que o crescimento do número de membros do CA torna a tomada de decisão mais lenta e menos eficiente em razão de ser mais 
difícil realizar reuniões corporativas com a presença destes e de se chegar a um consenso sobre as decisões corporativas.

De acordo com Yermack (1996, p. 186-187) um Conselho de Administração composto por menos membros tem mais probabilidade de substituir o CEO em razão de baixa performance que um conselho maior, além de tornar a remuneração deste mais sensível ao seu desempenho. O autor cita ainda que o mercado de capitais precifica o aumento ou diminuição do número de membros do Conselho de Administração, valorizando as ações da empresa quando do encolhimento do órgão e desvalorizando suas ações quando o movimento contrário ocorre. Apesar de o trabalho de Yermack (1996) não ser recente, é importante destacarmos que foi um trabalho de grande importância na área, citado por praticamente todas as pesquisas posteriores. Já Andrade et al. (2009) afirmam que a influência do tamanho do Conselho de Administração no valor de mercado da empresa vai depender do tamanho desta, mas que a monitoração da alta administração é feita de forma mais eficaz com um maior número de conselheiros.

$\mathrm{O}$ ato de manter o Conselho de Administração com poucos membros pode melhorar o desempenho empresarial, de acordo com Jensen (1993). Lipton e Lorsch (1992) sugerem que o CA deveria ser composto por um número máximo de 10 membros (ou um órgão formado por 8 a 9 membros) onde pelo menos dois destes membros seriam independentes. Lipton e Lorsch (1992) argumentam ainda que com este número os conselheiros podem se conhecer melhor e é provável que haja um melhor consenso sobre as decisões tomadas por estes. Jensen (1993, p. 865) cita ainda que "pesquisas suportam o enunciado de que quando os grupos aumentam de tamanho eles tornam-se menos efetivos em razão dos problemas de coordenação e processamento que sobrecarregam as vantagens obtidas por se ter mais pessoas para recorrer".

Para Coles et al. (2008) há um número ótimo de membros que devem fazer parte do Conselho de Administração de uma empresa. Porém, o número ideal de membros dependerá das características desta empresa (escopo das operações, nível de endividamento e setores de atuação). A alteração destas características da empresa exigiria alteração no número de membros do órgão como forma de se conservar o número ótimo de conselheiros, o que faria com que o valor de mercado da empresa não caísse em razão da diferença entre o número ótimo e o número atual de membros. Porém, a mudança no número de membros para um número ótimo pretendido pode não ocorrer na mesma velocidade que as mudanças que afetam a estrutura empresarial. Diversos fatores são responsáveis pela restrição às rápidas mudanças no tamanho do Conselho de Administração, dentre elas: a) a estrutura política do conselho, que pode exigir votação periódica para a eleição ou destituição dos seus membros; b) a impossibilidade de remoção de membros com o objetivo apenas de se atingir o número ótimo de conselheiros, não estando este fato ligado ao desempenho do órgão, o que pode ferir a imagem da empresa perante o mercado; c) rede de relacionamentos construída entre o conselho, o CEO e o possível membro a ser removido; d) custos legais de remoção de um membro caso este não tenha tido o tempo acordado para desempenhar suas funções; e) tempo necessário para identificar futuros membros com os requisitos técnicos necessários para as funções que lhe serão atribuídas; e f) custos associados à contratação de um novo membro.

Uma explicação para a influência que o tamanho do Conselho de Administração exerce no valor de mercado das empresas é dada por Eisenberg et al. (1998). Para os autores, o efeito não se dá pelo aumento do número de membros em si, porém pelo aumento do número de conselheiros independentes, que está positivamente correlacionado com o aumento do número de membros do Conselho de Administração. Segundo Eisenberg et al. (1998), os conselheiros independentes apresentam um viés para rejeitar projetos mais arriscados, mesmo estes projetos 
sendo benéficos para a empresa. Deste modo, a rejeição de projetos considerados mais arriscados, mesmo sendo estes lucrativos, pode diminuir o valor de mercado da empresa.

Outra hipótese para as inferências sobre a relação entre o tamanho do Conselho de Administração e o desempenho e valor de mercado das empresas está relacionada ao seu desempenho passado. Levando em consideração que o aumento do número de membros num Conselho de Administração torna este um órgão com maior poder de monitoração, um aumento no número de membros pode ser resultado de tentativas da administração de recuperar empresas com fraco desempenho gerencial, o que explicaria alguns resultados encontrados, onde um conselho maior está ligado a um fraco desempenho e baixo valor de mercado. Após a melhora no desempenho da empresa causada por um maior nível de monitoração, o tamanho do Conselho de Administração poderia diminuir em virtude da adequação deste órgão ao novo nível de monitoração pretendido, sendo este menor quando a empresa em questão mostrasse recuperação (YERMACK, 1996; EISENBERG et al., 1998).

Outros fatores citados por Yermack (1996), além do desempenho passado da empresa, são o tamanho da empresa e o número de setores nos quais opera. Segundo Yermack (1996) empresas maiores são mais propensas a apresentar conselhos maiores, ocorrendo o mesmo para empresas mais diversificadas (EISENBERG et al., 1998; COLES et al., 2008) e empresas com alto endividamento (COLES et al., 2008). Eisenberg et al. (1998, p. 41) afirmam que "conselhos de empresas mais diversificadas podem exigir mais áreas de competência" o que aumenta o número de membros em razão das várias especialidades requeridas. Estes últimos citam também que o aumento do número de membros do CA está correlacionado com a maturidade da empresa. Eisenberg et al. (1998, p. 51) citam ainda que em empresas pequenas, maior é a probabilidade de o número de membros do Conselho de Administração aumentar em razão de pressões para a inclusão de familiares e parentes no órgão, mesmo que esta adição de novos membros não adicione valor à empresa. Coles et al. (2008) afirmam que pela função do Conselho de Administração em assessorar a alta administração da empresa, empresas mais complexas (maiores, mais diversificadas e com maior dependência de capital de terceiros) devem apresentar um maior número de membros neste órgão.

Observa-se que não há um consenso sobre uma influência do tamanho do CA na lucratividade, uma vez que são citadas características benéficas (YERMACK, 1996; CHENG, 2008; ANDRADE et al., 2009) e prejuduciais ao desempenho empresarial advindas de um CA composto por maior número de membros (YERMACK, 1996; EISENBERG et al., 1998; COLES et al., 2008).

\subsection{Independência do Conselho de Administração}

A independência do conselho de administração pode ser medida pela capacidade dos membros em tomar decisões que não beneficiem agentes específicos. É importante destacar que o Conselho de Administração tem por função a monitoração e avaliação das atividades da administração além de substituir membros da alta administração (especialmente o CEO) quando estes demonstram baixo desempenho (BYRD; HICKMAN, 1992). Esta função é dada basicamente aos membros do conselho os quais não ocupam cargos de direção na empresa (membros externos), sendo que os membros da administração da empresa que monitoram as atividades da alta administração certamente pretendem não criar conflitos com seus superiores (WEISBACH, 1988). Seguindo esta lógica, Geneen (1984, p. 262 apud WEISBACH, 1988, p. 433) já afirmava que "certamente, nenhum dos diretores desafiaria substancialmente seu chefe na sala de reuniões". 
Rosenstein e Wyatt (1990, p. 177-178) consideram que os conselheiros independentes "não são atuais ou ex-empregados da empresa e sua única ligação com a empresa são seus deveres como diretor" além de acrescentar o fato de que estes não podem possuir ações da empresa. Esta definição é próxima da utilizada por Cheng (2008) para diretores independentes. Cheng (2008, p. 160) diferencia os membros do Conselho de Administração externos à empresa dos conselheiros independentes, onde estes últimos "não são empregados, ex-executivos, parentes de um atual executivo da empresa e não têm relações comerciais importantes com a empresa, pessoalmente ou através de seu principal empregador". Hermalin e Weisbach (1988, p. 591) trazem a figura dos "grey directors", que "estão intimamente associados com a empresa, mas não são funcionários desta em tempo integral [...] foram relacionados a um funcionário da empresa ou mantinha extensas relações comerciais com a empresa, o que torna sua independência da gestão questionável", ou seja, membros que apresentam conflitos de interesses entre suas funções no CA e seu relacionamento com a empresa.

Byrd e Hickman (1992, p. 199) classificam os membros do Conselho de Administração em três categorias: a) membros internos (empregados atuais ou aposentados da empresa e seus familiares); b) membros externos afiliados (não são empregados em tempo integral, mas apresentam alguma ligação com a empresa além de sua participação no Conselho de Administração); c) membros externos independentes (não apresentam ligações com a empresa além do Conselho de Administração). Neste contexto, os membros externos afiliados de Byrd e Hickman (1992) assemelham-se aos "grey directors" definidos por Hermalin e Weisbach (1988) e os membros externos independentes possuem as mesmas características dos conselheiros independentes definidos por Rosenstein e Wyatt (1990) e Cheng (2008).

A influência de composição do Conselho de Administração na monitoração exercida sobre a alta administração gera controvérsias entre pesquisadores. Fama (1980) afirma que um órgão formado por detentores de títulos não se mostra ótimo em razão da diferença entre a participação dos membros no capital da empresa levar a diferentes opiniões sobre a assunção de riscos, além do fato de que muitos investidores diversificam suas aplicações, não se mostrando interessados em dispender muito tempo e esforço focando sua atenção em uma empresa específica, o que pode diminuir o poder de monitoração deste órgão.

Os executivos abaixo do cargo de CEO teriam mais incentivos para monitorar as atividades da alta administração uma vez que seriam os primeiros na linha de sucessão para assumir o cargo de CEO no caso de destituição deste após períodos de fraco desempenho gerencial. Esta linha sucessória torna-se natural em razão de os executivos possuírem profundos conhecimentos sobre as operações da empresa, o que seria necessário caso estes viessem a assumir a gestão de suas operações. Porém, ao ocupar uma cadeira no CA, os executivos podem decidir pela expropriação da riqueza dos acionistas e detentores de títulos ao invés de iniciarem uma competição entre si pelo cargo de CEO (FAMA, 1980).

A decisão dos membros da administração pela expropriação da riqueza dos acionistas e detentores de títulos pode ser perturbada pela inclusão de membros externos à administração no conselho da empresa. Fama (1980, p. 293-294) argumenta que os membros externos "podem ser considerados como árbitros profissionais cuja função é estimular e supervisionar a concorrência entre os membros da alta gestão da empresa [...] os quais são precificados pelo mercado de acordo com sua performance como árbitros", sendo também considerados um mecanismo de governança de baixo custo.

Outro fator de incentivo para os membros externos do Conselho de Administração assegurarem o bom andamento das operações da empresa é o desejo de desenvolver uma boa reputação no mercado corporativo, em especial os acadêmicos e administradores de outras empresas, dado que um bom desempenho destes conselheiros sinalizaria sua competência para 
o mercado (FAMA; JENSEN, 1983; WEISBACH, 1988). Sua capacidade de monitoração e assessoramento é tão reconhecida pelo mercado que, após períodos de baixo desempenho, uma empresa tende a adicionar ou preencher as vagas do Conselho de Administração com mais membros externos (HERMALIN; WEISBACH, 1988).

Porém, os benefícios advindos da adição de conselheiros independentes/externos podem não ser iguais para todas as empresas. Pequenas empresas poderiam se beneficiar mais pela adição destes membros em seu Conselho de Administração por estes membros portarem conhecimentos e informações de alto nível sobre o ambiente empresarial. A adição de um profissional com reputação reconhecida pelo mercado impactaria de forma bem mais significativa empresas pequenas, que geralmente são pouco monitoradas pelo mercado (ROSENSTEIN; WYATT, 1990).

Weisbach (1988), porém, argumenta que um Conselho de Administração composto exclusivamente por membros externos não seria benéfico para a empresa, tendo os membros internos maior capacidade para, no caso de destituição de algum membro da administração, indicar seu sucessor, além de acrescer sua experiência no caso de serem indicados como substitutos dos membros depostos. A inclusão de membros da equipe de administração da empresa no CA também pode ajudar os membros do conselho a avaliar seu desempenho no caso de algum destes ser indicado para o cargo de CEO, sendo que os conselhos de administração mistos (composto por membros internos e externos à empresa) podem desempenhar melhor sua função.

Hermalin e Weisbach (1988) também consideram que quando o CEO aproxima-se da aposentadoria, maior será a probabilidade de diretores da empresa serem adicionados ao Conselho de Administração para que sejam treinados para sucedê-lo. Hermalin e Weisbach (1988) argumentam ainda que, após escolhido o CEO substituto, a proporção de diretores da empresa que fazem parte do Conselho de Administração diminui. Esta diminuição se dá tanto pelo fato de alguns membros internos abandonarem a empresa por não terem sido escolhidos para se tornar o novo CEO, quanto pelo fato de que o novo CEO estará mais propenso a substituí-los por membros externos, os quais provém o CEO e o Conselho de Administração de melhor assessoramento, suprindo também a demanda do mercado por membros independentes no órgão.

O maior ativismo e monitoração exercidos pelos membros do Conselho de Administração externos à empresa também pode fazer com que o CEO restrinja a participação dos membros independentes/externos no órgão. Weisbach (1988) argumenta que os CEOs que possuem participação na empresa detêm mais poderes, usados para reduzir a participação de membros externos no Conselho de Administração. Uma explicação alternativa seria a de que, ao possuir participação na empresa, os objetivos do CEO estariam alinhados aos objetivos dos demais acionistas, sendo desnecessária a inclusão de membros independentes no Conselho de Administração para monitorar as atividades, o que resultaria em custos maiores. Esta última hipótese está de acordo com a Teoria da Agência de Jensen e Meckling (1976).

É também papel dos membros do Conselho de Administração a monitoração das tentativas de aquisição de outras empresas pela empresa que representam. Nestes casos, membros externos à empresa podem avaliar melhor os custos e benefícios inerentes à operação de aquisição por seu alto conhecimento a respeito do mercado no qual a empresa está inserida e pelo conflito de interesses que membros da diretoria executiva e membros do Conselho de Administração podem apresentar por manter ligações com a empresa (BYRD; HICKMAN, 1992). 
$\mathrm{O}$ vencimento do mandato de um conselheiro também pode ser fator que influencie na possível independência deste em relação à gestão da empresa. Um conselheiro interno, externo ou independente pode necessitar da influência de acionistas, do CEO ou de outros membros da equipe de gestão mais para continuar no cargo. Este fato faria com que o conselheiro tomasse atitudes que beneficiassem um agente específico, diminuindo sua independência no cargo. Esta questão, porém, não é explorada mais a fundo nesta pesquisa.

\subsection{Dualidade do CEO/Chairman}

O principal termo utilizado para designar o fato de o CEO ser também o Presidente do Conselho de Administração (Chairman) é a expressão "dualidade" ou "dualidade do CEO/Chairman". Brickley et al. (1997) denominam estrutura de liderança unitária o fato de o CEO ocupar também o cargo de Chairman e estrutura de liderança dupla a separação entre estas duas funções. Assim, enquanto o papel do CEO é coordenar as atividades da empresa, a principal função do Conselho de Administração é "projetar uma imagem da empresa para o mundo externo".

Diante das funções estabelecidas para o CEO e o Chairman, Harrison et al. (1988, p. 214) afirmam que a função de Chairman "foi enxergada como sendo relativamente menos poderosa e mais cerimonial e simbólica que a função de CEO". Mesmo sendo uma posição provida de menor poder e influência, o fato de o CEO ocupar também uma cadeira, ou até mesmo a presidência do Conselho de Administração, tem levado a muitos estudos sobre as causas e consequências desta estrutura de poder.

O conflito de interesses inerente ao fato de o Conselho de Administração ser preenchido pelo agente o qual é objeto de avaliação deste é um tema bastante pesquisado sob a ótica principalmente da Teoria da Agência (JENSEN, 1993), da "Stewardship Theory" ou Teoria da Mordomia (DONALDSON; DAVIS, 1991), e até do estudo da remuneração baseada no Poder Gerencial (BEBCHUK; FRIED, 2003).

Jensen (1993, p. 866) cita que as funções do presidente do Conselho de Administração (Chairman) são as de "executar as reuniões e supervisionar o processo de contratação, demissão, avaliação e compensação do CEO", ficando evidente o conflito de interesses quando uma mesma pessoa executa simultaneamente as duas funções, argumentando que isto leva ao comprometimento da função de monitoração exercida pelo conselho. Neste caso, o CEO pode utilizar seu maior poder e influência para guiar a empresa em direção aos seus interesses, sacrificando a riqueza dos acionistas e gerando mais custos de agência (DONALDSON; DAVIS, 1991). Weidenbaum (1986, p. 78) cita ainda o fato de que o CEO também pode influenciar os procedimentos e a agenda do Conselho de Administração, além de controlar as operações da empresa, diminuindo o poder dos outros membros do conselho.

Porém, ao contrário da Teoria da Agência, que prega a tendência do agente maximizar a sua utilidade pessoal ao invés da maximização da riqueza do principal, algumas teorias concorrentes argumentam que podem haver outros fatores motivacionais no comportamento dos executivos, tal como sua satisfação pessoal e reconhecimento profissional ao invés do aumento da sua riqueza, onde esta primeira qualidade estaria ligada ao fato de estes realizarem um bom trabalho e obterem um desempenho acima da média no comando das suas funções. Donaldson e Davis (1991) exemplificam que, ao sentir que parte de sua riqueza futura (composta pela compensação futura e planos de aposentadoria e pensões) está ligada à riqueza de seus empregadores, o executivo percebe um alinhamento de seus interesses com os de seus empregadores. Esta é a ideia principal da Teoria da Mordomia, onde o executivo tende a agir 
em prol da maximização da riqueza dos acionistas, mesmo na ausência de participação acionária na empresa.

Conforme a Teoria da Mordomia, o desempenho do CEO está relacionado a implantação de uma adequada estrutura organizacional que o ajudará a alcançar os objetivos pretendidos para maximizar a riqueza dos acionistas. A questão fundamental é saber se tais estruturas organizacionais encontradas no seu ambiente de trabalho são adequadas o suficiente para ajudálo a implantar os projetos pretendidos. Tais estruturas devem prover o CEO de alto poder gerencial, que será usado na aplicabilidade de suas estratégias corporativas. Em razão disto, o fato de o CEO ocupar também a presidência do Conselho de Administração delega a este agente uma autoridade maior, possibilitando a implantação mais rápida e efetiva de projetos que gerem uma alta lucratividade para a empresa (DONALDSON; DAVIS, 1991).

Contrastando com a ideia da Teoria da Mordomia, o estudo da remuneração executiva sob a abordagem do Poder Gerencial (BEBCHUK; FRIED, 2003) parte do pressuposto de que a formulação do contrato de remuneração não é independente, ou seja, os agentes econômicos responsáveis pela formulação do contrato podem ter relação entre si. Nesta abordagem é assumido que os administradores se utilizarão do seu poder gerencial para extrair rendas da empresa tanto quanto possível, num montante que não estaria condizente com sua remuneração caso a formulação do contrato de compensação se desse entre partes independentes. Ao mesmo tempo, um Conselho de Administração mais independente e mais ativo pode restringir remunerações consideradas excessivas. É esperado que o agente tente formular um contrato de remuneração que legitime a extração de renda excessiva da empresa, geralmente utilizando-se de cláusulas ineficientes na estruturação deste contrato, onde estas cláusulas de desempenho muitas vezes podem reduzir a riqueza dos acionistas ao invés de maximizá-la (BEBCHUK; FRIED, 2003). De acordo com essa abordagem, o poder gerencial obtido pela ocupação dos cargos de CEO e Chairman simultaneamente possibilitaria a este extrair mais renda da empresa, reduzindo a riqueza dos acionistas e consequentemente o desempenho e valor de mercado da empresa. Bebchuk e Fried (2003, p. 76) argumentam também que o disclosure exerce um importante papel na política de remuneração e nos excessos cometidos pela administração em se tratando de abusos nas compensações recebidas, onde o mercado pode penalizar o valor de mercado destas empresas.

Em sua pesquisa, Brickley et al. (1997) listam os principais custos e benefícios atribuídos à dualidade do CEO. Se por um lado a separação de funções ajuda a controlar e exercer uma maior monitoração sobre o comportamento do $\mathrm{CEO}$, são criados custos de agência relativos à monitoração do comportamento do indivíduo indicado como Chairman, onde o poder atribuído a este permite que o agente possa extrair mais rendas da empresa utilizando de sua influência. Outro custo associado à separação destes cargos é atribuído à escolha do indivíduo ao qual será concedido o cargo de Chairman, onde os acionistas devem investigar seu histórico de esforço dispendido na execução de suas obrigações e de suas preferências a respeito de tomada de risco e escolha de investimentos. $\mathrm{O}$ fato de o candidato a Chairman possuir ou não participação relevante na empresa também pode influir no desempenho das atividades e no nível de esforço dispendido (BRICKLEY et al., 1997).

De acordo com Brickley et al. (1997), estruturas de liderança duais também apresentam a desvantagem de aumentar os custos de transferência de informação e a qualidade destas. Visto que o Chairman necessita de informações específicas das atividades da empresa para desempenhar suas funções de maneira eficiente, este poderá requisitar tais informações ao CEO. Porém, a transferência de informações pode tornar-se custosa e/ou incompleta, onde uma estrutura de liderança unitária (dualidade do CEO) eliminaria este problema por concentrar as informações em um só indivíduo. 
Outra forma de mitigar esse problema seria a manutenção do CEO anterior como Chairman ou como um membro efetivo do Conselho de Administração, o qual terá condições de transferir as informações especializadas adquiridas durante os anos em que desempenhou a função de CEO. Brickley et al. (1997) citam ainda outros custos associados à separação de cargos, dentre os quais o surgimento de rivalidades entre os ocupantes das duas funções, a dificuldade na atribuição das responsabilidades por baixo desempenho.

Os custos e benefícios associados à existência da dualidade entre o CEO/Chairman e suas possíveis consequências sobre o desempenho e valor de mercado das empresas discutidos acima, mostram-nos a complexidade do tema e a incerteza quanto aos resultados esperados, visto que as teorias discutidas permitem-nos esperar relações positivas ou negativas entre a dualidade e o desempenho/valor de mercado.

\subsection{Literatura empírica sobre as características do Conselho de Administração}

A literatura empírica a respeito dos reflexos das características do Conselho de Administração nas empresas é ampla e aborda temas variados. Tais temas incluem a influência da estrutura do conselho na destituição/substituição do CEO (HERMALIN; WEISBACH,1988; WEISBACH,1988), na sua sucessão (HERMALIN; WEISBACH,1988), na variabilidade dos resultados (CHENG, 2008), no desempenho/lucratividade (DONALDSON; DAVIS, 1991; YERMACK, 1996; BRICKLEY et al., 1997; EISENBERG et al., 1998; ANDRADE et al., 2009; GONDRIGE et al., 2012; MASULIS et al., 2012; CHOU et al., 2013; LIANG et al., 2013) e no valor de mercado/retorno acionário (DONALDSON; DAVIS, 1991; YERMACK, 1996; BRICKLEY et al., 1997; EISENBERG et al., 1998; MAK; KUSNADI, 2005; COLES et al., 2008; ANDRADE et al., 2009; BRICK; CHIDAMBARAN, 2010; GONDRIGE et al., 2012). Apesar de não ser o foco do atual estudo, os trabalhos que tem como base analisar a influência das características do CA no valor de mercado das empresas também são citados neste estudo. $\mathrm{O}$ valor de mercado de uma empresa apresenta forte correlação com sua lucratividade, uma vez que as alterações neste primeiro podem ser reflexo de mudanças nas expectativas de lucros e fluxos de caixa da empresa. Por fim, o valor de mercado também é muito utilizado como uma proxy para o desempenho da empresa, do mesmo modo que a lucratividade.

Este tópico é dividido em três seções que mostram os resultados de pesquisas que focam no impacto nas empresas do tamanho do Conselho de Administração, sua independência e a dualidade do CEO.

\subsubsection{Tamanho do Conselho de Administração}

Os resultados dos estudos internacionais sobre a influência do tamanho do CA no desempenho e valor de mercado das empresas indicam principalmente uma relação negativa entre estes dois fatores. Yermack (1996) encontrou evidências de uma maior efetividade de pequenos conselhos de administração, concluindo que há uma relação negativa entre o tamanho do Conselho de Administração e o valor de mercado das empresas. Mak e Kusnadi (2005) encontraram resultados semelhantes ao analisar empresas em Singapura e na Malásia, o que indica que a influência negativa do Conselho de Administração no valor de mercado das empresas não é uma exclusividade dos mercados de capitais situados em países desenvolvidos. Os resultados de Yermack (1996) indicam também que a substituição do CEO e seus incentivos 
financeiros tornam-se menos eficazes quando o tamanho do conselho aumenta. Por fim, o autor encontra evidências de que o mercado de capitais avalia positivamente o fato de empresas anunciarem a redução do número de membro dos seus conselhos, gerando retornos anormais, ocorrendo o contrário para aquelas que anunciam uma expansão do número de membros do Conselho de Administração.

Na mesma linha de pesquisa, Eisenberg et al. (1998) estudaram o reflexo do tamanho do Conselho de Administração em pequenas e médias empresas finlandesas. Os autores observaram uma relação negativa entre o tamanho do Conselho de Administração e a lucratividade. Esses resultados são semelhantes aos achados por Liang et al. (2013), que encontraram uma associação negativa entre o tamanho do conselho e o desempenho empresarial, ao estudar uma amostra composta por bancos. Eisenberg et al. (1998) descobriram, ainda, uma relação entre o desempenho empresarial passado e o turnover dos membros do Conselho de Administração, sendo a frequência de substituição destes conselheiros maior quando a empresa apresenta fraco desempenho. Porém, convergentes com Yermack (1996), os mesmos não obtiveram evidências de aumento ou diminuição do tamanho do conselho relacionado ao desempenho passado das empresas. Estes resultados indicam que o tamanho do Conselho de Administração pode influenciar o desempenho da empresa, ao invés do contrário.

Cheng (2008) verificou que o tamanho do conselho está negativamente relacionado à variabilidade dos retornos mensais das ações das empresas, à variabilidade do desempenho e ao valor de mercado. Os resultados também mostraram uma relação negativa entre o tamanho do conselho e a variabilidade dos accruals, accruals anormais e itens extraordinários, indicando que empresas com conselhos de administração maiores tendem a gerenciar menos resultados utilizando-se de accruals e itens extraordinários. Por fim, Cheng (2008) encontrou ainda evidências de que o tamanho do conselho está negativamente relacionado à variabilidade das despesas com pesquisa e desenvolvimento, o que significa que empresas com conselhos maiores estão menos propensas a empreenderem projetos de alto risco.

Já Coles et al. (2008) observaram que o valor de mercado das empresas tende a ser maior para conselhos de administração maiores em empresas complexas (empresas maiores e/ou que atuam em vários setores e/ou com alto grau de dependência de capital de terceiros), porém este efeito é inverso quando comparadas com as empresas simples (empresas menores e/ou que atuam em poucos segmentos e/ou com um baixo nível de alavancagem financeira).

Apesar de escassas, as pesquisas brasileiras sobre a influência do Conselho de Administração no desempenho e valor de mercado das empresas têm crescido nos últimos anos. Andrade et al. (2009) analisaram uma amostra composta por 147 empresas listadas no mercado de capitais brasileiro no período de 2004 a 2006 e verificaram que o tamanho do Conselho de Administração pode gerar impactos diferentes no valor de mercado da empresa, dependendo do tamanho da empresa. Os autores mostraram que o tamanho do órgão está positivamente relacionado com o desempenho da empresa. Gondrige et al. (2012) tomaram como referência um conjunto de 208 empresas listadas na BM\&FBOVESPA no ano de 2008 para inferir a respeito da influência das características do Conselho de Administração no valor de mercado das empresas. Os autores encontraram resultados semelhantes aos de Andrade et al. (2009), dado que o tamanho do Conselho de Administração, medido pela quantidade de membros, mostrou relação positiva com o valor de mercado das empresas. 


\subsubsection{Independência do Conselho de Administração}

Os artigos sobre a independência do Conselho de Administração têm encontrado fortes evidências de uma relação positiva entre o nível de independência do CA e o desempenho empresarial. Chou et al. (2013) investigaram a relação entre as características do Conselho de Administração e o desempenho das empresas Taiwanesas. Os autores descobriram que a independência dos diretores está positivamente relacionada com o desempenho empresarial. Resultados semelhantes foram obtidos por Liang et al. (2013) que encontraram uma relação positiva entre a proporção de diretores independentes, o desempenho bancário e a qualidade dos ativos dos bancos.

Ao estudaram a relação entre a sucessão do CEO, o desempenho da empresa e a estrutura do Conselho de Administração, Hermalin e Weisbach (1988) encontraram evidências de que membros externos são adicionados ao CA após a empresa apresentar fraco desempenho, porém não imediatamente. Os resultados também indicam que os executivos de algumas empresas deixaram o Conselho de Administração numa pequena janela temporal antes e após a escolha do sucessor do CEO, indicando que aqueles executivos preteridos no processo sucessório abandonam o conselho. Os autores descobriram que a diversificação das operações da empresa desempenha papel importante na composição do conselho, uma vez que a saída da empresa de algum mercado faz com que a empresa adicione mais conselheiros externos. Outro achado importante da pesquisa é o fato de que após a consolidação do processo sucessório, novos executivos são adicionados ao Conselho de Administração, talvez como parte do treinamento para uma provável nova sucessão do CEO.

Weisbach (1988) afirmou que membros do Conselho de Administração externos à empresa são mais independentes para exercer seu papel na monitoração das atividades da alta administração. Ele tentou estudou o reflexo da proporção de membros externos na probabilidade de destituição do CEO por baixo desempenho. Os resultados do trabalho indicam que membros do Conselho de Administração externos à empresa exercem um importante papel de monitoração. Estes resultados indicam que conselheiros externos são mais sensíveis ao desempenho da empresa quando é necessário avaliar o desempenho do CEO. Weisbach (1988) encontrou evidências de que a probabilidade de destituição do CEO por fraco desempenho é maior quando o Conselho de Administração é formado principalmente por membros externos. Outras evidências indicam que a destituição do CEO gera aumento no valor da empresa quando o Conselho de Administração é formado majoritariamente por membros externos.

Coles et al. (2008) descobriram que o valor de mercado das empresas é maior para as empresas complexas com CAs mais independentes, porém este efeito é inverso quando comparadas as empresas simples. Os resultados indicam que as empresas complexas se beneficiam de uma maior proporção de diretores independentes, enquanto que as empresas simples apresentam menor valor de mercado quando do aumento do número de membros independentes. Já Cheng (2008) encontrou uma relação positiva entre a proporção de conselheiros externos e o gerenciamento de resultados por meio dos accruals e accruals anormais. $\mathrm{O}$ autor também observou uma relação negativa entre a proporção de conselheiros independentes e os itens extraordinários.

Dentre os estudos nacionais, Andrade et al. (2009) depararam-se com o fato de que quanto maior o percentual de conselheiros externos, menor a probabilidade de o CEO ocupar também a presidência do Conselho de Administração. Andrade et al. (2009) também encontraram evidências de que o impacto da independência dos membros do conselho pode variar em função do nível de endividamento da empresa, onde conselheiros independentes estariam mais 
propensos a rejeitar projetos mais arriscados em favor de priorizarem o pagamento das dívidas, diminuindo assim o desempenho das empresas. Gondrige et al. (2012) não encontrou relação entre a independência do Conselho de Administração e o valor de mercado das empresas brasileiras listadas na BM\&FBOVESPA.

\subsubsection{Dualidade do CEO/Chairman}

Analisando uma amostra composta por empresas americanas no ano de 1987, Donaldson e Davis (1991) desenvolveram sua pesquisa sobre a ótica da Teoria da Mordomia. A Teoria da Mordomia estabelece que o CEO estará motivado a realizar seu trabalho para gerar os melhores resultados para os acionistas, independentemente dos incentivos financeiros recebidos para isto, e que o seu desempenho está ligado à estrutura organizacional da empresa a qual este dirige. Conforme Donaldson e Davis (1991), quanto maior o poder e autoridade que o CEO detém sobre a empresa, mais facilmente este poderá implantar projetos de alta lucratividade. Foi testada a validade da Teoria da Mordomia em relação à Teoria da Agência para se inferir a respeito do desempenho do CEO em razão do seu poder e incentivos oferecidos para a execução de suas tarefas. Para se mensurar o poder e autoridade delegados ao CEO, foi utilizado o fato de o CEO ser também o Chairman da empresa. Os autores encontraram evidências de que quanto maior o poder e autoridade delegados ao CEO maior a lucratividade obtida. Os resultados também indicaram que incentivos a longo prazo oferecidos aos CEOs não influenciavam o desempenho da empresa.

Listando os principais custos e benefícios da manutenção do CEO como Chairman, Brickley et al. (1997) revisaram a literatura e a regulação inerente ao tema e observaram que, apesar das recomendações emitidas por autoridades, a maioria das empresas americanas em 1988 não apresentavam um conselheiro independente como Chairman. Ao mesmo tempo, na quase totalidade dos casos, o Chairman da empresa era seu atual ou antigo CEO. Os autores também forneceram evidências de que a obtenção do título de Chairman pelo CEO deu-se, na maioria dos casos, quando este apresentou bom desempenho sobre sua gestão durante um chamado "período probatório", sendo a concessão da titulação semelhante a uma recompensa pelos serviços prestados. Por fim, os resultados não indicaram diferença significativa no desempenho e retornos acionários das empresas que optavam por estruturas de liderança unitárias ao invés de duplas/duais, contrariando os achados das principais pesquisas à época.

Quando analisadas as pesquisas nacionais, observou-se que os resultados obtidos por Andrade et al. (2009) e Gondrige et al. (2012) foram semelhantes. Ambos os autores não encontraram relação entre a dualidade do CEO e o desempenho/valor de mercado das empresas brasileiras listadas na BM\&FBOVESPA.

A seguir, os principais resultados obtidos nas pesquisas a respeito da influência das características do Conselho de Administração no desempenho e valor de mercado das empresas são resumidos no Quadro 2. 
Quadro 2 - Influência das características do Conselho de Administração no desempenho e valor de mercado das empresas: Principais resultados obtidos

\begin{tabular}{|c|c|}
\hline Autores & Principais resultados obtidos \\
\hline Donaldson e Davis (1991) & $\begin{array}{l}\text { - Um maior poder e autoridade delegados ao CEO está relacionado a uma } \\
\text { maior lucratividade; } \\
\text { - Incentivos a longo prazo oferecidos aos CEOs não influenciaram o } \\
\text { desempenho da empresa. }\end{array}$ \\
\hline Yermack (1996) & $\begin{array}{l}\text { - Relação negativa entre o tamanho do Conselho de Administração e o valor } \\
\text { de mercado; } \\
\text { - Relação negativa entre o aumento do número de membros do Conselho de } \\
\text { Administração e o desempenho empresarial; } \\
\text { - O mercado de capitais avalia positivamente anúncios sobre a redução do } \\
\text { número de membros do conselho. }\end{array}$ \\
\hline Brickley et al. (1997) & $\begin{array}{l}\text { - A dualidade do CEO/Chairman não influencia o desempenho da empresa } \\
\text { (lucratividade ou retorno das ações). }\end{array}$ \\
\hline Eisenberg et al. (1998) & $\begin{array}{l}\text { - Relação negativa entre o tamanho do Conselho de Administração e o valor } \\
\text { de mercado. }\end{array}$ \\
\hline Mak e Kusnadi (2005) & $\begin{array}{l}\text { - Relação negativa entre o tamanho do Conselho de Administração e o valor } \\
\text { de mercado. }\end{array}$ \\
\hline Coles et al. (2008) & $\begin{array}{l}\text { - A influência do tamanho do Conselho de Administração e da } \\
\text { independência dos membros no valor de mercado depende da complexidade } \\
\text { das operações das empresas. }\end{array}$ \\
\hline Andrade et al. (2009) & $\begin{array}{l}\text { - A influência do tamanho do Conselho de Administração e da } \\
\text { independência dos membros no valor de mercado depende do tamanho da } \\
\text { empresa; } \\
\text { - A influência da independência dos membros do conselho no desempenho } \\
\text { empresarial pode variar em função do nível de endividamento da empresa. }\end{array}$ \\
\hline Gondrige et al. (2012) & $\begin{array}{l}\text { - O número de membros do Conselho de Administração relaciona-se } \\
\text { positivamente com o valor de mercado da empresa; } \\
\text { - A proporção de conselheiros externos e a dualidade de CEO não mostram } \\
\text { relação com o valor de mercado. }\end{array}$ \\
\hline Chou et al. (2013) & $\begin{array}{l}\text { - A assiduidade nas reuniões corporativas influencia positivamente o } \\
\text { desempenho empresarial; } \\
\text { - Relação positiva entre o percentual de conselheiros independentes e a } \\
\text { performance empresarial. }\end{array}$ \\
\hline Liang et al. (2013) & $\begin{array}{l}\text { - A frequência do número de reuniões corporativas tem relação positiva com } \\
\text { o desempenho bancário e a qualidade dos seus ativos; } \\
\text { - Relação positiva entre o percentual de conselheiros independentes e o } \\
\text { desempenho empresarial. } \\
\text { - Relação negativa entre o tamanho do Conselho de Administração e o } \\
\text { desempenho empresarial. }\end{array}$ \\
\hline
\end{tabular}

Fonte: Elaboração própria. 


\section{PROCEDIMENTOS METODOLÓGICOS}

\subsection{Especificação dos modelos e variáveis}

Para identificar a relação entre as características do Conselho de Administração e a lucratividade das empresas listadas na BM\&FBOVESPA foram utilizados modelos de regressão com dados em painel. A técnica de dados em painel combina dados originários de cortes transversais e séries temporais, onde cada indivíduo $i$ é observado ao longo de vários períodos de tempo $t$.

Klevmarken (1989, apud Baltagi, 2003) e Hsiao (2003, apud Baltagi, 2003) listam alguns benefícios do uso desta técnica, destacando-se: a) controle da heterogeneidade individual, dado que os estudos em contabilidade e finanças geralmente utilizam-se de observações advindas de indivíduos como empresas, estados ou países, os quais são heterogêneos; b) maior variabilidade de dados, menos colinearidade entre as variáveis e mais eficiência; c) maior poder para examinar a dinâmica do ajustamento, sendo necessários para o estudo das relações intertemporais e ciclos de vida; e, d) melhor mensuração de efeitos que não podem ser detectados em estudos com cortes transversais ou séries temporais.

Os modelos de regressão de dados em painel foram estimados em forma de regressões múltiplas sequenciais, similares às utilizadas por Andrade et al. (2009). Este modelo de regressão múltipla é similar à regressão stepwise, onde as variáveis independentes são adicionadas cumulativamente ao modelo, porém, no modelo de regressão stepwise, as variáveis são selecionadas de acordo com a sua contribuição para o coeficiente de determinação $\mathrm{R}^{2}$ (COHEN et al., 2003). No modelo de regressão utilizado, o pesquisador que determina a ordem de adição das variáveis incluídas no modelo.

Assim, foram adicionadas primeiramente as principais variáveis de interesse do estudo e, em seguida, as variáveis que denominamos de variáveis de controle. As variáveis de interesse incluem as três principais características do Conselho de Administração estudadas na literatura: I) Tamanho; II) Independência do Conselho de Administração e; III) Dualidade do CEO. As variáveis de controle são separadas em outros dois grupos, sendo que o primeiro grupo é composto pelas características financeiras da empresa e pela identidade do controlador, e o segundo grupo composto por variáveis dummies temporais, para captar os efeitos de fatores regulatórios e macroeconômicos na lucratividade das empresas, como a inflação, taxa básica de juros, crescimento econômico, tributação, etc.

Sendo assim, a Equação (1) apresenta os grupos de variáveis utilizados nos modelos estimados:

Lucratividade $_{\mathrm{i}, \mathrm{t}}=\beta_{0}+\beta_{1}$ TamanhoCA $_{\mathrm{i}, \mathrm{t}}+\beta_{2}$ Independência $_{\mathrm{i}, \mathrm{t}}+\beta_{3}$ DualidadeCEO $_{\mathrm{i}, \mathrm{t}}+$ $\beta_{4} \log _{\text {Ativos }_{i, t}}+\beta_{5}$ Endividamento $_{\mathrm{i}, \mathrm{t}}+\beta_{6}$ Estrangeiro $_{\mathrm{i}, \mathrm{t}}+\beta_{7}$ Estatal $_{\mathrm{i}, \mathrm{t}}+\beta_{8}$ Ano2011 + $\beta_{9}$ Ano $2012+\beta_{10}$ Ano $2013+\beta_{11}$ Ano2014 $+\varepsilon_{i, t}$

Onde as variáveis são calculadas para uma empresa $i$ para um período $t$. Descriminando cada uma das variáveis inseridas no modelo, temos: 
- Variável Dependente

A Lucratividade é a variável dependente do modelo e representa o desempenho empresarial de uma empresa $i$ em determinado período $t$, sendo medida de quatro maneiras distintas: a) Retorno sobre os Ativos Totais (Return on Assets - ROA); b) ROA ajustado à mediana; c) Retorno sobre o Patrimônio Líquido (Return on Equity - ROE); e, d) ROE ajustado à mediana.

O ROA é calculado pela razão entre o lucro líquido de um período e os ativos totais da empresa, e tem por objetivo avaliar o retorno gerado em relação aos recursos aplicados em ativos. Seu cálculo é obtido conforme a Equação (2):

$$
\mathrm{ROA}_{\mathrm{i}, \mathrm{t}}=\frac{\text { Lucro Líquido }_{\mathrm{i}, \mathrm{t}}}{\text { Ativo Total }}
$$

O ROA ajustado à mediana mede o retorno gerado pelos ativos totais da empresa em determinado período em comparação à mediana do setor, utilizada como benchmark. Para cada setor e em cada ano da amostra, foi calculada a mediana do ROA para representar a lucratividade do mercado a ser utilizada como benchmark. Valores positivos indicam que a empresa apresentou lucratividade acima da mediana de mercado, enquanto valores negativos indicam que a empresa mostrou um desempenho inferior ao benchmark utilizado na pesquisa. Seu valor é calculado conforme a Equação (3):

$$
\text { ROAajMediana }_{\mathrm{i}, \mathrm{t}}=\mathrm{ROA}_{\mathrm{i}, \mathrm{t}}-\mathrm{ROA}(\text { mediano })_{\mathrm{s}, \mathrm{t}}
$$

O ROE mede o retorno gerado para os acionistas da empresa, onde quanto maior o valor, melhor o investimento remunerou seus acionistas. Seu cálculo se dá pela razão entre o lucro líquido de um período e o valor do patrimônio líquido da empresa para o início do período, como mostrado na Equação (4):

$$
\mathrm{ROE}_{\mathrm{i}, \mathrm{t}}=\frac{\text { Lucro Líquido }_{\mathrm{i}, \mathrm{t}}}{\text { Patrimônio Líquido (inicial) })_{\mathrm{i}, \mathrm{t}}}
$$

O último indicador de lucratividade é o ROE ajustado à mediana, que mede o retorno gerado para os acionistas da empresa em comparação com a mediana do mercado. A mediana do ROE foi calculada para cada setor e em cada ano da amostra. É outra medida de lucratividade ajustada ao mercado que utiliza a mediana do setor como benchmark, assim como o ROA ajustado à mediana. Seu cálculo é mostrado na Equação (5):

$$
\text { ROEajMediana }_{\mathrm{i}, \mathrm{t}}=\mathrm{ROE}_{\mathrm{i}, \mathrm{t}}-\mathrm{ROE}(\text { mediano })_{\mathrm{s}, \mathrm{t}}
$$

Trabalhos anteriores utilizaram o ROA (YERMACK, 1996; MAK; KUSNADI, 2005; CHENG, 2008; COLES et al., 2008; LIANG et al., 2013), ROA ajustado (VAFEAS, 1999; 
BRICK; CHIDAMBARAN, 2010; CHENG, 2008) e ROE (LIANG et al., 2013) como medidas de lucratividade/desempenho. Apesar de não ter sido observado o seu uso nos trabalhos anteriores utilizados como referência, o ROE ajustado permanece como variável dos modelos por gerar uma medida do retorno gerado para os acionistas em relação à mediana das empresas do mesmo setor, dado que, conforme Matarazzo (2010) o ROE é uma das mais importantes medidas de retorno do capital investido, tornando-se importante o seu uso enquanto variável ajustada à lucratividade do setor para a auferição da lucratividade da empresa frente a suas concorrentes.

As medianas das variáveis foram calculadas para um dado setor $s$ (do total de 20 setores e um grupo denominado como "Outros") num respectivo período (ano) $t$. Optou-se pela utilização da mediana em razão de esta medida ser mais robusta a valores extremos, quando comparada à média, o que poderia enviesar os resultados e a análise (DIEZ et al., 2012). A mediana da lucratividade setorial foi calculada utilizando todas as empresas listadas na BM\&FBOVESPA e com dados disponíveis para dado período $t$ e não apenas aquelas que foram utilizadas na amostra.

\section{- Variáveis Independentes}

Como variáveis independentes, está o grupo de variáveis de interesse que representa as características do Conselho de Administração: I - o tamanho do Conselho de Administração (TamanhoCA); II - a independência dos seus membros (Independência); e, III - a dualidade do CEO (DualidadeCEO), onde são analisados os resultados para os coeficientes $\beta_{1}, \beta_{2}$ e $\beta_{3}$ da Equação (1).

I - O Tamanho do Conselho de Administração foi medido pela quantidade de membros efetivos no conselho ao final do período, que incluem tanto membros internos como membros externos. Essa medida foi utilizada também por Mak e Kusnadi (2005), Coles et al. (2008), Andrade et al. (2009), Brick e Chidambaran (2010) e Liang et al. (2013).

II - A Independência é medida de duas maneiras distintas. Na primeira, é utilizada a proporção de membros do Conselho de Administração classificados pelas empresas como "independentes" em relação ao total de membros (MAK; KUSNADI, 2005; CHENG, 2008; BRICK; CHIDAMBARAN, 2010; LIANG et al., 2013), enquanto na segunda utilizou-se a proporção de conselheiros externos em relação ao total de membros do conselho (YERMACK, 1996; ANDRADE et al., 2009). Como mencionado anteriormente, os conselheiros independentes diferenciam-se dos externos em razão de estes primeiros apresentarem algumas características adicionais que vão além da ausência de relações trabalhistas com a empresa. Tais diferenças incluem a ausência de relações comerciais entre os conselheiros independentes e a empresa e a ausência de parentesco com seus executivos, motivos estes que podem comprometer a independência dos conselheiros (CHENG, 2008). Os conselheiros externos são caracterizados apenas pela falta de vínculo trabalhista com a empresa.

III - A DualidadeCEO é representada por uma variável dummy que assume valor um (1) quando o CEO é também Presidente do Conselho de Administração/Chairman e zero (0), do contrário (MAK; KUSNADI, 2005; CHENG, 2008; ANDRADE et al., 2009; BRICK; CHIDAMBARAN, 2010; GONDRIGE et al., 2012; LIANG et al., 2013). No Brasil, o termo CEO não é usado frequentemente, sendo adotadas várias nomenclaturas para o executivo que exerce as atividades relativas a tal. $\mathrm{Na}$ amostra, a principal nomenclatura utilizada foi de Diretor Presidente. Nas empresas as quais não identificavam seu Diretor Presidente, o CEO foi tomado como sendo o Diretor Superintendente. 
O segundo grupo de variáveis representa as características financeiras da empresa e o tipo de controlador, sendo composto por quatro variáveis: I - tamanho da empresa; II - nível de endividamento; III - presença de controlador estrangeiro, e; IV presença de controlador estatal. Estas variáveis são geralmente usadas em trabalhos que relacionam a estrutura do Conselho de Administração ou a qualidade da governança corporativa da empresa com seu desempenho ou valor de mercado.

I - O Tamanho da Empresa (LogAtivos) pode ser mensurado de várias formas, neste trabalho foi utilizada como proxy para o tamanho da empresa o logaritmo dos ativos totais. As medidas de tamanho da empresa mais comumente usadas são o logaritmo do valor de mercado do patrimônio líquido (YERMACK, 1996), da empresa como um todo (VAFEAS, 1999), das vendas (COLES et al., 2008) e dos ativos totais (MAK; KUSNADI, 2005; ANDRADE et al., 2009; BRICK; CHIDAMBARAN, 2010; LIANG et al., 2013; CHOU et al., 2013). A utilização do logaritmo do ativo como proxy para o tamanho da empresa apresenta vantagens em relação às medidas de valor de mercado, uma vez que, podendo as ações de uma empresa ser pouco negociadas no mercado de capitais, seu valor de mercado não seria mensurado confiavelmente. Ao mesmo tempo, a utilização das vendas como medida de tamanho limita-se ao fato de algumas empresas apresentarem resultados relevantes como outras receitas, que não seriam consideradas neste cálculo. Espera-se que o tamanho da empresa tenha uma relação positiva com a sua lucratividade, assim como nos achados de alguns estudos anteriores (ANDRADE $e t$ al., 2009; CHOU et al., 2013), o que pode ser indício de um maior poder de mercado ou da geração de economias de escala e escopo em razão de seu maior tamanho, o que melhora o desempenho empresarial, materializando-se num melhor resultado. Brick e Chidambaran (2010) encontraram relações inversas entre esta variável e a lucratividade.

II - O Nível de Endividamento (Endividamento) foi medido pela relação entre o passivo exigível e o ativo total. O nível de endividamento é medido por diversas proxies em trabalhos anteriores que relacionaram as características do Conselho de Administração com o desempenho e valor de mercado das empresas. Entre estas medidas estão a relação entre os passivos de longo prazo e os ativos totais (BRICK; CHIDAMBARAN, 2010), o endividamento financeiro em relação aos ativos (GONDRIGE et al., 2012), a razão inversa, o patrimônio líquido em relação aos ativos (LIANG et al., 2013) ou o passivo exigível em relação aos ativos totais (MAK; KUSNADI, 2005; COLES et al., 2008; ANDRADE et al., 2009; CHOU et al., 2013), onde esta última foi usada como proxy para o nível de endividamento.

Apesar das vantagens do endividamento financeiro, tais como o benefício fiscal da dedução dos juros da base de cálculo de impostos sobre a renda e uma maior monitoração do comportamento dos executivos por parte dos credores, o grau de alavancagem financeira pode também ser prejudicial ao desempenho empresarial. A alavancagem financeira advinda de um alto endividamento pode melhorar a lucratividade quando esta usa os recursos captados para gerar resultados superiores ao custo do financiamento. Porém, quando a empresa não consegue atingir tais resultados, a operação torna-se mais onerosa, diminuindo o resultado global da empresa. Sendo assim, de acordo com os resultados encontrados para a maioria dos estudos anteriores, espera-se que o nível de endividamento se relacione negativamente com a lucratividade, como em Andrade et al. (2009) e Chou et al. (2013). Novamente, Brick e Chidambaran (2010) encontraram resultados divergentes ao utilizar o endividamento como variável de controle, onde esta variável relacionava-se positivamente com a lucratividade.

No segundo grupo de variáveis, é representado ainda o tipo de controlador da empresa. $\mathrm{Na}$ literatura mundial, destacam-se três tipos principais de controladores: os controladores privados, os quais dividem-se em domésticos e estrangeiros, e os controladores estatais. Foram 
utilizadas variáveis dummies para identificar o tipo de controlador, uma vez que as empresas destacam tal característica nos seus respectivos Formulários de Referência. Sendo assim, utilizou-se duas variáveis dummies: a primeira representou o III - Controlador Estrangeiro, assumindo valor um (1) quando a empresa identifica seu controlador como sendo estrangeiro e zero (0), caso contrário, assim como em Micco et al. (2007), Grasseni (2010), Baum et al. (2010) e Chen e Liu (2013); a segunda variável dummy representou o IV - Controlador Estatal, apresentando valor um (1) quando tal ente foi identificado como controlador da empresa e zero (0), caso contrário, da mesma forma como utilizado em trabalhos anteriores (MICCO et al., 2007; BAUM et al., 2010; CHEN; LIU, 2013). A presença de cada tipo de controlador é representada na Equação (1) pelas denominações "Estrangeiro" e "Estatal". Quando o controlador é identificado como privado nacional, as duas variáveis dummies apresentam valor zero (0).

As empresas controladas pelo estado que combinam atividades com entes privados são conhecidas como empresas de economia mista. O fato de o estado deter o controle destas empresas pode afetar a maneira como estas operam, uma vez que o estado possui suas próprias motivações para o investimento em certo tipo de atividade. Dentre as razões para o investimento direto do estado na atividade empresarial, destaca-se a falta de mercados financeiros desenvolvidos para fornecer capital a empresas de setores estratégicos da economia, muitos dos quais podem apresentar-se naturalmente deficitários ou pouco rentáveis, o que inibe o interesse dos já escassos investidores (SILVEIRA, 2010, p. 318). Por outro lado, diversos autores documentaram que os controladores das empresas estatais muitas vezes utilizam seu poder econômico para razões políticas, utilizando-se do aumento do quadro de pessoal e da realização de obras de retorno econômico duvidoso como contraparte para o recebimento de apoio político nas eleições, uma vez que a alta remuneração e a flexibilidade conferida aos indivíduos eleitos para cargos eletivos aumenta a motivação para que estes se utilizem dos bens públicos para benefício próprio (SHLEIFER; VISHNY, 1994; LA PORTA et al., 2002; SILVEIRA, 2010). Essas características inerentes aos controladores estatais podem desencadear reflexos no desempenho e valor de mercado das empresas, onde vários estudos associam as empresas sob controle estatal a uma baixa eficiência e desempenho, se comparadas com as empresas privadas domésticas ou estrangeiras (MIAN, 2003; BARBOSA; LOURI, 2005; MICCO et al., 2007; LI et al., 2009).

Já a presença de controladores estrangeiros está relacionada a uma melhora no desempenho empresarial, visto que o foco em objetivos de longo prazo é determinante quando da aquisição do controle de uma empresa. Acredita-se que estes investidores apresentam uma alta capacidade de monitoração das atividades da empresa investida. A transferência de tecnologia, técnicas de gestão e recursos financeiros também são características associadas a este tipo de controlador, as quais contribuem para o estabelecimento de empresas de alto desempenho (DOUMA et al., 2006; VARCHOLOVA; BESLEROVA, 2013).

Ao final, foram inseridas as variáveis dummies temporais que assumem o valor um (1) para o ano que representam. $\mathrm{O}$ ano de 2010 foi utilizado como comparação para os demais anos. Tais variáveis foram inseridas com o objetivo de captar os efeitos da passagem do tempo, fatores macroeconômicos e regulatórios que podem afetar a lucratividade das empresas listadas. Estes fatores incluem a inflação acumulada, a variação da taxa de juros básica da economia, variação no Produto Interno Bruto (PIB) e alterações na tributação das empresas.

Cada grupo de variáveis foi adicionado ao modelo na ordem em que aparecem na Equação (1), onde primeiro foram adicionadas as variáveis relativas ao Conselho de Administração, em seguida as variáveis relativas às características financeiras e ao tipo do controlador e, por fim, 
as variáveis dummies temporais. No Quadro 3 são apresentadas resumidamente as variáveis utilizadas, suas especificações e resultados esperados.

Quadro 3 - Resumo das variáveis dependentes e independentes utilizadas na pesquisa, sua forma de mensuração, os trabalhos semelhantes que utilizaram esta variável e o sinal esperado para seu coeficiente angular

\begin{tabular}{|c|c|c|c|}
\hline Variável & Métrica da Variável & Utilizado por & $\begin{array}{c}\text { Sinal } \\
\text { Esperado }\end{array}$ \\
\hline \multicolumn{4}{|c|}{ VARIÁVEIS DEPENDENTES } \\
\hline $\mathrm{ROA}_{\mathrm{i}, \mathrm{t}}$ & $\frac{\text { Lucro Líquido }_{\mathrm{i}, \mathrm{t}}}{\text { Ativo }_{\text {Total }} \mathrm{i}, \mathrm{t}}$ & $\begin{array}{l}\text { Yermack (1996); Mak e Kusnadi } \\
\text { (2005); Cheng (2008); Coles et al. } \\
\text { (2008); Liang et al. }(2013)\end{array}$ & \\
\hline ROAajMediana $_{\mathrm{i}, \mathrm{t}}$ & $\mathrm{ROA}_{\mathrm{i}, \mathrm{t}}-\mathrm{ROA}(\text { mediano })_{\mathrm{s}, \mathrm{t}}$ & $\begin{array}{l}\text { Vafeas (1999); Cheng (2008); Brick e } \\
\text { Chidambaran (2010) }\end{array}$ & \\
\hline $\mathrm{ROE}_{\mathrm{i}, \mathrm{t}}$ & $\frac{\text { Lucro Líquido }_{i, t}}{\text { Pat. Líquido (inicial) }}$ & Liang et al. (2013) & \\
\hline ROEajMediana $_{\mathrm{i}, \mathrm{t}}$ & $\mathrm{ROE}_{\mathrm{i}, \mathrm{t}}-\mathrm{ROE}(\text { mediano })_{\mathrm{s}, \mathrm{t}}$ & - & \\
\hline \multicolumn{4}{|c|}{ VARIÁVEIS INDEPENDENTES } \\
\hline \multicolumn{4}{|c|}{ Características do Conselho de Administração } \\
\hline TamanhoCA & $\begin{array}{l}\text { Número de membros do } \\
\text { Conselho de Administração }\end{array}$ & $\begin{array}{l}\text { Mak e Kusnadi (2005); Coles et al. } \\
\text { (2008); Andrade et al. (2009); Brick e } \\
\text { Chidambaran (2010); Liang et al. } \\
\text { (2013) }\end{array}$ & $+1-$ \\
\hline$\%$ Independentes & $\frac{\text { № Membros Independentes }}{\text { № Membros Totais }}$ & $\begin{array}{l}\text { Mak e Kusnadi (2005); Cheng (2008); } \\
\text { Brick e Chidambaran (2010); Liang et } \\
\text { al. (2013) }\end{array}$ & $+1-$ \\
\hline$\%$ Externos & $\frac{\text { № Membros Externos }}{\text { № Membros Totais }}$ & Yermack (1996); Andrade et al. (2009) & $+1-$ \\
\hline DualidadeCEO & $\begin{array}{l}\text { Valor um (1) quando o CEO } \\
\text { ocupa também o cargo de } \\
\text { Chairman e zero }(0) \text {, do } \\
\text { contrário }\end{array}$ & $\begin{array}{l}\text { Mak e Kusnadi (2005); Cheng (2008); } \\
\text { Andrade } \text { et al. (2009); Brick e } \\
\text { Chidambaran (2010); Gondrige et al. } \\
\text { (2012); Liang } \text { et al. }(2013)\end{array}$ & $+1-$ \\
\hline \multicolumn{4}{|c|}{ Características Financeiras e de Controle } \\
\hline LogAtivos & $\begin{array}{l}\text { Logaritmo do valor dos ativos } \\
\text { totais ao final do período }\end{array}$ & $\begin{array}{l}\text { Mak e Kusnadi (2005); Andrade } \text { et al. } \\
\text { (2009); Brick e Chidambaran (2010); } \\
\text { Liang } \text { et al. (2013); Chou et al. (2013) }\end{array}$ & + \\
\hline Endividamento & $\frac{\text { Passivos Exigíveis }}{\text { Ativos Totais }}$ & $\begin{array}{c}\text { Mak e Kusnadi (2005); Coles et al. } \\
\text { (2008); Andrade et al. (2009); Chou et } \\
\text { al. (2013) }\end{array}$ & - \\
\hline Estrangeiro & $\begin{array}{l}\text { Valor um (1) quando a } \\
\text { empresa define o tipo de } \\
\text { controlador como Estrangeiro } \\
\text { ou Estrangeiro Holding e zero } \\
(0), \text { do contrário }\end{array}$ & $\begin{array}{l}\text { Micco et al. (2007); Grasseni (2010); } \\
\text { Baum et al. (2010); Chen e Liu (2013) }\end{array}$ & + \\
\hline Estatal & $\begin{array}{c}\text { Valor um (1) quando a } \\
\text { empresa define o tipo de } \\
\text { controlador como Estatal ou } \\
\text { Estatal Holding e zero (0), do } \\
\text { contrário }\end{array}$ & $\begin{array}{l}\text { Micco et al. (2007); Baum et al. } \\
\text { (2010); Chen e Liu (2013) }\end{array}$ & - \\
\hline
\end{tabular}

Fonte: Elaboração própria. 


\subsection{Escolha dos Estimadores e Testes de Robustez}

De acordo com a literatura teórica-empírica sobre o tema, a heterogeneidade não observada das empresas é fator determinante para a avaliação do desempenho individual de cada uma delas. Este fato justifica a utilização do método de estimação de dados em painel, onde trabalhos anteriores utilizaram este mesmo método, destacando-se o uso do estimador de efeitos fixos (YERMACK, 1996; CHENG, 2008; BRICK; CHIDAMBARAN, 2010) ${ }^{1}$.

Neste sentido, visando captar o efeito da heterogeneidade não observada foram utilizados testes de especificação para a escolha do estimador que melhor se ajusta aos dados do modelo. Inicialmente, testou-se a adequação do modelo de efeitos fixos (fixed effects within-group model - FE) contra a hipótese de adequação do modelo de efeitos aleatórios (random effects RE). Para a escolha entre estes dois estimadores, optou-se pela utilização do teste de SarganHansen uma vez que este teste é válido também na presença de heterocedasticidade e/ou autocorrelação nos resíduos da regressão. As hipóteses nula $\left(\mathrm{H}_{0}\right)$ e alternativa $\left(\mathrm{H}_{\mathrm{A}}\right)$ do teste de Sargan-Hansen são similares às do teste de Hausman, onde a não rejeição da hipótese nula indica a adequação do modelo RE em relação ao modelo FE (SCHAFFER; STILLMAN, $2016)^{2}$. Nos testes utilizados para seleção dos estimadores, rejeitou-se a hipótese nula $\left(\mathrm{H}_{0}\right)$ quando o $p$-value foi igual ou inferior a $10 \%$

O modelo FE apresenta a limitação de não calcular coeficientes para variáveis que apresentam os mesmos valores ao longo do tempo para os mesmos indivíduos (como o controle estatal, que não muda ao longo do tempo). Nas regressões onde os testes de seleção dos modelos indicaram a adequação do modelo $\mathrm{FE}$ em relação ao modelo RE e ao mesmo tempo possuíam o controle estatal como variável independente, os coeficientes foram calculados através do modelo Least Square Dummy Variables (LSDV). Nos modelos LSDV as variáveis dummies são inseridas para cada grupo de indivíduos $i$, sendo uma destas subtraída para evitar a existência de colinearidade perfeita entre as dummies (GUJARATI; PORTER, 2011).

Em seguida, foram testados alguns dos pressupostos subjacentes ao modelo de regressão linear: ausência de um alto grau de multicolinearidade, homocedasticidade da variância dos resíduos e a presença de correlação serial de primeira ordem (autocorrelação dos resíduos). Para detectar a presença de multicolinearidade, utilizou-se o teste do fator de inflação da variância (Variance Inflation Factor - VIF), sendo uma variável considerada altamente colinear quando o valor do seu VIF foi igual ou maior que 10 (GUJARATI; PORTER, 2011).

A presença de heterocedasticidade na variância dos resíduos foi analisada pelos testes de Wald e White para os modelos FE e LSDV, respectivamente. A hipótese nula $\left(\mathrm{H}_{0}\right)$ indica a ausência de heterocedasticidade na variância dos resíduos e a hipótese alternativa $\left(\mathrm{H}_{\mathrm{A}}\right)$ a sua presença. Nos modelos onde foi constatada a ausência de homocedasticidade, para os modelos LSDV, os erros-padrão foram estimados na sua forma robusta para a heterocedasticidade pelo procedimento de White (1980) enquanto para os modelos FE os erros-padrão foram estimados de forma robusta clusterizada por indivíduo.

O pressuposto da ausência de correlação serial de primeira ordem nos resíduos foi verificado pelo teste de Wooldridge para os modelos FE e RE. Nos modelos onde foi detectada

\footnotetext{
${ }^{1}$ A literatura indica o uso de modelos de dados em painel com estimadores de efeitos fixos ou aleatórios dado que estes consideram a natureza de de corte transversal e séries temporais dos dados (GUJARATI; PORTER, 2011).

${ }^{2} \mathrm{O}$ teste de Hausman foi executado para oferecer uma comparação os estimadores selecionados por este teste e os estimadores selecionados através do teste de Sargan-Hansen. Os resultados de ambos os testes são mostrados na Tabela 3.
} 
a presença de correlação serial de primeira ordem, os erros-padrão robustos foram estimados pela sua forma robusta clusterizada por indivíduo (WOOLDRIDGE, 2001). Adicionalmente, recorremos ao Teorema do Limite Central ao não testar o pressuposto da normalidade dos resíduos, assumindo, portanto, que os resíduos serão assintoticamente normalmente distribuídos em grandes amostras, tornando possível a inferência pelas estatísticas $\mathrm{t}$ e $\mathrm{F}$ (GUJARATI; PORTER, 2011).

Por fim, como teste de robustez, também foram estimadas regressões quantílicas. As regressões quantílicas testam a relação entre as variáveis independentes e quantis condicionais da variável dependente. As regressões foram estimadas nos quantis $25^{\circ}, 50^{\circ}$ e $75^{\circ}$ da variável dependente com o objetivo de verificar se a influência do Conselho de Administração na lucratividade das empresas muda quando consideradas as empresas menos e mais lucrativas da amostra. A regressão quantílica possui algumas vantagens em comparação a outros estimadores, dentre as quais a robustez a outliers (CHENG, 2008) e o fato de não ser necessário que os resíduos da regressão sejam distribuídos normalmente para que sejam feitas as inferências (GREENE, 2014). Todas as estimações foram feitas através do software Stata®.

\subsection{Seleção e Composição da Amostra}

A população da pesquisa é composta por todas as empresas listadas na BM\&FBOVESPA entre os anos de 2010 a 2014. O período foi escolhido em razão de apresentar todas as informações sobre os membros do CA e suas classificações, como exigido pela Instrução CVM $\mathrm{n}^{\circ} 480$, aprovada no ano de 2009. Foram coletadas informações sobre o tamanho do Conselho de Administração, os membros que o compõem, os dados contábeis referentes ao valor de seus ativos, passivos, patrimônio líquido e lucro líquido, o setor no qual operam e o tipo de controlador das empresas.

Para selecionar as empresas a serem utilizadas na amostra final, foram excluídas aquelas que: - i) Possuam informações ausentes para quaisquer das variáveis utilizadas na pesquisa em dado período analisado. O critério de exclusão das empresas deu-se pela falta de alguma das seguintes informações: a) valor dos ativos; b) valor dos passivos; c) valor do patrimônio líquido; e, d) valor do lucro líquido para o ano. Após este filtro, foram excluídas as empresas classificadas como em "Fase Pré-Operacional", "Em Recuperação Judicial ou Equivalente", "Em Recuperação Extrajudicial", "Paralisada" ou aquelas que não apresentaram nenhuma denominação no seu Formulário de Referência, sendo admitidas apenas as empresas classificadas como em "Fase Operacional" nos respectivos formulários no tópico "Situação do Emissor", na aba "Tipo de Registro". Este filtro teve por objetivo considerar apenas empresas comparáveis, onde a fase operacional pode levar a vieses nos índices de desempenho/lucratividade;

- ii) Não identificavam corretamente ou não possuíam executivos denominados como CEO ou Chairman, não especificavam os membros do Conselho de Administração como sendo efetivos ou suplentes, e, não apresentavam dados sobre os membros do Conselho de Administração ou diretoria executiva;

- iii) Estava classificadas como bancos (13 empresas) em razão de apresentarem características distintas das empresas não financeiras, principalmente se tratando do reflexo do tamanho da empresa e de seu endividamento na lucratividade empresarial, uma vez que são esperadas relações diferentes para empresas financeiras e não-financeiras. 
Por fim, do total de 490 empresas tomadas inicialmente, restaram 182 empresas que continuam informações para os 5 anos analisados, resultando portando em um painel balanceado com 910 observações $^{3}$.

Os Formulários de Referência ativos para cada empresa nos anos utilizados na amostra foram obtidas através dos sites da Comissão de Valores Mobiliários (www.cvm.gov.br) e da BM\&FBOVESPA (www.bmfbovespa.com.br) e serviram para retirar as informações sobre o número de membros do Conselho de Administração, se estes membros faziam parte também da diretoria executiva, se eram membros suplentes ou efetivos, se estes membros eram independentes e a identidade do CEO da empresa (Diretor Presidente/Superintendente). Todas essas informações foram retiradas do item "12. Assembleia geral e administração", subitem "12.6/8 - Composição e experiência profissional da administração e do Conselho Fiscal".

Concluindo, as informações sobre a situação do emissor e espécie de controle acionário foram coletadas no item "Dados Cadastrais", subitem "Dados Gerais" na aba "Tipo de Registro" dos respectivos Formulários de Referência. As informações financeiras utilizadas na pesquisa foram coletadas através do software Economatica ${ }^{\circledR}$, dentre as quais: a) o valor dos ativos totais; b) passivos exigíveis / ativos totais; c) ROA, d) ROE; e, e) Setor de Atuação. Destaca-se, ainda, que todas as variáveis foram coletadas em bases anuais.

\footnotetext{
${ }^{3}$ Optou-se pela formação de um painel balanceado em razão da eliminação de poucas observações e de um possível viés de atrito decorrente do uso de um painel desbalanceado. Para mais informações a respeito das vantagens e desvantagens do uso de um painel balanceado em relação ao painel desbalanceado, ver Baltagi (2005, p. 165) e Cameron e Trivedi (2005, p. 739).
} 


\section{ANÁLISE DOS RESULTADOS}

\subsection{Estatísticas Descritivas}

A amostra foi composta por 182 empresas não-financeiras com ações negociadas na BM\&FBOVESPA. Na Tabela 1 constam as informações estatísticas do ROA, ROA ajustado à mediana, ROE, ROE ajustado à mediana, tamanho do Conselho de Administração, percentual de membros independentes/externos, dualidade do CEO, ativos totais ao fim do período, nível de endividamento e informações sobre o tipo de controlador, para os anos 2010 a 2014.

Ao longo dos períodos, observou-se uma sensível queda nas estatísticas referentes às medidas de lucratividade. A média, mediana e valores máximos e mínimos para o retorno gerado pelos ativos da empresa (ROA) passaram, respectivamente, de 8,09\%, 5,89\%, 199,31\% e $-60,74 \%$, em 2010 , para $2,51 \%, 3,52 \%, 34,75 \%$ e $-70,04 \%$. O mesmo padrão foi observado nas outras medidas de lucratividade, indicando que com o tempo as empresas passaram a apresentar uma menor lucratividade.

Dentre as variáveis representativas das características do Conselho de Administração, o número de componentes do conselho mostrou-se estável ao longo dos anos, com média e mediana variando entre 6,8 e 7,0, respectivamente, em 2010 e, aproximadamente, 6,8 e 7,0 em 2014. A similaridade entre os valores da média e mediana indica uma tendência central das empresas em compor seu Conselho de Administração com 6 ou 7 membros. Estes valores supõem uma adequação das empresas listadas na BM\&FBOVESPA às boas práticas de governança corporativa sugeridas pelo IBGC (2009) cujo Conselho de Administração deveria ser formado por, no mínimo, 5 (cinco) e, no máximo, 11 (onze) conselheiros.

O destaque neste quesito vai para as empresas que apresentaram mais ou menos conselheiros do que o previsto pelo IBGC como um número adequado. Para o período analisado, 43 (quarenta e três) empresas apresentaram conselhos de administração formado por menos de 5 (cinco) membros, destacando-se aquelas que apresentaram um órgão formado por 2 (dois) conselheiros, sendo estas a Alfa Holdings S. A. (2014), América Latina Logística Malha Norte (2011) e J. B. Duarte (2010).

A independência do Conselho de Administração, medida pelo percentual de conselheiros independentes em relação ao total, apresentou leve alteração entre os anos da pesquisa. Os valores médio e mediano passaram de $15 \%$ e $0 \%$, em 2010 , para $20 \%$ e $16,7 \%$, em 2014 , indicando uma tendência crescente de as empresas incluírem membros independentes, possivelmente esperando que sua adição ao órgão melhore o desempenho empresarial e também com o objetivo de sinalizar ao mercado a adoção de boas práticas de governança corporativa. No entanto, há indícios de que o percentual de conselheiros externos não variou significativamente ao longo dos períodos. No período de análise, os conselhos de administração apresentavam, em média, uma proporção de $86 \%$ de membros externos, com a mediana indicando valores próximos a este. Tais constatações confirmam a tendência das empresas em ocupar as vagas do seu CA com uma maior proporção de conselheiros externos, que podem apresentar maior independência quando da tomada de decisão e avaliação de desempenho gerencial. Porém, ao mesmo tempo, uma proporção muito alta destes membros no conselho aumenta os custos de transferência de informação entre os executivos da empresa e os diretores do Conselho de Administração, o que pode levar à tomada de decisões com informações incompletas. 
A última característica do Conselho de Administração analisada foi a dualidade do CEO. Em 2010, aproximadamente $28 \%$ das empresas apresentavam um único indivíduo como ocupante dos cargos de Diretor Presidente e Presidente do Conselho de Administração/Chairman. Essa proporção caiu ao longo dos anos, com o percentual de reduzindo-se para 24\% (2011), 21\% (2012), 20\% (2014) e 17\% (2014). A queda na proporção de CEOs que também ocupam o cargo de Chairman está alinhada com as boas práticas de governança corporativa a serem adotadas pelas empresas, sugeridas pelo IBGC (2009, p. 35) e pela CVM (2002), em sua cartilha de recomendações sobre as melhores práticas de governança corporativa. As boas práticas de governança corporativa recomendam fortemente a separação dos cargos de CEO e Chairman para diferentes indivíduos, no intuito de evitar prejuízos sobre a adequada supervisão da empresa.

A análise do tamanho das empresas listadas sinaliza um crescimento das aplicações em ativos. $\mathrm{O}$ valor do capital aplicado em ativos pela maior empresa foi $\mathrm{R} \$ 520$ bilhões em 2010 , chegando a $\mathrm{R} \$ 793$ bilhões em 2014. O endividamento das empresas permaneceu relativamente constante para o período estudado, com a proporção de passivos exigíveis em relação aos ativos variando entre $50 \%$ e $60 \%$, tanto em termos médios quando medianos. A presença de valores acima ou próximos de 1,0000 indica empresas em que os passivos exigíveis são maiores que seus ativos totais, gerando um patrimônio líquido negativo, também conhecido como passivo a descoberto. Esta situação, no entanto, foi observada apenas no ano de 2014, onde uma empresa apresentou um valor de 1,3090 para esta variável, indicando uma dívida $31 \%$ maior que o valor dos ativos totais desta empresa.

Em relação aos tipos de controlador, a proporção de empresas sob controle estrangeiro e estatal permaneceu relativamente constante ao longo do período analisado. O percentual de empresas sob controle estrangeiro aumentou de 4,40\% (8 empresas) em 2010 para 4,95\% (9 empresas) a partir de 2013. A proporção de empresas sob controle estatal também permaneceu constante em todo o período analisado, correspondendo a 5,49\% das observações (10 empresas). Logicamente, o percentual restante $(90,11 \%$ de 2010 a 2012 e 89,56\% em 2013 e 2014) corresponde às empresas sob controle privado doméstico, que compõem a maioria da amostra. 
Tabela 1 - Estatísticas descritivas da amostra composta por 182 empresas não-financeiras listadas na BM\&FBOVESPA 2010-2014

\begin{tabular}{|c|c|c|c|c|c|}
\hline Variável & Média & Mediana & Desvio-padrão & Máximo & Mínimo \\
\hline \multicolumn{6}{|c|}{2010} \\
\hline $\mathrm{ROA}_{\text {i.t }}$ & 0,0802 & 0,0589 & 0,1706 & 1,9931 & $-0,6074$ \\
\hline ROAajMediana $_{\text {i.t }}$ & 0,0371 & 0,0191 & 0,1706 & 1,9727 & $-0,6187$ \\
\hline $\mathrm{ROE}_{\mathrm{i.t}}$ & 0,3380 & 0,1760 & 1,1967 & 13,6120 & $-2,7200$ \\
\hline ROEajMediana $_{\text {i.t }}$ & 0,1750 & 0,0183 & 1,1910 & 13,4460 & $-2,9685$ \\
\hline TamanhoCA & 6,8352 & 7,0000 & 2,6395 & 17,0000 & 2,0000 \\
\hline$\%$ Independentes & 0,1514 & 0,0000 & 0,2066 & 0,8750 & 0,0000 \\
\hline$\%$ Externos & 0,8517 & 0,8571 & 0,1404 & 1,0000 & 0,3333 \\
\hline DualidadeCEO & 0,2802 & 0,0000 & 0,4503 & 1,0000 & 0,0000 \\
\hline Ativos Totais (mil) & 10.758 .881 & 2.395 .831 & 46.270 .180 & 519.970 .003 & 14.116 \\
\hline Endividamento & 0,5231 & 0,5540 & 0,1946 & 0,9310 & 0,0110 \\
\hline Estrangeiro & 0,0440 & 0,0000 & 0,2056 & 1,0000 & 0,0000 \\
\hline Estatal & 0,0549 & 0,0000 & 0,2285 & 1,0000 & 0,0000 \\
\hline \multicolumn{6}{|c|}{2011} \\
\hline $\mathrm{ROA}_{\text {i.t }}$ & 0,0617 & 0,0501 & 0,1054 & 0,8644 & $-0,1520$ \\
\hline RoAajMediana $_{\text {i.t }}$ & 0,0259 & 0,0130 & 0,1038 & 0,8463 & $-0,1760$ \\
\hline $\mathrm{ROE}_{\mathrm{i} . \mathrm{t}}$ & 0,1714 & 0,1205 & 0,4869 & 6,0870 & $-0,5860$ \\
\hline ROEajMediana $_{\text {i.t }}$ & 0,0434 & 0,0028 & 0,4759 & 5,9330 & $-0,7350$ \\
\hline TamanhoCA & 6,9341 & 7,0000 & 2,7363 & 16,0000 & 2,0000 \\
\hline$\%$ Independentes & 0,1879 & 0,1603 & 0,2173 & 1,0000 & 0,0000 \\
\hline$\%$ Externos & 0,8587 & 0,8750 & 0,1331 & 1,0000 & 0,5000 \\
\hline DualidadeCEO & 0,2418 & 0,0000 & 0,4293 & 1,0000 & 0,0000 \\
\hline Ativos Totais (mil) & 12.341 .770 & 2.833 .698 & 53.090 .899 & 599.149 .983 & 8.854 \\
\hline Endividamento & 0,5361 & 0,5710 & 0,2015 & 0,9550 & 0,0090 \\
\hline Estrangeiro & 0,0440 & 0,0000 & 0,2056 & 1,0000 & 0,0000 \\
\hline Estatal & 0,0549 & 0,0000 & 0,2285 & 1,0000 & 0,0000 \\
\hline \multicolumn{6}{|c|}{2012} \\
\hline $\mathrm{ROA}_{\text {i.t }}$ & 0,0473 & 0,0435 & 0,0828 & 0,5176 & $-0,1799$ \\
\hline ROAajMediana $_{\text {i.t }}$ & 0,0230 & 0,0163 & 0,0809 & 0,4977 & $-0,2202$ \\
\hline $\mathrm{ROE}_{\mathrm{i.t}}$ & 0,1220 & 0,1030 & 0,2488 & 1,6290 & $-0,6860$ \\
\hline ROEajMediana $_{\text {i.t }}$ & 0,0498 & 0,0238 & 0,2288 & 1,4555 & $-0,8330$ \\
\hline TamanhoCA & 6,9505 & 7,0000 & 2,7174 & 15,0000 & 3,0000 \\
\hline$\%$ Independentes & 0,1893 & 0,1667 & 0,2019 & 0,7778 & 0,0000 \\
\hline$\%$ Externos & 0,8559 & 0,8571 & 0,1275 & 1,0000 & 0,6000 \\
\hline DualidadeCEO & 0,2143 & 0,0000 & 0,4115 & 1,0000 & 0,0000 \\
\hline Ativos Totais (mil) & 13.977 .134 & 3.341 .855 & 60.279 .571 & 677.716 .287 & 12.366 \\
\hline Endividamento & 0,5469 & 0,5900 & 0,2071 & 0,9630 & 0,0070 \\
\hline Estrangeiro & 0,0440 & 0,0000 & 0,2056 & 1,0000 & 0,0000 \\
\hline Estatal & 0,0549 & 0,0000 & 0,2285 & 1,0000 & 0,0000 \\
\hline \multicolumn{6}{|c|}{2013} \\
\hline $\mathrm{ROA}_{\text {i.t }}$ & 0,0421 & 0,0400 & 0,1030 & 0,8034 & $-0,5178$ \\
\hline ROAajMediana $_{\text {i.t }}$ & 0,0277 & 0,0155 & 0,1261 & 0,7880 & $-0,5261$ \\
\hline $\mathrm{ROE}_{\mathrm{i.t}}$ & 0,1083 & 0,0930 & 0,3164 & 2,9010 & $-0,9890$ \\
\hline ROEajMediana $_{\text {i.t }}$ & 0,0352 & 0,0133 & 0,3112 & 2,7680 & $-1,0965$ \\
\hline TamanhoCA & 6,9341 & 7,0000 & 2,6018 & 16,0000 & 3,0000 \\
\hline$\%$ Independentes & 0,1999 & 0,1818 & 0,2038 & 0,8333 & 0,0000 \\
\hline$\%$ Externos & 0,8601 & 0,8750 & 0,1285 & 1,0000 & 0,6000 \\
\hline DualidadeCEO & 0,1978 & 0,0000 & 0,3994 & 1,0000 & 0,0000 \\
\hline Ativos Totais (mil) & 12.976 .237 & 3.237 .076 & 60.194 .373 & 752.966 .638 & 12.418 \\
\hline Endividamento & 0,5353 & 0,5540 & 0,2166 & 0,9690 & 0,0050 \\
\hline Estrangeiro & 0,0495 & 0,0000 & 0,2174 & 1,0000 & 0,0000 \\
\hline Estatal & 0,0549 & 0,0000 & 0,2285 & 1,0000 & 0,0000 \\
\hline \multicolumn{6}{|c|}{2014} \\
\hline $\mathrm{ROA}_{\mathrm{i} . \mathrm{t}}$ & 0,0251 & 0,0352 & 0,1127 & 0,3475 & $-0,7004$ \\
\hline ROAajMediana $_{\text {i.t }}$ & 0,0085 & 0,0094 & 0,1226 & 0,7131 & $-0,7303$ \\
\hline $\mathrm{ROE}_{\mathrm{i.t}}$ & $-0,0358$ & 0,0800 & 0,9656 & 0,9690 & $-12,1960$ \\
\hline ROEajMediana $_{\text {i.t }}$ & $-0,1074$ & 0,0085 & 0,9610 & 0,7230 & $-12,2470$ \\
\hline TamanhoCA & 6,7857 & 7,0000 & 2,5841 & 15,0000 & 2,0000 \\
\hline$\%$ Independentes & 0,2016 & 0,1667 & 0,2212 & 0,8571 & 0,0000 \\
\hline$\%$ Externos & 0,8553 & 0,8571 & 0,1377 & 1,0000 & 0,3333 \\
\hline DualidadeCEO & 0,1703 & 0,0000 & 0,3770 & 1,0000 & 0,0000 \\
\hline Ativos Totais (mil) & 14.245 .397 & 3.637 .922 & 63.725 .252 & 793.375 .000 & 12.749 \\
\hline Endividamento & 0,5521 & 0,5700 & 0,2362 & 1,3090 & 0,0070 \\
\hline Estrangeiro & 0,0495 & 0,0000 & 0,2174 & 1,0000 & 0,0000 \\
\hline Estatal & 0,0549 & 0,0000 & 0,2285 & 1,0000 & 0,0000 \\
\hline
\end{tabular}

Fonte: Economatica® e Formulários de Referência. 
$\mathrm{Na}$ Tabela 2 são mostradas as 5 empresas que apresentaram os maiores/menores valores para as variáveis ROA, ROA ajustado à mediana, ROE, ROE ajustado à mediana, tamanho do Conselho de Administração, percentual de membros independentes/externos, ativos totais ao fim do período, nível de endividamento.

Dentre as empresas que apresentaram os maiores valores para as medidas de lucratividade utilizadas, destacam-se a Tarpon Investimentos S. A., apresentando os maiores valores para o ROA, ROA ajustado à mediana, ROE e ROE ajustado à mediana. Valores similares para os índices de lucratividade obtidos pela Tarpon Investimentos S. A. foram obtidos também por 521 Participações S. A., Telefônica Brasil S. A., LPS Brasil S. A. e Terminal G. M. C. S. A.

Por outro lado, os destaques negativos para os índices de lucratividade são obtidos principalmente pelas empresas OSX Brasil S. A. e Tectoy S. A., que revezaram pelo posto de empresa que obteve os piores retorno e retorno ajustado. A Tectoy S. A. apresentou para o ano de 2014 um prejuízo correspondente a 12 vezes o valor do seu patrimônio líquido.

A Oi S. A. e a Telefônica Brasil apresentaram Conselhos de Administração com maior número de membros, entre 15 e 17 (valor máximo atingido para a Telefônica Brasil em 2010), contrariando as indicações do IBGC (2009) que sugere órgãos formados por até 11 membros e de Lipton e Lorsch (1992), que consideram um Conselho de Administração ótimo aquele formado por 8 ou 9 membros. Por outro lado, várias foram as empresas que mostraram um órgão formado por menos de 5 membros, tamanho considerado adequado pelo IBGC. Destas empresas, a Alfa Holdings S. A. (2014), All Malha Norte S. A. (2011) e Industrias J. B. Duarte S. A. (2010) apresentaram um Conselho de Administração formado por apenas dois membros.

Quando comparada a proporção de membros independentes em relação aos demais, as empresas que apresentaram um maior percentual de diretores independentes foram a Embraer (2010, 2011 e 2014), a Eternit S. A. (2014) e a Totvs S. A. (2011). O destaque vai para a Embraer que apresentou, em 2011, um Conselho de Administração formado exclusivamente por diretores independentes. No outro extremo da análise, várias empresas não identificaram nenhum dos membros do seu Conselho de Administração como sendo independente.

Ao analisar a proporção de membros externos em relação ao total, várias empresas apresentaram um Conselho de Administração formado exclusivamente por membros externos, enquanto que a Polpar S. A. (2014), Guararapes Confecções S. A. (2010) e a Cia Paulista de Força e Luz (2010) foram as únicas que apresentaram um Conselho de Administração formado majoritariamente por membros internos.

A Petrobras S. A. foi responsável pelos valores máximos do indicador Ativos Totais em todos os períodos da amostra. Por outro lado, a Polpar S. A. e a Dinâmica Energia S. A. apresentaram os menores valores para os ativos, com menos de R \$ 20 milhões em aplicações nestes itens, onde o menor valor foi registrado pela Polpar em 2011 (R 8.854 mil).

E, por fim, as empresas que apresentaram o maior endividamento no período estudado foram a OSX Brasil (2014), Tec Toy S. A. (2014) e a Gol (2014); todas com um índice maior que 1,0000. Por outro lado, 9 empresas apresentaram um índice de endividamento menor que $10 \%$, indicando que apenas uma baixa proporção das aplicações em ativos são financiadas por capitais de terceiros através da captação de recursos em forma de dívida. 
Tabela 2 - Empresas que apresentaram os 5 Valores máximos e mínimos para as variáveis do estudo 20102014

\begin{tabular}{|c|c|c|c|c|c|}
\hline \multicolumn{3}{|c|}{ Valores Máximos } & \multicolumn{3}{|c|}{ Valores Mínimos } \\
\hline \multicolumn{6}{|c|}{ ROA } \\
\hline Tarpon Investimentos S. A. & 2010 & 1,9931 & OSX Brasil S. A. & 2014 & $-0,7004$ \\
\hline Tarpon Investimentos S. A. & 2011 & 0,8644 & Jereissati Telecom S. A. & 2014 & $-0,6455$ \\
\hline Tarpon Investimentos S. A. & 2013 & 0,8034 & Industrias J B Duarte S. A. & 2010 & $-0,6074$ \\
\hline 521 Participações S. A. & 2011 & 0,7098 & Itautec S. A. & 2013 & $-0,5178$ \\
\hline Bahema S. A. & 2010 & 0,5465 & Tec Toy S. A. & 2014 & $-0,4542$ \\
\hline \multicolumn{6}{|c|}{ ROA ajustado à mediana } \\
\hline Tarpon Investimentos S. A. & 2010 & 1,9727 & OSX Brasil S. A. & 2014 & $-0,7303$ \\
\hline Tarpon Investimentos S. A. & 2011 & 0,8463 & Industrias J B Duarte S. A. & 2010 & $-0,6187$ \\
\hline Tarpon Investimentos S. A. & 2013 & 0,7880 & Itautec S. A. & 2013 & $-0,5261$ \\
\hline Telefônica Brasil S. A. & 2014 & 0,7131 & Tec Toy S. A. & 2014 & $-0,4745$ \\
\hline Cia Gás de São Paulo S. A. & 2013 & 0,6939 & Metalgrafica Iguaçu S. A. & 2013 & $-0,3275$ \\
\hline \multicolumn{6}{|c|}{ ROE } \\
\hline Tarpon Investimentos S. A. & 2010 & 13,6120 & Tec Toy S. A. & 2014 & $-12,1960$ \\
\hline LPS Brasil S. A. & 2010 & 6,6840 & OSX Brasil S. A. & 2010 & $-2,7200$ \\
\hline Tarpon Investimentos S. A. & 2011 & 6,0870 & General Shopping BR S. A. & 2014 & $-1,9660$ \\
\hline Terminal G. M. C. S. A. & 2010 & 3,3750 & OSX Brasil S. A. & 2014 & $-1,9230$ \\
\hline Azevedo e Travassos S. A. & 2010 & 2,9820 & Forjas Taurus S. A. & 2014 & $-1,270$ \\
\hline \multicolumn{6}{|c|}{ ROE ajustado à mediana } \\
\hline Tarpon Investimentos S. A. & 2010 & 13,4460 & Tec Toy S. A. & 2014 & $-12,2470$ \\
\hline LPS Brasil S. A. & 2010 & 6,5915 & OSX Brasil S. A. & 2010 & $-2,9685$ \\
\hline Tarpon Investimentos S. A. & 2011 & 5,9330 & OSX Brasil S. A. & 2014 & $-2,0285$ \\
\hline Terminal G. M. C. S. A. & 2010 & 3,1125 & General Shopping BR S. A. & 2014 & $-2,0170$ \\
\hline Azevedo e Travassos S. A. & 2010 & 2,7880 & Forjas Taurus S. A. & 2014 & $-1,2980$ \\
\hline \multicolumn{6}{|c|}{ TamanhoCA } \\
\hline Telefônica Brasil S. A. & 2010 & 17 & Alfa Holdings S. A. & 2014 & 2 \\
\hline Telefônica Brasil S. A. & 2011 & 16 & All Malha Norte S. A. & 2011 & 2 \\
\hline Oi S. A. & 2011 & 16 & Industrias J B Duarte S. A. & 2010 & 2 \\
\hline Oi S. A. & 2013 & 16 & Brasmotor S. A. & 2013 & 3 \\
\hline Telefônica Brasil S. A. & 2012 & 15 & Alfa Holdings S. A. & 2013 & 3 \\
\hline \multicolumn{6}{|c|}{ \%Independentes } \\
\hline Embraer S. A. & 2011 & 1,0000 & Alfa Holdings S. A. & 2014 & 0,0000 \\
\hline Embraer S. A. & 2010 & 0,8750 & All Malha Norte S. A. & 2011 & 0,0000 \\
\hline Eternit S. A. & 2014 & 0,8751 & Industrias J B Duarte S. A. & 2010 & 0,0000 \\
\hline TOTVS S. A. & 2011 & 0,8751 & Brasmotor S. A. & 2013 & 0,0000 \\
\hline Embraer S. A. & 2014 & 0,8751 & Alfa Holdings S. A. & 2013 & 0,0000 \\
\hline \multicolumn{6}{|c|}{$\%$ Externos } \\
\hline Brasmotor S. A. & 2010 & 1,0000 & Polpar S. A. & 2014 & 0,3333 \\
\hline Metalgrafica Iguaçu S. A. & 2011 & 1,0000 & Guararapes Confecções S. A. & 2010 & 0,3333 \\
\hline Metalgrafica Iguaçu S. A. & 2010 & 1,0000 & Cia Paulista de Força e Luz & 2010 & 0,3333 \\
\hline Panatlantica S. A. & 2011 & 1,0000 & Alfa Holdings S. A. & 2014 & 0,5000 \\
\hline Panatlantica S. A. & 2010 & 1,0000 & All Malha Norte S. A. & 2011 & 0,5000 \\
\hline \multicolumn{6}{|c|}{ Ativos Totais (em mi) } \\
\hline Petrobras S. A. & 2014 & 793.375 & Polpar S. A. & 2011 & 9 \\
\hline Petrobras S. A. & 2013 & 752.967 & Dinâmica Energia S. A. & 2012 & 12 \\
\hline Petrobras S. A. & 2012 & 677.716 & Dinâmica Energia S. A. & 2013 & 12 \\
\hline Petrobras S. A. & 2011 & 599.150 & Polpar S. A. & 2012 & 13 \\
\hline Petrobras S. A. & 2010 & 519.970 & Dinâmica Energia S. A. & 2014 & 13 \\
\hline \multicolumn{6}{|c|}{ Endividamento } \\
\hline OSX Brasil S. A. & 2014 & 1,3090 & Brasmotor S. A. & 2013 & 0,0050 \\
\hline Tec Toy S. A. & 2014 & 1,3030 & Alfa Holdings S. A. & 2013 & 0,0070 \\
\hline Gol Linhas Aéreas I. S. A. & 2014 & 1,0330 & Brasmotor S. A. & 2014 & 0,0070 \\
\hline Mundial S. A. & 2014 & 0,9890 & Brasmotor S. A. & 2012 & 0,0070 \\
\hline CEEE-D S. A. & 2014 & 0,9700 & Alfa Holdings S. A. & 2014 & 0,0080 \\
\hline
\end{tabular}

Fonte: Economatica ${ }^{\circledR}$ e Formulários de Referência. 


\subsection{Testes de Especificação dos Modelos}

A Tabela 3 traz os dados dos testes de especificação do método a ser adotado para a estimação dos modelos de dados em painel (FE ou RE) ${ }^{4}$. A coluna 1 (Modelo) refere-se às 24 estimações feitas com os grupos de variáveis correspondentes. A coluna 2 (Grupos) indica quantos grupos de variáveis foram adicionados aos modelos. Os testes com um (1) grupo referem-se à entrada das variáveis relativas ao Conselho de Administração (TamanhoCA, \% Independentes/ \% Externos e DualidadeCEO); os testes com dois (2) grupos adicionam ao grupo 1 as variáveis relativas às características financeiras da empresa e à identidade do controlador (LogAtivos, Endividamento, Estrangeiro e Estatal) e, por fim, o teste com três (3) grupos, adiciona às estimações com dois grupos também as variáveis dummies temporais ou time dummies.

A coluna 3 (Sargan-Hansen) indica os resultados do teste de especificação dos estimadores e a coluna 4 (Estimador) especifica o método de estimação (RE ou FE). $\mathrm{O}$ estimador de efeitos fixos (FE) é substituído pelo estimador LSDV quando as regressões são calculadas para dois (2) ou três (3) grupos de variáveis, em razão da limitação deste estimador em não reportar valores para variáveis fixas ao longo do tempo (caso da variável Estatal).

Tabela 3 - Resultado dos testes de especificação de Sargan-Hansen para a escolha do método de estimação de dados em painel $2010-2014$

\begin{tabular}{|c|c|c|c|}
\hline Modelo & Grupos & Sargan-Hansen & Estimador \\
\hline 1 & Grupo $1^{+}$ & $5,423(0,1433)$ & $\mathrm{RE}^{*}$ \\
\hline 2 & Grupo $1^{+}+$Grupo 2 & $9,567(0,1441)$ & $\mathrm{RE}^{*}$ \\
\hline 3 & Grupo $1^{+}+$Grupo $2+$ Grupo 3 & $8,661(0,1936)$ & $\mathrm{RE}^{*}$ \\
\hline 4 & Grupo $1^{++}$ & $3,284(0,3499)$ & RE \\
\hline 5 & Grupo $1^{++}+$Grupo 2 & $7,064(0,3150)$ & $\mathrm{RE}^{*}$ \\
\hline 6 & Grupo $1^{++}+$Grupo $2+$ Grupo 3 & $7,807(0,2526)$ & $\mathrm{RE}^{*}$ \\
\hline 7 & Grupo $1^{+}$ & $2,311(0,5103)$ & $\mathrm{RE}$ \\
\hline 8 & Grupo $1^{+}+$Grupo 2 & $11,213(0,0820)$ & FE \\
\hline 9 & Grupo $1^{+}+$Grupo $2+$ Grupo 3 & $11,504(0,0740)$ & $\mathrm{FE}^{*}$ \\
\hline 10 & Grupo $1^{++}$ & $0,607(0,8949)$ & RE \\
\hline 11 & Grupo $1^{++}+$Grupo 2 & $9,065(0,1699)$ & RE \\
\hline 12 & Grupo $1^{++}+$Grupo $2+$ Grupo 3 & $10,052(0,1225)$ & RE \\
\hline 13 & Grupo $1^{+}$ & $3,970(0,2648)$ & $\mathrm{RE}^{*}$ \\
\hline 14 & Grupo $1^{+}+$Grupo 2 & $9,582(0,1434)$ & $\mathrm{RE}$ \\
\hline 15 & Grupo $1^{+}+$Grupo $2+$ Grupo 3 & $9,450(0,1498)$ & RE \\
\hline 16 & Grupo $1^{++}$ & $4,502(0,2121)$ & $\mathrm{RE}^{*}$ \\
\hline 17 & Grupo $1^{++}+$Grupo 2 & $9,792(0,1337)$ & RE \\
\hline 18 & Grupo $1^{++}+$Grupo $2+$ Grupo 3 & $8,309(0,2164)$ & RE \\
\hline 19 & Grupo $1^{+}$ & $3,174(0,3656)$ & $\mathrm{RE}^{*}$ \\
\hline 20 & Grupo $1^{+}+$Grupo 2 & $10,368(0,1100)$ & RE \\
\hline 21 & Grupo $1^{+}+$Grupo $2+$ Grupo 3 & $11,621(0,0710)$ & $\mathrm{FE}^{*}$ \\
\hline 22 & Grupo $1^{++}$ & $3,886(0,2741)$ & $\mathrm{RE}^{*}$ \\
\hline 23 & Grupo $1^{++}+$Grupo 2 & $10,174(0,1175)$ & RE \\
\hline 24 & Grupo $1^{++}+$Grupo $2+$ Grupo 3 & $10,138(0,1190)$ & RE \\
\hline
\end{tabular}

Fonte: Economatica ${ }^{\circledR}$ e Formulário de Referências.

Notas: O Teste de Sargan-Hansen reporta o valor da estatística $\chi^{2}$. Os valores entre parênteses indicam os respectivos $p$-values, onde a hipótese nula de cada teste é rejeitada quando o p-value é menor que $0,1(10 \%)$. Grupo $1^{+}$indica que as variáveis utilizadas neste grupo foram o TamanhoCA, \%Independentes e DualidadeCEO; Grupo $1^{++}$indica que as variáveis utilizadas neste grupo foram o TamanhoCA, \%Externos e DualidadeCEO. * Indica que pelo teste de Hausman seria selecionado um estimador diferente.

\footnotetext{
${ }^{4}$ A escolha dentre estes dois métodos de estimação, em detrimento ao modelo pooled, baseia-se na argumentação de que os estimadores de painel controlam a heterogeneidade entre indivíduos e efeitos dinâmicos não visíveis nos estimadores de cortes transversais (WOOLDRIDGE, 2001).
} 
No teste de Sargan-Hansen, a rejeição da hipótese nula de adequação do modelo de RE dá-se quando os p-values obtidos nos testes forem iguais ou inferiores a $10 \%$. Os valores dos testes indicam os valores críticos da estatísticas $\chi^{2}$ e os valores entre parênteses indicam seus $p$ values. Os testes indicam a rejeição da hipótese nula de adequação do modelo RE em 3 dos 24 modelos testados 5 .

\subsection{Resultados das Estimações dos Modelos de Dados em Painel}

Para verificar a influência das características do Conselho de Administração no desempenho empresarial foram estimados 24 modelos de regressões hierárquicas com dados em painel (FE, LSDV e RE). Os resultados são apresentadas nas tabelas listadas de 4 a 7. Como proxy para a independência do Conselho de Administração são utilizadas as variáveis \% Independentes e \% Externos alternadamente nos modelos de regressão. Os resultados para cada proxy são comparados em seguida.

Foi estabelecido um nível de confiança para a rejeição da hipótese nula individual de cada coeficiente $\left(\mathrm{H}_{0}: \beta_{\mathrm{n}}=0\right)$ de 5\%. Porém, as análises terão breves comentários sobre o relacionamento entre as variáveis quando o nível de confiança para a rejeição da hipótese nula individual estiver entre $10 \%$ e 5\%, não sendo estes resultados considerados aceitos neste estudo. Para os testes de significância geral do modelo de regressão $\left(\mathrm{H}_{0}: \beta_{1}=\beta_{2}=\ldots=\beta_{n}=0\right)$, utilizouse um nível de confiança mínimo de $10 \%$, assim como para os testes de heterocedasticidade (White/Wald) e correlação serial de primeira ordem (Wooldridge).

É importante destacar que nenhuma variável dos modelos estimados apresentou valores iguais ou acima de 10 para o VIF, indicando a ausência de um alto grau de colinearidade entre as variáveis independentes, evitando assim problemas relacionados ao aumento da variância dos estimadores, tendência de não rejeição da hipótese nula de que os coeficientes, isolados ou agrupados, são iguais a zero e a indicação de valores altos para o coeficiente de determinação (R²) (GUJARATI; PORTER, 2011).

Na Tabela 4 são apresentados os modelos que utilizam o ROA como variável dependente. O teste $\mathrm{F}$ indicou má especificação dos modelos 1 e 4, indicando que a utilização conjunta apenas das variáveis que representam as características do Conselho de Administração não é suficiente para estabelecer uma relação linear entre estas características e a lucratividade medida pelo ROA. Os regressores apresentam significância conjunta nos modelos 2, 3, 5 e 6 . O teste de Wooldridge indicou a presença de correlação serial de primeira ordem para os citados modelos, sendo os erros-padrão estimados de forma robusta.

A primeira variável de interesse é o tamanho do Conselho de Administração. Observa-se, nos modelos de 2 a 3, que a variável perdeu sua significância estatística (10\%) com a adição das variáveis dummies temporais. Isso indica que sua significância obtida nos modelos anteriores deveu-se à ausência destas variáveis explicativas (visto que as variáveis dummies temporais apresentaram alta significância estatística) e não a uma relação positiva entre o tamanho do Conselho de Administração e o ROA. Nos modelos 5 a 6, onde a variável \% Externos é utilizada no lugar da variável \% Independentes, o coeficiente da variável que representa o tamanho do Conselho de Administração permaneceu estatisticamente significante

\footnotetext{
${ }^{5}$ Apesar de serem comparados os estimadores selecionados pelo teste de Sargan-Hansen com os selecionados pelo teste de Hausman, os estimadores obtidos pelo primeiro teste são executados em razão de os pressupostos do teste de Hausman terem sido violados na presença de heterocedasticidade e autocorrelação.
} 
mesmo após a adição de todos os grupos de variáveis, a um nível de 10\%. O fato de o coeficiente mostrar uma relação positiva entre esta variável e a lucratividade na maioria dos modelos estimados indica que o tamanho do Conselho de Administração está associado a uma maior lucratividade empresarial. Esta associação também foi encontrada por Andrade et al. (2009), porém, os autores mediram a lucratividade/desempenho empresarial utilizando a Margem Operacional ao invés do ROA. Estes resultados estão em desacordo com Yermack (1996), Mak e Kusnadi (2005) e Liang et al. (2013), que encontraram uma relação negativa entre o tamanho do Conselho de Administração e a lucratividade, quando medida pelo ROA.

As variáveis utilizadas como proxies para a independência do CA (\%Independentes e \%Externos) não foram significativas em nenhum dos modelos indicando que a independência do Conselho de Administração não está associada à lucratividade empresarial. Estes resultados são similares aos encontrados por Mak e Kusnadi (2005) e diferentes dos encontrados por Liang et al. (2013) que observaram uma relação positiva, porém fraca, entre a proporção de diretores independentes e o ROA. Os resultados para a variável \% Externos são convergentes com os encontrados por Yermack (1996) e Andrade et al. (2009) que também não encontraram uma relação significativa entre a proporção de diretores externos e a lucratividade/desempenho empresarial, respectivamente.

A variável que representa o fato de o CEO ocupar também o cargo de Presidente do Conselho de Administração também não se mostrou relevante nos modelos que utilizaram o ROA como variável dependente. Os resultados obtidos estão de acordo com os encontrados por Mak e Kusnadi (2005) e Liang et al. (2013), que também não encontraram relação estatisticamente significante entre a dualidade do CEO e a lucratividade medida pelo ROA, mas em desacordo com Donaldson e Davis (1991) e Brickley et al. (1997), que argumentam que a acumulação dos cargos de CEO e Chairman seria benéfico para a empresa em razão de conceder maiores poderes para que o agente empreenda projetos de alto desempenho, aumentando a lucratividade.

O Logaritmo dos Ativos Totais não se mostrou estatisticamente significante nos modelos considerados, indicando que o tamanho da empresa não está relacionado com a lucratividade, ao contrário do que encontraram Mak e Kusnadi (2005) e Andrade et al. (2009). Este resultado assemelha-se ao de Liang et al. (2013), porém, estes autores utilizaram uma amostra composta por bancos, dos quais pode-se esperar relações diferentes entre o tamanho das instituições e a lucratividade, quando comparados com empresas não-financeiras. $\mathrm{O}$ endividamento apresenta um coeficiente negativo e estatisticamente significante ao nível de $10 \%$. Apesar de um baixo nível de confiança, sua significância estatística está presente em todos os modelos que utilizaram esta variável $(2,3,5$ e 6$)$, sugerindo que um maior nível de dívida está ligado a um baixo ROA, assim como em Liang et al. (2013).

O controle estrangeiro também aparece como significante ao nível de 10\%, apresentando um coeficiente positivo, assim como em Grasseni (2010), mas apenas nos modelos que utilizam todos os grupos de variáveis. Já o coeficiente do controle estatal foi negativo, sugerindo que que o controle estatal está relacionado a uma baixa lucratividade. Estes resultados são convergentes com Micco et al. (2007) e Chen e Liu (2013). Por fim, a adição de variáveis dummies mostrou que os fatores macroeconômicos e regulatórios desempenham um importante papel na lucratividade empresarial, dado que estas variáveis apresentam alta significância estatística nos modelos estimados. 
Tabela 4 - Resultado das estimações dos modelos de dados em painel para a variável dependente ROA. 2010-2014

\begin{tabular}{|c|c|c|c|c|c|c|}
\hline & Modelo 1 & Modelo 2 & Modelo 3 & Modelo 4 & Modelo 5 & Modelo 6 \\
\hline Variáveis & $\begin{array}{c}\text { Coef. } \\
\text { (Erro-P) }\end{array}$ & $\begin{array}{c}\text { Coef. } \\
\text { (Erro-P) }\end{array}$ & $\begin{array}{c}\text { Coef. } \\
\text { (Erro-P) }\end{array}$ & $\begin{array}{c}\text { Coef. } \\
\text { (Erro-P) }\end{array}$ & $\begin{array}{c}\text { Coef. } \\
\text { (Erro-P) }\end{array}$ & $\begin{array}{c}\text { Coef. } \\
\text { (Erro-P) }\end{array}$ \\
\hline TamanhoCA & $\begin{array}{l}0,0041^{*} \\
(0,0025)\end{array}$ & $\begin{array}{l}0,0056^{*} \\
(0,0033)\end{array}$ & $\begin{array}{c}0,0044 \\
(0,0031)\end{array}$ & $\begin{array}{l}0,0045^{*} \\
(0,0023)\end{array}$ & $\begin{array}{l}0,0060^{*} \\
(0,0031)\end{array}$ & $\begin{array}{l}0,0051 * \\
(0,0030)\end{array}$ \\
\hline$\%$ Independentes & $\begin{array}{l}-0,0184 \\
(0,0215)\end{array}$ & $\begin{array}{l}-0,0080 \\
(0,0187)\end{array}$ & $\begin{array}{c}0,0087 \\
(0,0188)\end{array}$ & - & - & - \\
\hline$\%$ Externos & - & - & - & $\begin{array}{l}-0,0339 \\
(0,0486)\end{array}$ & $\begin{array}{l}-0,0314 \\
(0,0466)\end{array}$ & $\begin{array}{l}-0,0418 \\
(0,0458)\end{array}$ \\
\hline DualidadeCEO & $\begin{array}{l}0,0376^{*} \\
(0,0227)\end{array}$ & $\begin{array}{c}0,0340 \\
(0,0227)\end{array}$ & $\begin{array}{c}0,0260 \\
(0,0216)\end{array}$ & $\begin{array}{c}0,0353 \\
(0,0235)\end{array}$ & $\begin{array}{c}0,0314 \\
(0,0236)\end{array}$ & $\begin{array}{c}0,0216 \\
(0,0225)\end{array}$ \\
\hline LogAtivos & - & $\begin{array}{c}0,0004 \\
(0,0217)\end{array}$ & $\begin{array}{c}0,0076 \\
(0,0210)\end{array}$ & - & $\begin{array}{c}0,0006 \\
(0,0216)\end{array}$ & $\begin{array}{c}0,0082 \\
(0,0210)\end{array}$ \\
\hline Endividamento & - & $\begin{array}{c}-0,1363^{*} \\
(0,0740)\end{array}$ & $\begin{array}{c}-0,1340^{*} \\
(0,0729)\end{array}$ & - & $\begin{array}{c}-0,1367^{*} \\
(0,0745)\end{array}$ & $\begin{array}{c}-0,1334^{*} \\
(0,0736)\end{array}$ \\
\hline Estrangeiro & - & $\begin{array}{c}0,0520 \\
(0,0331)\end{array}$ & $\begin{array}{l}0,0550 * \\
(0,0322)\end{array}$ & - & $\begin{array}{c}0,0526 \\
(0,0322)\end{array}$ & $\begin{array}{l}0,0551^{*} \\
(0,0316)\end{array}$ \\
\hline Estatal & - & $\begin{array}{c}-0,0367 * * * \\
(0,0142)\end{array}$ & $\begin{array}{c}-0,0352 * * * \\
(0,0132)\end{array}$ & - & $\begin{array}{c}-0,0360 * * * \\
(0,0138)\end{array}$ & $\begin{array}{c}-0,0366^{* * * *} \\
(0,0130)\end{array}$ \\
\hline Ano2011 & - & - & $\begin{array}{c}-0,0169 * * \\
(0,0088)\end{array}$ & - & - & $\begin{array}{c}-0,0165^{* *} \\
(0,0085)\end{array}$ \\
\hline Ano2012 & - & - & $\begin{array}{c}-0,0295 * * * \\
(0,0096)\end{array}$ & - & - & $\begin{array}{c}-0,0294 * * * \\
(0,0094)\end{array}$ \\
\hline Ano2013 & - & - & $\begin{array}{c}-0,0362 * * * \\
(0,0085)\end{array}$ & - & - & $\begin{array}{c}-0,0360 * * * \\
(0,0083)\end{array}$ \\
\hline Ano2014 & - & - & $\begin{array}{c}-0,0498 * * * \\
(0,0111)\end{array}$ & - & - & $\begin{array}{c}-0,0497 * * * \\
(0,0109)\end{array}$ \\
\hline Intercepto & $\begin{array}{c}0,0179 \\
(0,0193)\end{array}$ & $\begin{array}{c}0,0769 \\
(0,0957)\end{array}$ & $\begin{array}{c}0,0633 \\
(0,0962)\end{array}$ & $\begin{array}{c}0,0416 \\
(0,0464)\end{array}$ & $\begin{array}{c}0,0992 \\
(0,0911)\end{array}$ & $\begin{array}{c}0,0922 \\
(0,0939)\end{array}$ \\
\hline Estimador & $\mathrm{RE}$ & $\mathrm{RE}$ & $\mathrm{RE}$ & $\mathrm{RE}$ & $\mathrm{RE}$ & $\mathrm{RE}$ \\
\hline Teste F & 0,1384 & 0,0018 & 0,0000 & 0,1354 & 0,0006 & 0,0000 \\
\hline $\mathrm{R}^{2}$ within & 0,0241 & 0,0389 & 0,0878 & 0,0220 & 0,0380 & 0,0886 \\
\hline $\mathrm{R}^{2}$ between & 0,0013 & 0,1111 & 0,1091 & 0,0036 & 0,1165 & 0,1102 \\
\hline $\mathrm{R}^{2}$ overall & 0,0057 & 0,0827 & 0,1007 & 0,0079 & 0,0857 & 0,1017 \\
\hline Teste de Wooldridge & 0,0009 & 0,0007 & 0,0021 & 0,0009 & 0,0007 & 0,0021 \\
\hline $\mathrm{N}^{\circ}$ Observações & 910 & 910 & 910 & 910 & 910 & 910 \\
\hline $\mathrm{N}^{\mathrm{o}}$ Empresas & 182 & 182 & 182 & 182 & 182 & 182 \\
\hline
\end{tabular}

Fonte: Formulário de Referência e Economatica ${ }^{\circledR}$.

Notas: Erros-padrão robustos apresentados para os modelos nos quais foram detectados a presença de autocorrelação através do Teste de Wooldridge; Significância estatística: ***1\%, **5\% e *10\%; RE indica que a estimação foi feita através do modelo de efeitos aleatórios (Random Effects). Os valores para o teste $\mathrm{F}$ e o teste de Wooldridge indicam os seus respectivos $p$-values.

A Tabela 5 refere-se aos modelos que utilizam o ROA ajustado como medida de desempenho. O teste $\mathrm{F}$ não identificou erros de especificação nos modelos. Para os modelos LSDV, os erros-padrão foram estimados novamente de forma robusta, dada a presença de heterocedasticidade nos resíduos da regressão. Como nos modelos RE não foi indicada a presença de correlação serial de primeira ordem pelo teste de Wooldridge, os erros-padrão não foram calculados em sua forma robusta clusterizada. Os resultados destes modelos são comparados principalmente com os de Brick e Chidambaran (2010), que utilizaram a mesma proxy para inferir sobre a influência das características do Conselho de Administração na lucratividade empresarial.

Quando analisada a relação entre o tamanho do CA e a lucratividade ajustada ao setor, observa-se que o coeficiente desta variável apresenta um sinal positivo e significante na maioria dos modelos contidos na Tabela 5. Apesar desta variável perder sua significância após a adição dos outros dois grupos de variáveis nos modelos 8 e 9, nos modelos de 10 a 12 ela mantém sua significância estatística de 5\% após a adição de todos os grupos de variáveis. Este resultado sugere que um Conselho de Administração com maior número de membros está associado a uma maior lucratividade ajustada, diferentemente de Brick e Chidambaran (2010) que não encontraram uma relação entre estas duas variáveis. 
As proxies utilizadas para representar a independência do Conselho de Administração não se mostraram relevantes nos modelos utilizados. A variável \%Independentes perdeu sua significância estatística após a adição das variáveis dummies temporais no modelo 9. Para a outra proxy representativa da independência do Conselho de Administração (\%Externos) também não foi encontrada ligação com o ROA ajustado. Estes resultados são divergentes dos encontrados por Brick e Chidambaran (2010) onde a proporção de conselheiros independentes está positivamente relacionada com a lucratividade ajustada ao setor

A última característica do Conselho de Administração é a dualidade do CEO. Nos modelos que utilizam apenas um grupo de variáveis (modelos 7 e 10) o coeficiente da dualidade do CEO mostra-se positivo e significativo. Com a adição dos demais grupos de variáveis, o coeficiente permanece positivo, embora perca um pouco de sua significância até os modelos 9 (significante ao nível de 10\%) e 12 (significante ao nível de 5\%). Estes resultados corroboram o proposto por Donaldson e Davis (1991) e Brickley et al. (1997), de que a dualidade do CEO gera benefícios para a empresa, traduzidos numa maior lucratividade e competitividade frente às suas concorrentes e de acordo com o proposto pela Teoria da Mordomia de Donaldson e Davis (1991).

Tabela 5 - Resultado das estimações dos modelos de dados em painel para a variável dependente ROA ajustado. 2010-2014

\begin{tabular}{|c|c|c|c|c|c|c|}
\hline & Modelo 7 & Modelo 8 & Modelo 9 & Modelo 10 & Modelo 11 & Modelo 12 \\
\hline Variáveis & $\begin{array}{c}\text { Coef. } \\
\text { (Erro-P) }\end{array}$ & $\begin{array}{c}\text { Coef. } \\
\text { (Erro-P) }\end{array}$ & $\begin{array}{c}\text { Coef. } \\
\text { (Erro-P) }\end{array}$ & $\begin{array}{c}\text { Coef. } \\
\text { (Erro-P) }\end{array}$ & $\begin{array}{c}\text { Coef. } \\
\text { (Erro-P) }\end{array}$ & $\begin{array}{c}\text { Coef. } \\
\text { (Erro-P) }\end{array}$ \\
\hline TamanhoCA & $\begin{array}{c}0,0049 * * \\
(0,0022)\end{array}$ & $\begin{array}{c}0,0064 \\
(0,0043)\end{array}$ & $\begin{array}{c}0,0059 \\
(0,0044)\end{array}$ & $\begin{array}{c}0,0051 * * \\
(0,0023)\end{array}$ & $\begin{array}{c}0,0060 * * \\
(0,0025)\end{array}$ & $\begin{array}{c}0,0056^{* *} \\
(0,0025)\end{array}$ \\
\hline$\%$ Independentes & $\begin{array}{l}-0,0141 \\
(0,0254)\end{array}$ & $\begin{array}{c}-0,0391 * * \\
(0,0192)\end{array}$ & $\begin{array}{l}-0,0247 \\
(0,0189)\end{array}$ & - & - & - \\
\hline$\%$ Externos & - & - & - & $\begin{array}{l}-0,0171 \\
(0,0465)\end{array}$ & $\begin{array}{l}-0,0190 \\
(0,0452)\end{array}$ & $\begin{array}{l}-0,0232 \\
(0,0452)\end{array}$ \\
\hline DualidadeCEO & $\begin{array}{c}0,0351 \text { *** } \\
(0,0117)\end{array}$ & $\begin{array}{l}0,0388^{*} \\
(0,0208)\end{array}$ & $\begin{array}{l}0,0330^{*} \\
(0,0198)\end{array}$ & $\begin{array}{c}0,0341 * * * \\
(0,0125)\end{array}$ & $\begin{array}{c}0,0300 * * \\
(0,0122)\end{array}$ & $\begin{array}{c}0,0264 * * \\
(0,0124)\end{array}$ \\
\hline LogAtivos & - & $\begin{array}{l}0,0764^{*} \\
(0,0424)\end{array}$ & $\begin{array}{c}0,0953 * * \\
(0,0455)\end{array}$ & - & $\begin{array}{c}0,0106 \\
(0,0099)\end{array}$ & $\begin{array}{c}0,0128 \\
(0,0100)\end{array}$ \\
\hline Endividamento & - & $\begin{array}{c}-0,1851^{*} \\
(0,1005)\end{array}$ & $\begin{array}{c}-0,1871^{*} \\
(0,0993)\end{array}$ & - & $\begin{array}{c}-0,1614 * * * \\
(0,0271)\end{array}$ & $\begin{array}{c}-0,1592 \text { *** } \\
(0,0271)\end{array}$ \\
\hline Estrangeiro & - & $\begin{array}{l}-0,0117 \\
(0,0289)\end{array}$ & $\begin{array}{l}-0,0062 \\
(0,0321)\end{array}$ & - & $\begin{array}{c}0,0422 \\
(0,0299)\end{array}$ & $\begin{array}{c}0,0427 \\
(0,0299)\end{array}$ \\
\hline Estatal & - & $\begin{array}{l}-0,1901 \\
(0,1352)\end{array}$ & $\begin{array}{l}-0,2242 \\
(0,1456)\end{array}$ & - & $\begin{array}{l}-0,0447 \\
(0,0296)\end{array}$ & $\begin{array}{l}-0,0445 \\
(0,0297)\end{array}$ \\
\hline Ano2011 & - & - & $\begin{array}{l}-0,0120 \\
(0,0100)\end{array}$ & - & - & $\begin{array}{l}-0,0092 \\
(0,0094)\end{array}$ \\
\hline Ano2012 & - & - & $\begin{array}{l}-0,0158 \\
(0,0097)\end{array}$ & - & - & $\begin{array}{l}-0,0103 \\
(0,0094)\end{array}$ \\
\hline Ano2013 & - & - & $\begin{array}{l}-0,0131 \\
(0,0105)\end{array}$ & - & - & $\begin{array}{l}-0,0071 \\
(0,0094)\end{array}$ \\
\hline Ano2014 & - & - & $\begin{array}{c}-0,0295^{* *} * \\
(0,0114)\end{array}$ & - & - & $\begin{array}{c}-0,0225^{* *} \\
(0,0095)\end{array}$ \\
\hline Intercepto & $\begin{array}{l}-0,0147 \\
(0,0174)\end{array}$ & $\begin{array}{l}-0,2550 \\
(0,2329)\end{array}$ & $\begin{array}{l}-0,3300 \\
(0,2364)\end{array}$ & $\begin{array}{l}-0,0033 \\
(0,0393)\end{array}$ & $\begin{array}{c}0,0123 \\
(0,0635)\end{array}$ & $\begin{array}{c}0,0139 \\
(0,0637)\end{array}$ \\
\hline Estimador & RE & FE(LSDV) & FE(LSDV) & $\mathrm{RE}$ & $\mathrm{RE}$ & $\mathrm{RE}$ \\
\hline Teste F & 0,0052 & 0,0000 & 0,0000 & 0,0056 & 0,0000 & 0,0000 \\
\hline $\mathrm{R}^{2}$ within & 0,0167 & - & - & 0,0154 & 0,0345 & 0,0427 \\
\hline $\mathrm{R}^{2}$ between & 0,0079 & - & - & 0,0101 & 0,1402 & 0,1391 \\
\hline $\mathrm{R}^{2}$ ajustado / overall & 0,0104 & 0,5945 & 0,5995 & 0,0116 & 0,0953 & 0,0980 \\
\hline Teste de White & - & 0,0039 & 0,0148 & - & - & - \\
\hline Teste de Wooldridge & 0,2133 & - & - & 0,2099 & 0,2104 & 0,2128 \\
\hline $\mathrm{N}^{\circ}$ Observações & 910 & 910 & 910 & 910 & 910 & 910 \\
\hline $\mathrm{N}^{\mathrm{o}}$ Empresas & 182 & 182 & 182 & 182 & 182 & 182 \\
\hline
\end{tabular}

Fonte: Formulário de Referência e Economatica®.

Notas: Erros-padrão robustos apresentados para os modelos RE e LSDV nos quais foram detectados a presença de heterocedasticidade ou autocorrelação através dos Testes White (LSDV) e Wooldridge (RE); Significância estatística: ***1\%, **5\% e *10\%; RE indica que a estimação foi feita através do modelo de efeitos aleatórios (Random Effects), LSDV indica que a estimação foi feita através do modelo Least Square Dummy Variables. Os valores para o teste F, o teste de White e Wooldridge indicam os seus respectivos p-values. 
Dentre as variáveis de controle, apenas o endividamento apresenta significância estatística em todos os modelos. Seu coeficiente negativo indica que empresas mais endividadas apresentam uma menor lucratividade ajustada ao setor, resultado similar ao trabalho de Brick e Chidambaran (2010). O tamanho da empresa mostra-se relevante apenas nos modelos 8 e 9, com coeficiente positivo. As variáveis que representam o tipo de controlador não se mostraram relevantes nos modelos que utilizaram o ROA ajustado como variável dependente, assim como as variáveis dummies temporais, que mostraram significância apenas no ano de 2014.

Os modelos de regressão que utilizaram o ROE como variável dependente são numerados de 13 a 18 e estão contidos na Tabela 6.0 teste $\mathrm{F}$ indica erro de especificação apenas no modelo 17. Erros-padrão robustos são estimados para todos os modelos em questão, uma vez que o teste de Wooldridge detectou a presença de correlação serial de primeira ordem em todos eles.

Os coeficientes das variáveis representativas das características do Conselho de Administração (tamanho, independência e dualidade do CEO) não se mostraram estatisticamente significantes, com exceção da dualidade do CEO. Porém, esta perdeu sua significância após a adição dos demais grupos de variáveis. Estes resultados são divergentes dos encontrados por Liang et al. (2013), onde as variáveis que representam o tamanho, a proporção de diretores independentes e a dualidade do CEO mostraram-se estatisticamente significantes. Na pesquisa citada, o tamanho do Conselho de Administração e a dualidade do CEO apresentaram coeficientes negativos, indicando que um Conselho de Administração maior e a concentração dos cargos de CEO e Chairman em um só agente estão ligados a um menor ROE. Por outro lado, a proporção de diretores independentes apresenta uma relação positiva com o ROE.

Os resultados divergentes do de Liang et al. (2013), que utiliza como amostra apenas os bancos, enquanto no presente trabalho as empresas não-financeiras não fazem parte da amostra. As diferentes características das duas amostras podem levar a resultados divergentes. Para as demais variáveis, observa-se que as empresas controladas pelo estado apresentam lucratividade inferior às demais, assim como em Micco et al. (2007) e Chen e Liu (2013). Por fim, como observado na Tabela 1, onde as estatísticas descritivas indicaram a diminuição do ROE com o passar dos anos, observa-se que o aspecto temporal é determinante na lucratividade empresarial, uma vez que as variáveis dummies temporais apresentam alta significância estatística e coeficiente negativo em todos os modelos em que foram adicionadas. 
Tabela 6 - Resultado das estimações dos modelos de dados em painel para a variável dependente ROE. 2010-2014

\begin{tabular}{|c|c|c|c|c|c|c|}
\hline & Modelo 13 & Modelo 14 & Modelo 15 & Modelo 16 & Modelo 17 & Modelo 18 \\
\hline Variáveis & $\begin{array}{c}\text { Coef. } \\
\text { (Erro-P) }\end{array}$ & $\begin{array}{c}\text { Coef. } \\
\text { (Erro-P) }\end{array}$ & $\begin{array}{c}\text { Coef. } \\
\text { (Erro-P) }\end{array}$ & $\begin{array}{c}\text { Coef. } \\
\text { (Erro-P) }\end{array}$ & $\begin{array}{c}\text { Coef. } \\
\text { (Erro-P) }\end{array}$ & $\begin{array}{c}\text { Coef. } \\
\text { (Erro-P) }\end{array}$ \\
\hline TamanhoCA & $\begin{array}{c}0,0194 * * \\
(0,0098)\end{array}$ & $\begin{array}{c}0,0267 \\
(0,0205)\end{array}$ & $\begin{array}{c}0,0200 \\
(0,0198)\end{array}$ & $\begin{array}{c}0,0224 * * \\
(0,0097)\end{array}$ & $\begin{array}{c}0,0298 \\
(0,0197)\end{array}$ & $\begin{array}{c}0,0251 \\
(0,0193)\end{array}$ \\
\hline$\%$ Independentes & $\begin{array}{c}0,0057 \\
(0,1115)\end{array}$ & $\begin{array}{c}0,0130 \\
(0,1157)\end{array}$ & $\begin{array}{c}0,0955 \\
(0,1271)\end{array}$ & - & - & - \\
\hline$\%$ Externos & - & - & - & $\begin{array}{l}-0,1586 \\
(0,1508)\end{array}$ & $\begin{array}{l}-0,1708 \\
(0,1668)\end{array}$ & $\begin{array}{l}-0,2238 \\
(0,1562)\end{array}$ \\
\hline DualidadeCEO & $\begin{array}{l}0,2917^{*} \\
(0,1687)\end{array}$ & $\begin{array}{l}0,2862 * \\
(0,1722)\end{array}$ & $\begin{array}{c}0,2467 \\
(0,1640)\end{array}$ & $\begin{array}{c}0,2745 \\
(0,1695)\end{array}$ & $\begin{array}{c}0,2673 \\
(0,1769)\end{array}$ & $\begin{array}{c}0,2190 \\
(0,1676)\end{array}$ \\
\hline LogAtivos & - & $\begin{array}{l}-0,0138 \\
(0,1560)\end{array}$ & $\begin{array}{c}0,0106 \\
(0,1556)\end{array}$ & - & $\begin{array}{l}-0,0117 \\
(0,1568)\end{array}$ & $\begin{array}{c}0,0143 \\
(0,1566)\end{array}$ \\
\hline Endividamento & - & $\begin{array}{l}-0,2307 \\
(0,5964)\end{array}$ & $\begin{array}{l}-0,2175 \\
(0,5915)\end{array}$ & - & $\begin{array}{l}-0,2332 \\
(0,5955)\end{array}$ & $\begin{array}{l}-0,2157 \\
(0,5918)\end{array}$ \\
\hline Estrangeiro & - & $\begin{array}{c}0,1589 \\
(0,1060)\end{array}$ & $\begin{array}{c}0,1683 \\
(0,1050)\end{array}$ & - & $\begin{array}{c}0,1596 \\
(0,1044)\end{array}$ & $\begin{array}{c}0,1670 \\
(0,1045)\end{array}$ \\
\hline Estatal & - & $\begin{array}{c}-0,1502 * * \\
(0,0651)\end{array}$ & $\begin{array}{c}-0,1360 * * * \\
(0,0584)\end{array}$ & - & $\begin{array}{c}-0,1540 * * \\
(0,0683)\end{array}$ & $\begin{array}{c}-0,1509^{* *} \\
(0,0637)\end{array}$ \\
\hline Ano2011 & - & - & $\begin{array}{c}-0,1603^{* * * *} \\
(0,0589)\end{array}$ & - & - & $\begin{array}{c}-0,1570 \text { *** } \\
(0,0568)\end{array}$ \\
\hline Ano2012 & - & - & $\begin{array}{c}-0,2014 * * * \\
(0,0768)\end{array}$ & - & - & $\begin{array}{c}-0,1996^{* * * *} \\
(0,0743)\end{array}$ \\
\hline Ano2013 & - & - & $\begin{array}{c}-0,2154 * * * \\
(0,0611)\end{array}$ & - & - & $\begin{array}{c}-0,2120 \text { *** } \\
(0,0582)\end{array}$ \\
\hline Ano2014 & - & - & $\begin{array}{c}-0,3464 * * * \\
(0,0946)\end{array}$ & - & - & $\begin{array}{c}-0,3441 * * * \\
(0,5825)\end{array}$ \\
\hline Intercepto & $\begin{array}{l}-0,0582 \\
(0,1008) \\
\end{array}$ & $\begin{array}{r}0,1054 \\
(0,5901) \\
\end{array}$ & $\begin{array}{c}0,1646 \\
(0,6075) \\
\end{array}$ & $\begin{array}{r}0,0617 \\
(0,1757) \\
\end{array}$ & $\begin{array}{c}0,2243 \\
(0,5609) \\
\end{array}$ & $\begin{array}{r}0,3192 \\
(0,5825) \\
\end{array}$ \\
\hline Estimador & $\mathrm{RE}$ & $\mathrm{RE}$ & $\mathrm{RE}$ & $\mathrm{RE}$ & $\mathrm{RE}$ & $\mathrm{RE}$ \\
\hline Teste F & 0,0764 & 0,0491 & 0,0002 & 0,0480 & 0,1313 & 0,0003 \\
\hline $\mathrm{R}^{2}$ within & 0,0316 & 0,0322 & 0,0631 & 0,0318 & 0,0322 & 0,0632 \\
\hline $\mathrm{R}^{2}$ between & 0,0023 & 0,0138 & 0,0148 & 0,0030 & 0,0152 & 0,0154 \\
\hline $\mathrm{R}^{2}$ overall & 0,0102 & 0,0181 & 0,0400 & 0,0107 & 0,0188 & 0,0404 \\
\hline Teste de Wooldridge & 0,0000 & 0,0000 & 0,0000 & 0,0000 & 0,0000 & 0,0000 \\
\hline $\mathrm{N}^{\circ}$ Observações & 910 & 910 & 910 & 910 & 910 & 910 \\
\hline $\mathrm{N}^{\circ}$ Empresas & 182 & 182 & 182 & 182 & 182 & 182 \\
\hline
\end{tabular}

Fonte: Formulário de Referência e Economatica ${ }^{\circledR}$.

Notas: Erros-padrão robustos apresentados para os modelos nos quais foram detectados a presença de autocorrelação através do Teste de Wooldridge; Significância estatística: ***1\%, **5\% e*10\%; RE indica que a estimação foi feita através do modelo de efeitos aleatórios (Random Effects). Os valores para o teste $\mathrm{F}$ e o teste de Wooldridge indicam os seus respectivos p-values.

Na Tabela 7 estão contidos os modelos numerados de 19 a 24. Nestes modelos o ROE ajustado é utilizado como variável dependente. Em razão da ausência de trabalhos anteriores que tenham utilizado essa proxy para a lucratividade empresarial, os resultados são comparados com os obtidos por Brick e Chidambaran (2010) e com os obtidos pelos modelos numerados de 7 a 12, que também utilizaram índices de lucratividade ajustado ao mercado.

Assim como no trabalho de Brick e Chidambaran (2010), o tamanho do Conselho de Administração não mostra relação estatisticamente significante com a lucratividade. Porém, estes resultados são diferentes dos encontrados quando o ROA ajustado foi utilizado como proxy para o desempenho em relação ao setor, onde é encontrada uma relação positiva entre o tamanho do Conselho de Administração e a lucratividade.

Já para as proxies que representam a independência deste órgão, os resultados são similares aos obtidos para os modelos 13 a 18 do presente trabalho, onde não é encontrada relação entre estas duas variáveis. Porém, os resultados são diferentes dos achados por Brick e Chidambaran (2010), onde uma maior independência do Conselho de Administração está ligada a uma maior lucratividade ajustada ao setor.

Os resultados para a variável que representa a dualidade do CEO mostram que esta característica está ligada a um melhor desempenho empresarial, porém, esta se mostra 
significante apenas no modelo 21 da Tabela 7, o que nos traz evidências de que a dualidade do CEO não exerce influência sobre o ROE ajustado. Resultados divergentes foram encontrados quando o ROA ajustado foi utilizado como variável dependente. Estes resultados estão em desacordo com o proposto anteriormente por Brickley et al. (1997) e Donaldson e Davis (1991). Por outro lado, Brick e Chidambaran (2010) encontraram uma relação negativa entre a dualidade do CEO e a lucratividade ajustada ao setor.

Dentre as variáveis de controle utilizadas no modelo, destaca-se o controle estatal, que se mostra relevante mesmo após a adição de todos os grupos de variáveis, no modelo 24 . $\mathrm{O}$ coeficiente negativo indica que empresas estatais apresentam um desempenho inferior ao setor em que operam, assim como proposto por Micco et al. (2007) e Chen e Liu (2013). A significância estatística e o coeficiente negativo obtido pelas dummies temporais indicam que com o passar do tempo, as empresas utilizadas na amostra apresentam uma lucratividade ajustada menor, assim como em muitos dos modelos anteriores do presente trabalho.

Tabela 7 - Resultado das estimações dos modelos de dados em painel para a variável dependente ROE ajustado. 2010-2014

\begin{tabular}{|c|c|c|c|c|c|c|}
\hline & Modelo 19 & Modelo 20 & Modelo 21 & Modelo 22 & Modelo 23 & Modelo 24 \\
\hline Variáveis & $\begin{array}{c}\text { Coef. } \\
\text { (Erro-P) }\end{array}$ & $\begin{array}{c}\text { Coef. } \\
\text { (Erro-P) }\end{array}$ & $\begin{array}{c}\text { Coef. } \\
\text { (Erro-P) }\end{array}$ & $\begin{array}{c}\text { Coef. } \\
\text { (Erro-P) }\end{array}$ & $\begin{array}{c}\text { Coef. } \\
\text { (Erro-P) }\end{array}$ & $\begin{array}{c}\text { Coef. } \\
\text { (Erro-P) }\end{array}$ \\
\hline TamanhoCA & $\begin{array}{c}0,0182 * * \\
(0,0091)\end{array}$ & $\begin{array}{c}0,0235 \\
(0,0200)\end{array}$ & $\begin{array}{c}0,0138 \\
(0,0242)\end{array}$ & $\begin{array}{c}0,0217 * * \\
(0,0092)\end{array}$ & $\begin{array}{c}0,0273 \\
(0,0193)\end{array}$ & $\begin{array}{c}0,0238 \\
(0,0191)\end{array}$ \\
\hline$\%$ Independentes & $\begin{array}{c}0,0227 \\
(0,1169)\end{array}$ & $\begin{array}{c}0,0282 \\
(0,1203)\end{array}$ & $\begin{array}{c}0,0381 \\
(0,1098)\end{array}$ & - & - & - \\
\hline$\%$ Externos & - & - & - & $\begin{array}{l}-0,1732 \\
(0,1441)\end{array}$ & $\begin{array}{l}-0,1924 \\
(0,1582)\end{array}$ & $\begin{array}{l}-0,2273 \\
(0,1515)\end{array}$ \\
\hline DualidadeCEO & $\begin{array}{c}0,2727 \\
(0,1668)\end{array}$ & $\begin{array}{c}0,2671 \\
(0,1705)\end{array}$ & $\begin{array}{c}0,4038 * * \\
(0,1683)\end{array}$ & $\begin{array}{c}0,2530 \\
(0,1674)\end{array}$ & $\begin{array}{c}0,2452 \\
(0,1750)\end{array}$ & $\begin{array}{c}0,2120 \\
(0,1662)\end{array}$ \\
\hline LogAtivos & - & $\begin{array}{c}0,0051 \\
(0,1537)\end{array}$ & $\begin{array}{c}0,3694 \\
(0,3113)\end{array}$ & - & $\begin{array}{c}0,0077 \\
(0,1545)\end{array}$ & $\begin{array}{c}0,0245 \\
(0,1543)\end{array}$ \\
\hline Endividamento & - & $\begin{array}{l}-0,2682 \\
(0,5826)\end{array}$ & $\begin{array}{l}-0,4521 \\
(1,0927)\end{array}$ & - & $\begin{array}{l}-0,2704 \\
(0,5819)\end{array}$ & $\begin{array}{l}-0,2575 \\
(0,5789)\end{array}$ \\
\hline Estrangeiro & - & $\begin{array}{c}0,1416 \\
(0,1051)\end{array}$ & $\begin{array}{c}0,0249 \\
(0,2021)\end{array}$ & - & $\begin{array}{c}0,1420 \\
(0,1039)\end{array}$ & $\begin{array}{c}0,1468 \\
(0,1041)\end{array}$ \\
\hline Estatal & - & $\begin{array}{c}-0,1624 * * \\
(0,0635)\end{array}$ & $\begin{array}{l}-0,0419 \\
(0,2632)\end{array}$ & - & $\begin{array}{c}-0,1685^{* *} \\
(0,0682)\end{array}$ & $\begin{array}{c}-0,1655^{* *} \\
(0,0652)\end{array}$ \\
\hline Ano2011 & - & - & $\begin{array}{c}-0,1316^{* * *} \\
(0,0678)\end{array}$ & - & - & $\begin{array}{c}-0,1221 * * \\
(0,0570)\end{array}$ \\
\hline Ano2012 & - & - & $\begin{array}{c}-0,1241^{*} \\
(0,0679)\end{array}$ & - & - & $\begin{array}{l}-0,1090 \\
(0,0747)\end{array}$ \\
\hline Ano2013 & - & - & $\begin{array}{c}-0,1410 * * \\
(0,0579)\end{array}$ & - & - & $\begin{array}{c}-0,1229 * * \\
(0,0586)\end{array}$ \\
\hline Ano2014 & - & - & $\begin{array}{c}-0,2708 * * * \\
(0,0864)\end{array}$ & - & - & $\begin{array}{c}-0,2533 * * * \\
(0,0902)\end{array}$ \\
\hline Intercepto & $\begin{array}{l}-0,1506 \\
(0,0985)\end{array}$ & $\begin{array}{l}-0,0733 \\
(0,5817)\end{array}$ & $\begin{array}{l}-2,1528 \\
(1,3776)\end{array}$ & $\begin{array}{l}-0,0179 \\
(0,1692)\end{array}$ & $\begin{array}{c}0,0612 \\
(0,5533)\end{array}$ & $\begin{array}{c}0,1282 \\
(0,5749)\end{array}$ \\
\hline Estimador & RE & RE & FE(LSDV) & $\mathrm{RE}$ & $\mathrm{RE}$ & $\mathrm{RE}$ \\
\hline Teste F & 0,0955 & 0,0441 & 0,0000 & 0,0365 & 0,0916 & 0,0056 \\
\hline $\mathrm{R}^{2}$ within & 0,0283 & 0,0291 & - & 0,0287 & 0,0291 & 0,0447 \\
\hline $\mathrm{R}^{2}$ between & 0,0024 & 0,0161 & - & 0,0031 & 0,0176 & 0,0179 \\
\hline $\mathrm{R}^{2}$ ajustado / overall & 0,0095 & 0,0182 & 0,4354 & 0,0100 & 0,0190 & 0,0308 \\
\hline Teste de White & - & - & 0,0000 & - & - & - \\
\hline Teste de Wooldridge & 0,0000 & 0,0000 & - & 0,0000 & 0,0000 & 0,0000 \\
\hline $\mathrm{N}^{\circ}$ Observações & 910 & 910 & 910 & 910 & 910 & 910 \\
\hline $\mathrm{N}^{\circ}$ Empresas & 182 & 182 & 182 & 182 & 182 & 182 \\
\hline
\end{tabular}

Fonte: Formulário de Referência e Economatica®.

Notas: Erros-padrão robustos apresentados para os modelos RE e LSDV nos quais foram detectados a presença de heterocedasticidade ou autocorrelação através dos Testes White (LSDV) e Wooldridge (RE); Significância estatística: ***1\%, **5\% e *10\%; RE indica que a estimação foi feita através do modelo de efeitos aleatórios (Random Effects), LSDV indica que a estimação foi feita através do modelo Least Square Dummy Variables. Os valores para o teste F, o teste de White e Wooldridge indicam os seus respectivos p-values. 
Em resumo, os resultados obtidos até aqui indicam que o tamanho do Conselho de Administração está relacionado com uma maior lucratividade, mas apenas quando esta é representada pelo ROA e ROA ajustado ao setor. Ao mesmo tempo, observa-se que a dualidade do CEO é benéfica para a empresa, estando associada a um desempenho superior ao obtido pelas empresas concorrentes, uma vez que seu coeficiente mostra-se positivo e estatisticamente. Porém, esta relação se mantém apenas quando utilizado o ROA ajustado como variável dependente. O resultado para esta variável é similar aos propostos por Brickley et al. (1997) e Donaldson e Davis (1991).

Para as proxies que representam a independência do Conselho de Administração (\% Independentes e \% Externos) não foram encontradas relações estatisticamente significantivas entre estas e a lucratividade ou a lucratividade ajustada ao setor, assim como nos trabalhos de Yermack (1996), Mak e Kusnadi (2005) e Andrade et al. (2009). A relação esperada ${ }^{6}$ do reflexo das variáveis independentes nos índices de lucratividade e os resultados obtidos são mostrados na Tabela 8 em forma de resumo. Este trabalho considera como resultados definitivos apenas as relações fortemente observadas entre as características do Conselho de Administração e a lucratividade. Porém, na Tabela 8 também são mostrados os resultados onde foi observada uma relação fraca entre as características do CA e a lucratividade. Adicionalmente, são citados os trabalhos que obtiveram resultados semelhantes aos obtidos nesta pesquisa.

Tabela 8 - Resumo dos resultados obtidos quando analisado o reflexo das características do Conselho de Administração na lucratividade empresarial

\begin{tabular}{|c|c|c|c|c|c|c|}
\hline \multirow[b]{2}{*}{ Variáveis } & \multirow{2}{*}{$\begin{array}{l}\text { Relação } \\
\text { Esperada }\end{array}$} & \multicolumn{4}{|c|}{ Relação observada } & \multirow[b]{2}{*}{ Resultados Similares } \\
\hline & & $\mathrm{ROA}$ & $\begin{array}{c}\text { ROA } \\
\text { ajustado }\end{array}$ & ROE & $\begin{array}{c}\text { ROE } \\
\text { ajustado }\end{array}$ & \\
\hline TamanhoCA & $+\mathrm{ou}-$ & $+($ forte $)$ & $+($ forte $)$ & $+($ fraca $)$ & $+($ fraca $)$ & $\begin{array}{c}\text { Andrade } \text { et al. } \text { (2009); Brick } \\
\text { e Chidambaran (2010) }\end{array}$ \\
\hline$\%$ Independentes & $+\mathrm{ou}-$ & $\begin{array}{c}\text { Não } \\
\text { observada }\end{array}$ & $-($ fraca $)$ & $\begin{array}{c}\text { Não } \\
\text { observada }\end{array}$ & $\begin{array}{c}\text { Não } \\
\text { observada }\end{array}$ & Mak e Kusnadi (2005) \\
\hline$\%$ Externos & $+\mathrm{ou}-$ & $\begin{array}{c}\text { Não } \\
\text { observada }\end{array}$ & $\begin{array}{c}\text { Não } \\
\text { observada }\end{array}$ & $\begin{array}{c}\text { Não } \\
\text { observada }\end{array}$ & $\begin{array}{c}\text { Não } \\
\text { observada }\end{array}$ & $\begin{array}{c}\text { Yermack (1996); Andrade } \\
\text { et al. }(2009)\end{array}$ \\
\hline DualidadeCEO & $+\mathrm{ou}-$ & $\begin{array}{c}\text { Não } \\
\text { observada }\end{array}$ & + (forte) & $+($ fraca $)$ & $+($ fraca $)$ & $\begin{array}{l}\text { Mak e Kusnadi (2005); } \\
\text { Liang et al. }(2013)\end{array}$ \\
\hline
\end{tabular}

Fonte: Formulário de Referência e Economatica®.

Notas: A relação positiva ou negativa fortemente (fracamente) observada acontece quando a variável mostrou-se estatisticamente significativa na maioria (minoria) dos modelos.

\footnotetext{
${ }^{6}$ A relação esperada diz respeito ao impacto de cada variável explicativa no desempenho da empresa, conforme pressupõe a literatura teórica. No entanto, é preciso levar em consideração que nos modelos estimados existe a influência de outras variáveis explicativas que, conjuntamente, são determinantes do desempenho empresarial.
} 


\subsection{Resultados das Estimações dos Modelos de Regressão Quantílica}

Este tópico tem por objetivo analisar os resultados das regressões quantílicas, o que permitirá verificar se há diferença na relação entre as características do Conselho de Administração e a lucratividade empresarial quando considerado os diferentes níveis de lucratividade das empresas. Acredita-se, neste contexto, que o Conselho de Administração possa ser estruturado de maneira diferente dependendo da situação econômica (em termos de lucratividade) da empresa.

Hermalin e Weisbach (1988) afirmam que após períodos de baixo desempenho, as empresas geralmente aumentam a proporção de conselheiros externos no Conselho de Administração, tanto pela adição de novos membros quanto pela substituição de membros internos por membros externos. Este fato poderia indicar uma falsa correlação negativa entre a proporção de conselheiros independentes/externos e a lucratividade, visto que os conselheiros externos seriam adicionados ao conselho quando a empresa apresentasse um baixo desempenho. Ao mesmo tempo, um Conselho de Administração formado por um maior número de membros poderia ser mais efetivo quando a empresa apresentasse baixo desempenho.

As regressões quantílicas foram estimadas com o objetivo de identificar possíveis diferenças no relacionamento entre as variáveis explicativas e as variáveis dependentes, dependendo da distribuição acumulada da variável dependente. Os modelos de regressão quantílica foram estimadas individualmente para cada ano, utilizando o ROA, ROA ajustado, ROE e ROE ajustado como variáveis dependentes, totalizando 120 estimações distribuídas entre 20 tabelas numeradas de 9 a 28 . As regressões foram estimadas utilizando os quantis $25^{\circ}$, $50^{\circ}$ e $75^{\circ}$. Nesta seção serão apresentados os resultados referentes ao ano de 2014, considerado o mais relevante por ser o ano mais recente do período histórico estudado. As regressões quantílicas estimadas para os anos restantes estão disponíveis no Apêndice I desta dissertação. Os modelos estimados têm por base a utilização das variáveis de acordo com o exposto na Tabela 3.

Na Tabela 9 estão contidos os modelos que utilizaram como variável dependente o ROA. Assim como nas estimações dos modelos de painel correspondentes, os resultados mostram uma relação positiva entre o tamanho do Conselho de Administração e o ROA. Porém, esta relação se dá apenas quando consideradas as empresas contidas nos quantis superiores, onde o tamanho apresenta um coeficiente positivo e estatisticamente significante ao nível de $1 \%$.

Quando observados os resultados obtidos pelas proxies de independência do CA, observase que a proporção de membros independentes apresenta uma relação positiva e estatisticamente significante ao nível de $10 \%$ com o ROA, como mostrado no modelo 25 . O mesmo não é observado quando esta variável é substituída pela proporção de membros externos. Por outro lado, percebe-se que, considerando as empresas mais lucrativas, contidas nos quantis superiores, a relação entre a independência do conselho e a lucratividade inverte-se, onde uma maior proporção de membros externos está ligada a um menor ROA.

Estes resultados dão pequenos indícios de que as empresas que apresentam baixo desempenho talvez promovam a adição de membros independentes ou a substituição de membros internos por membros independentes, os quais apresentam maior capacidade de melhorar os resultados da empresa, assim como proposto por Hermalin e Weisbach (1988). Por outro lado, a relação estatisticamente significante ao nível de $1 \%$ somada ao coeficiente negativo da variável \% Externos indica que uma maior proporção de conselheiros externos nos conselhos das empresas mais lucrativas teria um efeito contrário ao obtido pela adição de membros independentes pelas empresas com baixa lucratividade. Estes achados sugerem que 
os conselheiros independentes exercem seus papéis de maneira mais eficiente em empresas que apresentam um baixo desempenho, enquanto que uma maior proporção de membros externos exerce uma influência negativa em empresas que apresentam um maior nível de lucratividade.

A dualidade do CEO não apresentou uma ligação relevante com a lucratividade, assim como nos modelos similares que utilizaram a metodologia de dados em painel (modelos 1 a 6). Ao analisar as variáveis de controle, percebe-se que o endividamento relaciona-se negativamente com a lucratividade em todos os modelos considerados. Por fim, observa-se que o controle estrangeiro está ligado a um maior ROA. Estes resultados mantêm-se apenas quando considerados os quantis superiores da distribuição, assim como em Grasseni (2010).

Tabela 9 - Resultado das estimações dos modelos de regressão quantílica para a variável dependente ROA. 2014

\begin{tabular}{|c|c|c|c|c|c|c|}
\hline & Modelo 2 & Modelo 5 & Modelo 2 & Modelo 5 & Modelo 2 & Modelo 5 \\
\hline Variáveis & $\begin{array}{c}\text { Coef. } \\
\text { (Erro-P) }\end{array}$ & $\begin{array}{c}\text { Coef. } \\
\text { (Erro-P) }\end{array}$ & $\begin{array}{c}\text { Coef. } \\
\text { (Erro-P) }\end{array}$ & $\begin{array}{c}\text { Coef. } \\
\text { (Erro-P) }\end{array}$ & $\begin{array}{c}\text { Coef. } \\
\text { (Erro-P) }\end{array}$ & $\begin{array}{c}\text { Coef. } \\
\text { (Erro-P) }\end{array}$ \\
\hline & $\mathrm{Q}=0,25$ & $\mathrm{Q}=0,25$ & $\mathrm{Q}=0,50$ & $\mathrm{Q}=0,50$ & $\mathrm{Q}=0,75$ & $\mathrm{Q}=0,75$ \\
\hline TamanhoCA & $\begin{array}{c}0,0032 \\
(0,0042)\end{array}$ & $\begin{array}{c}0,0035 \\
(0,0045)\end{array}$ & $\begin{array}{c}0,0032 \\
(0,0029)\end{array}$ & $\begin{array}{c}0,0032 \\
(0,0032)\end{array}$ & $\begin{array}{c}0,0040 \\
(0,0033)\end{array}$ & $\begin{array}{c}0,0080 \text { *** } \\
(0,0030)\end{array}$ \\
\hline$\%$ Independentes & $\begin{array}{l}0,0802 * \\
(0,0411)\end{array}$ & - & $\begin{array}{c}0,0274 \\
(0,0286)\end{array}$ & - & $\begin{array}{l}-0,0101 \\
(0,0332)\end{array}$ & - \\
\hline$\%$ Externos & - & $\begin{array}{l}-0,0631 \\
(0,0794)\end{array}$ & - & $\begin{array}{l}-0,0308 \\
(0,0555)\end{array}$ & - & $\begin{array}{c}-0,1052^{* *} \\
(0,0531)\end{array}$ \\
\hline DualidadeCEO & $\begin{array}{c}0,0394 \\
(0,0252)\end{array}$ & $\begin{array}{l}-0,0031 \\
(0,0274)\end{array}$ & $\begin{array}{c}0,0013 \\
(0,0175)\end{array}$ & $\begin{array}{l}-0,0117 \\
(0,0191)\end{array}$ & $\begin{array}{l}-0,0159 \\
(0,0203)\end{array}$ & $\begin{array}{l}-0,0178 \\
(0,0183)\end{array}$ \\
\hline LogAtivos & $\begin{array}{c}0,0117 \\
(0,1334)\end{array}$ & $\begin{array}{c}0,0165 \\
(0,0138)\end{array}$ & $\begin{array}{l}-0,0016 \\
(0,0093)\end{array}$ & $\begin{array}{c}0,0025 \\
(0,0096)\end{array}$ & $\begin{array}{l}-0,0008 \\
(0,0108)\end{array}$ & $\begin{array}{l}-0,0029 \\
(0,0092)\end{array}$ \\
\hline Endividamento & $\begin{array}{c}-0,1727 * * * \\
(0,0388)\end{array}$ & $\begin{array}{c}-0,1759 * * * \\
(0,0400)\end{array}$ & $\begin{array}{c}-0,1199 * * * \\
(0,0270)\end{array}$ & $\begin{array}{c}-0,1181 * * * \\
(0,0279)\end{array}$ & $\begin{array}{c}-0,1930 * * * \\
(0,0314)\end{array}$ & $\begin{array}{c}-0,1836 \text { *** } \\
(0,0268)\end{array}$ \\
\hline Estrangeiro & $\begin{array}{c}0,0498 \\
(0,0385)\end{array}$ & $\begin{array}{c}0,0179 \\
(0,0397)\end{array}$ & $\begin{array}{c}0,0253 \\
(0,0268)\end{array}$ & $\begin{array}{c}0,0224 \\
(0,0278)\end{array}$ & $\begin{array}{c}0,0845 * * * \\
(0,0311)\end{array}$ & $\begin{array}{c}0,0895 * * * \\
(0,0266)\end{array}$ \\
\hline Estatal & $\begin{array}{l}-0,0192 \\
(0,0384)\end{array}$ & $\begin{array}{l}-0,0587 \\
(0,0391)\end{array}$ & $\begin{array}{l}-0,0205 \\
(0,0267)\end{array}$ & $\begin{array}{l}-0,0235 \\
(0,0273)\end{array}$ & $\begin{array}{l}-0,0413 \\
(0,0310)\end{array}$ & $\begin{array}{l}-0,0302 \\
(0,0262)\end{array}$ \\
\hline Intercepto & $\begin{array}{l}-0,0400 \\
(0,0735)\end{array}$ & $\begin{array}{c}0,0122 \\
(0,0950)\end{array}$ & $\begin{array}{l}0,0862 * \\
(0,0512)\end{array}$ & $\begin{array}{c}0,0924 \\
(0,0664)\end{array}$ & $\begin{array}{c}0,1630 * * * \\
(0,0593)\end{array}$ & $\begin{array}{c}0,2305 * * * \\
(0,0635) \\
\end{array}$ \\
\hline Teste de Wald & 0,0003 & 0,0027 & 0,0011 & 0,0050 & 0,0000 & 0,0000 \\
\hline Pseudo R ${ }^{2}$ & 0,1178 & 0,1107 & 0,0776 & 0,0791 & 0,1436 & 0,1534 \\
\hline $\mathrm{N}^{\circ}$ Observações & 182 & 182 & 182 & 182 & 182 & 182 \\
\hline $\mathrm{N}^{\mathrm{o}}$ Empresas & 182 & 182 & 182 & 182 & 182 & 182 \\
\hline
\end{tabular}

Fonte: Formulário de Referência e Economatica®.

Notas: Significância estatística: ***1\%, **5\% e *10\%.

Na Tabela 10 estão contidos os modelos que utilizam o ROA ajustado como variável dependente. Diferentemente dos modelos da Tabela 9, desta vez a significância estatística da variável que representa o tamanho do Conselho de Administração ocorre quando considerados os quantis inferiores. O coeficiente positivo aliado a um nível de significância de $5 \%$ no modelo 31 indica que as empresas menos lucrativas que têm um órgão formado por maior número de membros têm mais chances de apresentar um desempenho superior ao registrado pelas empresas do mesmo setor de atuação.

Não foi encontrada uma relação relevante entre a independência do Conselho de Administração e o ROA ajustado. Embora a Dualidade do CEO apresente um coeficiente positivo e estatisticamente significante no modelo 8 calculado para o quantil $25^{\circ}$, o nível de confiança para este coeficiente aliado à falta de confirmação deste resultado pelo modelo 11 calculado para o mesmo quantil, tornam este resultado irrelevante. Para todos os modelos considerados, o endividamento relaciona-se negativamente com a lucratividade, assim como nos modelos similares contidos na Tabela 5. Por sua vez, o controle estrangeiro exerce um impacto positivo na lucratividade quando considerados os quantis superiores da distribuição, o 
controle estatal está negativamente ligado à lucratividade empresarial, mas apenas quando consideradas as empresas menos lucrativas da amostra no ano de 2014. Estes resultados assemelham-se aos encontrados por Brick e Chidambaran (2010) e Grasseni (2010).

Tabela 10 - Resultado das estimações dos modelos de regressão quantílica para a variável dependente ROA ajustado. 2014

\begin{tabular}{|c|c|c|c|c|c|c|}
\hline & Modelo 8 & Modelo 11 & Modelo 8 & Modelo 11 & Modelo 8 & Modelo 11 \\
\hline Variáveis & $\begin{array}{l}\text { Coef. } \\
\text { (Erro-P) }\end{array}$ & $\begin{array}{l}\text { Coef. } \\
\text { (Erro-P) }\end{array}$ & $\begin{array}{l}\text { Coef. } \\
\text { (Erro-P) }\end{array}$ & $\begin{array}{l}\text { Coef. } \\
\text { (Erro-P) }\end{array}$ & $\begin{array}{c}\text { Coef. } \\
\text { (Erro-P) }\end{array}$ & $\begin{array}{l}\text { Coef. } \\
\text { (Erro-P) }\end{array}$ \\
\hline & $\mathrm{Q}=0,25$ & $\mathrm{Q}=0,25$ & $\mathrm{Q}=0,50$ & $\mathrm{Q}=0,50$ & $\mathrm{Q}=0,75$ & $\mathrm{Q}=0,75$ \\
\hline TamanhoCA & $\begin{array}{l}0,0090^{* *} \\
(0,0035)\end{array}$ & $\begin{array}{c}0,0068 \\
(0,0042)\end{array}$ & $\begin{array}{c}0,0023 \\
(0,0026)\end{array}$ & $\begin{array}{l}0,0049^{*} \\
(0,0028)\end{array}$ & $\begin{array}{c}0,0049 \\
(0,0032)\end{array}$ & $\begin{array}{c}0,0052 \\
(0,0035)\end{array}$ \\
\hline$\%$ Independentes & $\begin{array}{c}0,0482 \\
(0,0351)\end{array}$ & - & $\begin{array}{l}-0,0006 \\
(0,0260)\end{array}$ & - & $\begin{array}{l}-0,0001 \\
(0,0320)\end{array}$ & - \\
\hline$\%$ Externos & - & $\begin{array}{l}-0,0189 \\
(0,0738)\end{array}$ & - & $\begin{array}{l}-0,0383 \\
(0,0496)\end{array}$ & - & $\begin{array}{l}-0,0139 \\
(0,0618)\end{array}$ \\
\hline DualidadeCEO & $\begin{array}{l}0,0384^{*} \\
(0,0216)\end{array}$ & $\begin{array}{c}0,0112 \\
(0,0255)\end{array}$ & $\begin{array}{c}0,0039 \\
(0,0160)\end{array}$ & $\begin{array}{c}0,0035 \\
(0,0171)\end{array}$ & $\begin{array}{l}-0,0063 \\
(0,0197)\end{array}$ & $\begin{array}{c}0,0059 \\
(0,0213)\end{array}$ \\
\hline LogAtivos & $\begin{array}{c}0,0143 \\
(0,0114)\end{array}$ & $\begin{array}{c}0,0106 \\
(0,0128)\end{array}$ & $\begin{array}{l}0,0144 * \\
(0,0085)\end{array}$ & $\begin{array}{c}0,0118 \\
(0,0086)\end{array}$ & $\begin{array}{c}0,0017 \\
(0,0104)\end{array}$ & $\begin{array}{c}0,0019 \\
(0,0107)\end{array}$ \\
\hline Endividamento & $\begin{array}{c}-0,1998 * * * * \\
(0,0332)\end{array}$ & $\begin{array}{c}-0,1869 * * * \\
(0,0372)\end{array}$ & $\begin{array}{c}-0,1219 * * * \\
(0,0246)\end{array}$ & $\begin{array}{c}-0,1170 * * * \\
(0,0250)\end{array}$ & $\begin{array}{c}-0,1882 * * * \\
(0,0303)\end{array}$ & $\begin{array}{c}-0,1890^{* * * *} \\
(0,0311)\end{array}$ \\
\hline Estrangeiro & $\begin{array}{c}0,0261 \\
(0,0330)\end{array}$ & $\begin{array}{c}0,0244 \\
(0,0369)\end{array}$ & $\begin{array}{c}0,0189 \\
(0,0244)\end{array}$ & $\begin{array}{c}0,0115 \\
(0,0248)\end{array}$ & $\begin{array}{c}0,0611 * * \\
(0,0301)\end{array}$ & $\begin{array}{l}0,0603^{*} \\
(0,0309)\end{array}$ \\
\hline Estatal & $\begin{array}{c}-0,0823 * * \\
(0,0328)\end{array}$ & $\begin{array}{c}-0,1007 * * * \\
(0,0364)\end{array}$ & $\begin{array}{l}-0,0208 \\
(0,0243)\end{array}$ & $\begin{array}{l}-0,0238 \\
(0,0244)\end{array}$ & $\begin{array}{l}-0,0344 \\
(0,0299)\end{array}$ & $\begin{array}{l}-0,0347 \\
(0,0304)\end{array}$ \\
\hline Intercepto & $\begin{array}{l}-0,0919 \\
(0,0628)\end{array}$ & $\begin{array}{l}-0,0283 \\
(0,0883)\end{array}$ & $\begin{array}{l}-0,0322 \\
(0,0466)\end{array}$ & $\begin{array}{l}-0,0036 \\
(0,0594)\end{array}$ & $\begin{array}{l}0,1052 * \\
(0,0573)\end{array}$ & $\begin{array}{c}0,1144 \\
(0,0740)\end{array}$ \\
\hline $\begin{array}{l}\text { Teste de Wald } \\
\text { Pseudo R }{ }^{2}\end{array}$ & $\begin{array}{l}0,0000 \\
0,1595\end{array}$ & $\begin{array}{l}0,0000 \\
0,1509\end{array}$ & $\begin{array}{l}0,0004 \\
0,0822\end{array}$ & $\begin{array}{l}0,0005 \\
0,0834\end{array}$ & $\begin{array}{l}0,0000 \\
0,1425\end{array}$ & $\begin{array}{l}0,0000 \\
0,1429\end{array}$ \\
\hline $\begin{array}{l}\mathrm{N}^{\circ} \text { Observações } \\
\mathrm{N}^{\circ} \text { Empresas }\end{array}$ & $\begin{array}{l}182 \\
182\end{array}$ & $\begin{array}{l}182 \\
182\end{array}$ & $\begin{array}{l}182 \\
182\end{array}$ & $\begin{array}{l}182 \\
182\end{array}$ & $\begin{array}{l}182 \\
182\end{array}$ & $\begin{array}{l}182 \\
182\end{array}$ \\
\hline
\end{tabular}

Fonte: Formulário de Referência e Economatica®.

Notas: Significância estatística: ***1\%, **5\% e *10\%.

A análise segue pela apreciação dos resultados contidos na Tabela 11, onde a variável dependente utilizada nas estimações foi o ROE. O teste de Wald indica a não rejeição da hipótese nula ao nível de $10 \%$ de que todos os regressores são neutros para três dos modelos listados na Tabela 11 (modelo 17 quantil 0,25, modelo 14 quantil 0,5 e modelo 17 quantil 0,50). Sendo assim, estas estimações não são consideradas na análise.

De maneira similar aos modelos de regressão quantílica onde o ROA foi utilizado como variável dependente, o reflexo do tamanho do Conselho de Administração mostrou-se estatisticamente significante apenas quando considerados os quantis superiores da distribuição. Estes resultados indicam que o impacto que o tamanho do Conselho de Administração exerce na lucratividade empresarial é maior para as empresas que apresentam um maior desempenho.

A independência do conselho e a dualidade do CEO não mostraram resultados relevantes quando o ROE foi considerado como proxy para a lucratividade. $\mathrm{O}$ sinal do coeficiente do endividamento manteve-se constante para todos os modelos estimados na Tabela 11, apresentando significância estatística na maioria destes. Este resultado é convergente com Liang et al. (2013), onde um maior nível de dívida está ligado a um menor ROE. Por fim, o controle estrangeiro exerce uma influência positiva na lucratividade quando consideradas as empresas que fazem parte dos quantis superiores da distribuição, assim como em Grasseni (2010). 
Tabela 11 - Resultado das estimações dos modelos de regressão quantílica para a variável dependente ROE. 2014

\begin{tabular}{|c|c|c|c|c|c|c|}
\hline & Modelo 14 & Modelo 17 & Modelo 14 & Modelo 17 & Modelo 14 & Modelo 17 \\
\hline Variáveis & $\begin{array}{c}\text { Coef. } \\
\text { (Erro-P) }\end{array}$ & $\begin{array}{c}\text { Coef. } \\
\text { (Erro-P) }\end{array}$ & $\begin{array}{c}\text { Coef. } \\
\text { (Erro-P) }\end{array}$ & $\begin{array}{c}\text { Coef. } \\
\text { (Erro-P) }\end{array}$ & $\begin{array}{c}\text { Coef. } \\
\text { (Erro-P) }\end{array}$ & $\begin{array}{c}\text { Coef. } \\
(\text { Erro-P) }\end{array}$ \\
\hline & $\mathrm{Q}=0,25$ & $\mathrm{Q}=0,25$ & $\mathrm{Q}=0,50$ & $\mathrm{Q}=0,50$ & $\mathrm{Q}=0,75$ & $\mathrm{Q}=0,75$ \\
\hline TamanhoCA & $\begin{array}{c}0,0084 \\
(0,0169)\end{array}$ & $\begin{array}{c}0,0120 \\
(0,0203)\end{array}$ & $\begin{array}{c}0,0084 \\
(0,0082)\end{array}$ & $\begin{array}{c}0,0089 \\
(0,0092)\end{array}$ & $\begin{array}{c}0,0197 * * * \\
(0,0069)\end{array}$ & $\begin{array}{c}0,0235 * * * \\
(0,0069)\end{array}$ \\
\hline$\%$ Independentes & $\begin{array}{c}0,0148 \\
(0,1671)\end{array}$ & - & $\begin{array}{c}0,0417 \\
(0,0807)\end{array}$ & - & $\begin{array}{c}-0,0259 \\
(0,0685)\end{array}$ & - \\
\hline$\%$ Externos & - & $\begin{array}{c}-0,2091 \\
(0,3555)\end{array}$ & - & $\begin{array}{l}-0,1197 \\
(0,1607)\end{array}$ & - & $\begin{array}{c}-0,2188 * \\
(0,1209)\end{array}$ \\
\hline DualidadeCEO & $\begin{array}{l}-0,0317 \\
(0,1025)\end{array}$ & $\begin{array}{l}-0,0641 \\
(0,1225)\end{array}$ & $\begin{array}{c}0,0516 \\
(0,0495)\end{array}$ & $\begin{array}{l}-0,0798 \\
(0,0554)\end{array}$ & $\begin{array}{l}-0,0310 \\
(0,0420)\end{array}$ & $\begin{array}{l}-0,0560 \\
(0,0417)\end{array}$ \\
\hline LogAtivos & $\begin{array}{c}0,0483 \\
(0,0544)\end{array}$ & $\begin{array}{c}0,0493 \\
(0,0616)\end{array}$ & $\begin{array}{c}0,0125 \\
(0,0263)\end{array}$ & $\begin{array}{c}0,0258 \\
(0,0279)\end{array}$ & $\begin{array}{c}0,0067 \\
(0,0223)\end{array}$ & $\begin{array}{c}0,0042 \\
(0,0210)\end{array}$ \\
\hline Endividamento & $\begin{array}{c}-0,5394 * * * \\
(0,1580)\end{array}$ & $\begin{array}{c}-0,5018^{* * *} * \\
(0,1791)\end{array}$ & $\begin{array}{c}-0,1817 * * \\
(0,0763)\end{array}$ & $\begin{array}{c}-0,1957 * * \\
(0,0810)\end{array}$ & $\begin{array}{c}-0,1075 * * * \\
(0,0647)\end{array}$ & $\begin{array}{l}-0,0329 \\
(0,0609)\end{array}$ \\
\hline Estrangeiro & $\begin{array}{c}0,0498 \\
(0,1568)\end{array}$ & $\begin{array}{c}0,0730 \\
(0,1779)\end{array}$ & $\begin{array}{c}0,0470 \\
(0,0758)\end{array}$ & $\begin{array}{c}0,0602 \\
(0,0804)\end{array}$ & $\begin{array}{c}0,1540 * * \\
(0,0643)\end{array}$ & $\begin{array}{c}0,1998 * * * \\
(0,0605)\end{array}$ \\
\hline Estatal & $\begin{array}{c}-0,1226 \\
(0,1561)\end{array}$ & $\begin{array}{l}-0,1432 \\
(0,1750)\end{array}$ & $\begin{array}{c}-0,0655 \\
(0,0754)\end{array}$ & $\begin{array}{l}-0,0749 \\
(0,0792)\end{array}$ & $\begin{array}{c}-0,1275 \\
(0,0640)\end{array}$ & $\begin{array}{c}-0,0911 \\
(0,0596)\end{array}$ \\
\hline Intercepto & $\begin{array}{l}-0,1269 \\
(0,2989)\end{array}$ & $\begin{array}{c}0,0153 \\
(0,4254)\end{array}$ & $\begin{array}{c}0,0435 \\
(0,1444)\end{array}$ & $\begin{array}{c}0,0807 \\
(0,1923)\end{array}$ & $\begin{array}{c}0,0757 \\
(0,1225)\end{array}$ & $\begin{array}{c}0,2037 \\
(0,1447)\end{array}$ \\
\hline Teste de Wald & 0,0829 & 0,2502 & 0,1771 & 0,1656 & 0,0026 & 0,0003 \\
\hline Pseudo R ${ }^{2}$ & 0,0635 & 0,0653 & 0,0214 & 0,0224 & 0,0421 & 0,0519 \\
\hline $\mathrm{N}^{\circ}$ Observações & 182 & 182 & 182 & 182 & 182 & 182 \\
\hline $\mathrm{N}^{\circ}$ Empresas & 182 & 182 & 182 & 182 & 182 & 182 \\
\hline
\end{tabular}

Fonte: Formulário de Referência e Economatica®.

Notas: Significância estatística: ***1\%,**5\% e *10\%.

A Tabela 12 comporta os últimos modelos de regressão analisados nesta dissertação, onde o ROE ajustado é utilizado como variável dependente. Os resultados das estimações mostram evidências de que o tamanho do Conselho de Administração exerce uma influência positiva na lucratividade, quando considerados a mediana e os quantis mais altos da distribuição. Assim como quando o ROE foi utilizado como variável dependente, não há indícios de uma relação significativa entre a independência do conselho e a dualidade do CEO no desempenho empresarial medido pelo ROE ajustado.

Ao contrário dos modelos anteriores, há evidências de que o tamanho da empresa se relaciona positivamente com a lucratividade ajustada ao setor. Novamente, o endividamento parece impactar de maneira negativa na lucratividade empresarial. Por fim, é estabelecida uma relação positiva e estatisticamente significante entre o controle estrangeiro e o desempenho empresarial, corroborada pelos outros modelos de regressão quantílica estimados para o ano de 2014. 
Tabela 12 - Resultado das estimações dos modelos de regressão quantílica para a variável dependente ROE ajustado. 2014

\begin{tabular}{|c|c|c|c|c|c|c|}
\hline & Modelo 20 & Modelo 23 & Modelo 20 & Modelo 23 & Modelo 20 & Modelo 23 \\
\hline Variáveis & $\begin{array}{c}\text { Coef. } \\
\text { (Erro-P) }\end{array}$ & $\begin{array}{c}\text { Coef. } \\
\text { (Erro-P) }\end{array}$ & $\begin{array}{c}\text { Coef. } \\
\text { (Erro-P) }\end{array}$ & $\begin{array}{c}\text { Coef. } \\
\text { (Erro-P) }\end{array}$ & $\begin{array}{c}\text { Coef. } \\
\text { (Erro-P) }\end{array}$ & $\begin{array}{c}\text { Coef. } \\
(\text { Erro-P) }\end{array}$ \\
\hline & $\mathrm{Q}=0,25$ & $\mathrm{Q}=0,25$ & $\mathrm{Q}=0,50$ & $\mathrm{Q}=0,50$ & $\mathrm{Q}=0,75$ & $\mathrm{Q}=0,75$ \\
\hline TamanhoCA & $\begin{array}{c}0,0118 \\
(0,0147)\end{array}$ & $\begin{array}{c}0,0089 \\
(0,0185)\end{array}$ & $\begin{array}{c}0,0078 \\
(0,0068)\end{array}$ & $\begin{array}{l}0,0151 * * \\
(0,0074)\end{array}$ & $\begin{array}{l}0,0129 * \\
(0,0068)\end{array}$ & $\begin{array}{l}0,0124^{*} \\
(0,0071)\end{array}$ \\
\hline$\%$ Independentes & $\begin{array}{c}0,0966 \\
(0,1454)\end{array}$ & - & $\begin{array}{c}-0,0354 \\
(0,0670)\end{array}$ & - & $\begin{array}{c}0,0318 \\
(0,0678)\end{array}$ & - \\
\hline$\%$ Externos & - & $\begin{array}{l}-0,0364 \\
(0,3236)\end{array}$ & - & $\begin{array}{l}-0,1902 \\
(0,1300)\end{array}$ & - & $\begin{array}{l}-0,0395 \\
(0,1249)\end{array}$ \\
\hline DualidadeCEO & $\begin{array}{c}0,0028 \\
(0,0892)\end{array}$ & $\begin{array}{l}-0,0209 \\
(0,1116)\end{array}$ & $\begin{array}{l}-0,0350 \\
(0,0411)\end{array}$ & $\begin{array}{l}-0,0415 \\
(0,0448)\end{array}$ & $\begin{array}{c}-0,0386 \\
(0,0416)\end{array}$ & $\begin{array}{c}-0,0404 \\
(0,0431)\end{array}$ \\
\hline LogAtivos & $\begin{array}{c}0,0707 \\
(0,0473)\end{array}$ & $\begin{array}{c}0,0691 \\
(0,0561)\end{array}$ & $\begin{array}{c}0,0438 * * \\
(0,0218)\end{array}$ & $\begin{array}{l}0,0384^{*} \\
(0,0225)\end{array}$ & $\begin{array}{c}0,0269 \\
(0,0221)\end{array}$ & $\begin{array}{c}0,0248 \\
(0,0217)\end{array}$ \\
\hline Endividamento & $\begin{array}{c}-0,5735 * * * \\
(0,1375)\end{array}$ & $\begin{array}{c}-0,5283^{* * * *} \\
(0,1630)\end{array}$ & $\begin{array}{c}-0,1980 * * * \\
(0,0633)\end{array}$ & $\begin{array}{c}-0,2067 * * * \\
(0,0655)\end{array}$ & $\begin{array}{c}-0,1402 * * \\
(0,0641)\end{array}$ & $\begin{array}{c}-0,1344 * * \\
(0,0629)\end{array}$ \\
\hline Estrangeiro & $\begin{array}{c}0,0658 \\
(0,1364)\end{array}$ & $\begin{array}{c}0,0752 \\
(0,1619)\end{array}$ & $\begin{array}{c}0,0560 \\
(0,0629)\end{array}$ & $\begin{array}{c}0,1050 \\
(0,0651)\end{array}$ & $\begin{array}{c}0,1478 * * \\
(0,0636)\end{array}$ & $\begin{array}{c}0,1397 * * \\
(0,0625)\end{array}$ \\
\hline Estatal & $\begin{array}{l}-0,1513 \\
(0,1358)\end{array}$ & $\begin{array}{l}-0,1670 \\
(0,1593)\end{array}$ & $\begin{array}{l}-0,0657 \\
(0,0626)\end{array}$ & $\begin{array}{l}-0,0763 \\
(0,0640)\end{array}$ & $\begin{array}{l}-0,0693 \\
(0,0633)\end{array}$ & $\begin{array}{l}-0,0643 \\
(0,0615)\end{array}$ \\
\hline Intercepto & $\begin{array}{l}-0,3795 \\
(0,2601)\end{array}$ & $\begin{array}{l}-0,3150 \\
(0,3872) \\
\end{array}$ & $\begin{array}{l}-0,1959 \\
(0,1198) \\
\end{array}$ & $\begin{array}{l}-0,0562 \\
(0,1556)\end{array}$ & $\begin{array}{l}-0,0952 \\
(0,1212)\end{array}$ & $\begin{array}{l}-0,0449 \\
(0,1495)\end{array}$ \\
\hline Teste de Wald & 0,0055 & 0,0962 & 0,0136 & 0,0035 & 0,0038 & 0,0135 \\
\hline Pseudo R² & 0,0738 & 0,0734 & 0,0200 & 0,0270 & 0,0427 & 0,0441 \\
\hline $\begin{array}{l}\mathrm{N}^{\circ} \text { Observações } \\
\mathrm{N}^{\mathrm{o}} \text { Empresas }\end{array}$ & $\begin{array}{l}182 \\
182\end{array}$ & $\begin{array}{l}182 \\
182\end{array}$ & $\begin{array}{l}182 \\
182\end{array}$ & $\begin{array}{l}182 \\
182\end{array}$ & $\begin{array}{l}182 \\
182\end{array}$ & $\begin{array}{l}182 \\
182\end{array}$ \\
\hline
\end{tabular}

Fonte: Formulário de Referência e Economatica®.

Notas: Significância estatística: $* * * 1 \%, * * 5 \%$ e $* 10 \%$.

De maneira geral, os resultados das regressões quantílicas mostraram uma relação positiva e estatisticamente significante entre o tamanho do Conselho de Administração e a lucratividade empresarial. Esta relação mantém-se apenas quando consideradas as empresas constantes nos quantis superiores da distribuição, indicando que um CA composto por mais membros gera benefícios maiores para as empresas mais lucrativas. As variáveis \% Independentes e \% Externos não apresentaram muitos indícios de estarem relacionadas com a lucratividade, uma vez que a quase totalidade dos coeficientes destas variáveis não foram significativos. Fato similar ocorreu também para a variável DualidadeCEO. Esta última apresentou um coeficiente estatisticamente significante em apenas uma das 24 estimações realizadas através da técnica de regressão quantílica. Mesmo assim, seu nível de confiança foi baixo (10\%), indicando uma fraca relação entre esta variável e a lucratividade para o ano de 2014.

Finalizando, para a variável TamanhoCA, os resultados das estimações realizadas pelo método de regressão quantílica mostram-se similares com os obtidos quando utilizada a técnica de dados em painel. Porém, estes resultados apresentam similaridade de um modo geral, uma vez que os principais resultados obtidos nas estimações pela regressão quantílica indicam uma influência positiva do tamanho do CA na lucratividade quando o ROE e ROE ajustado são utilizados como variáveis dependentes. Destaca-se que estes resultados são divergentes dos obtidos para os modelos de painel, onde o tamanho do CA está relacionado positivamente com a lucratividade, porém, quando esta é medida pelo ROA e ROA ajustado.

Quando comparados os resultados obtidos pelas estimações por regressão quantílica para as variáveis \% Independentes e \% Externos, estes estão em convergência com os resultados obtidos pelas estimações realizadas por meio de painéis. Em ambos, os resultados não mostram relação entre a independência do CA e a lucratividade. Já a influência da dualidade do CEO na lucratividade apresenta resultados diferentes quando consideradas as diferentes formas de 
estimação dos modelos de regressão. Nas estimações feitas por meio da metodologia de dados em painel, esta variável mostrou-se estatisticamente significante quando o ROA ajustado foi utilizado como variável dependente. Porém, pela técnica de regressão quantílica, os mesmos resultados não foram alcançados. Dado que nesta última foi utilizado apenas o ano de 2014 como amostra, os resultados das estimações por painel podem ser originários da inclusão dos outros períodos estudados na estimação. 


\section{CONSIDERAÇÕES FINAIS}

O estudo da influência do Conselho de Administração na lucratividade das empresas encontra-se em estágio avançado quando analisada a literatura internacional sobre o assunto. No Brasil, porém, a divergência entre os poucos resultados encontrados acarreta uma demanda por mais pesquisas nesta área. A importância do estudo acerca da estrutura e influência do Conselho de Administração pode ser respaldada nas recomendações dos principais órgãos que disseminam boas práticas de governança corporativa para o mercado, a exemplo do IBGC, no seu Código das melhores práticas de governança corporativa (2009), e da CVM, no seu manual intitulado "Recomendações da CVM sobre governança corporativa" (2002).

Neste contexto, e dada a relevância do tema para a sociedade em geral, a presente dissertação buscou através das principais características do Conselho de Administração estudadas na literatura (tamanho, independência e a dualidade do CEO/Chairman), estudar sua influência na lucratividade empresarial, mensurada através de quatro indicadores (ROA, ROA ajustado à mediana do setor, ROE e ROE ajustado à mediana do setor), para os anos de $2010 \mathrm{a}$ 2014, no Brasil. Através da aplicação dos modelos econométricos estimados, chegou-se aos seguintes resultados principais:

I - O tamanho do Conselho de Administração relacionou-se positivamente com a lucratividade empresarial, quando esta variável foi representada pelo ROA e pelo ROA ajustado à mediana do Mercado; resultados similares aos encontrados por Andrade et al. (2009). Esta influência positiva do tamanho do CA na lucratividade advém principalmente do maior nível de monitoração exercido por um órgão maior, onde as tarefas podem ser divididas entre os conselheiros sem que estes fiquem sobrecarregados, melhorando sua eficácia.

II - Quanto ao percentual de conselheiros independentes/externos, observou-se que a independência do Conselho de Administração não apresentou relação com a lucratividade empresarial; resultados convergentes com os encontrados por Mak e Kusnandi (2005) e Andrade et al. (2009).

III - A dualidade do CEO está associada a um maior ROA ajustado ao setor, o que indica que o fato de o CEO assumir também o cargo de Chairman influi positivamente na lucratividade empresarial, assim como previsto por Brickley et al. (1997) e Donaldson e Davis (1991). A concentração de poder resultante de uma estrutura de autoridade unitária permite ao CEO tomar decisões mais tempestivas e reduz os custos de transferência de informação e o risco de transferência de informação incompleta entre os dois agentes. Estes resultados estão convergentes com os propostos pela Teoria da Mordomia de Donaldson e Davis (1991), que sugerem que uma maior concentração de poder nas mãos do CEO favorece a execução dos projetos pretendidos por este, sem expô-lo a todas as restrições e análises impostas pelo Conselho de Administração às suas ações. No entanto, contrariam fortemente o proposto pela Teoria da Agência de Jensen e Meckling (1976), onde a concentração de poder nas mãos do CEO, originária da acumulação do cargo de Chairman, poderia fomentar o comportamento oportunista do CEO. Sendo assim, para a amostra estudada e para o período analisado, as empresas que seguiram as recomendações do IBGC (2009) e da CVM (2002) de nomear indivíduos diferentes para os cargos de CEO e Chairman apresentaram desempenho ajustado ao mercado inferior àquelas que concentraram o poder nas mãos de um único indivíduo.

IV - Para as variáveis de controle, observou-se que: a) O tamanho da empresa, na maioria dos modelos, não mostrou relação com a lucratividade, similares aos observados por Liang et al. (2013); b) O nível de endividamento mostrou-se estatisticamente significante apenas nos modelos que utilizaram o ROA e o ROA ajustado como variáveis dependentes, relacionando- 
se negativamente com a lucratividade e a lucratividade ajustada ao mercado. Tal relação é um indício de que a alavancagem financeira oferece mais custos que benefícios às empresas da amostra, onde resultados semelhantes foram encontrados por Andrade et al. (2009), Chou et al. (2013) e Liang et al. (2013); c) O controle estrangeiro não se apresentou relevante como determinante da lucratividade empresarial, ao contrário do exposto em Micco et al. (2007), Grasseni (2010), Baum et al. (2010) e Chen e Liu (2013); d) A variável controle estatal mostrouse relevante na maior parte dos modelos estimados, apresentando um sinal negativo. Este resultado indica que o fato de um ente estatal controlar a empresa pode significar uma menor lucratividade devido ao fato de o estado estar explorando setores naturalmente deficitários ou a sua tendência em utilizar os ativos da empresa para fins políticos ao invés de para a maximização do seu valor (MICCO et al., 2007; BAUM et al., 2010; CHEN; LIU, 2013); e) O grupo de variáveis dummies temporais capturou alguns efeitos da passagem do tempo na lucratividade das empresas, onde algumas das variáveis utilizadas nos modelos perderam sua significância estatística quando estas primeiras foram adicionadas aos modelos. Tais variáveis temporais mostraram-se mais relevantes quando inseridas nos modelos que utilizaram o ROA e ROE como variáveis dependentes.

V - Por último, as regressões quantílicas indicaram que: a) O impacto positivo do tamanho do CA no desempenho da empresas se dá, principalmente, quando considerados os quantis superiores da distribuição, justamente onde estão contidas as empresas mais lucrativas; b) O nível de endividamento é negativamente relacionado com o desempenho da empresas, e que é maior nos quantis inferiores da distribuição.

De uma forma geral, alguns resultados encontram respaldos na literatura enquanto outros, talvez, necessitem de uma melhor diagnóstico para compreendê-los. Neste sentido, acredita-se que a ausência de relação entre a independência do Conselho de Administração e o desempenho evidenciada nos resultados pode ser melhor analisada dado que tais resultados podem estar relacionados ao fato de as empresas adicionarem membros ao CA apenas com o intuito de sinalizar boas práticas de governança corporativa ao mercado. Neste caso, as empresas estariam mais preocupadas com o título de independente/externo do conselheiro que com sua capacidade de monitoração e background necessário para a investidura no cargo. Já a relação positiva entre a dualidade do CEO e o desempenho, evidenciada nos resultados desta pesquisa, pode estar associada ao fato de o CEO possuir participação acionária relevante no capital da empresa, o que funcionaria como incentivo para que este dispendesse maior esforço na execução de suas tarefas. Por outro lado, ao invés de participação acionária, o CEO poderia ser incentivado a gerar melhores resultados se seu contrato de remuneração estivesse alinhado à melhora de indicadores contábeis, caso que justificaria a relação positiva entre a dualidade do CEO e o ROA ajustado.

Por fim, a importância e o ineditismo deste estudo é caracterizada na junção de dois fatores: I - Um estudo ampliado (em termos de anos) comparativamente ao usualmente adotado nas pesquisas nacionais, como em Andrade et al. (2009) e Gondrige et al. (2012); II - O uso de metodologias mais robustas, como o método de dados em painel e a estimação através das regressões quantílicas que controlam os resultados pelos efeitos individuais das empresas e a presença de valores extremos (outliers), respectivamente.

Como sugestão para estudos futuros, pode-se analisar o impacto de cada característica do Conselho de Administração no desempenho ou valor de mercado da empresa levando em conta a interação com o tamanho da empresa e os níveis de endividamento, dado que, de acordo com Andrade et al. (2009) esta relação pode mudar, dependendo do nível destes dois fatores. Também pode-se propor a utilização de outras proxies para representar as características do Conselho de Administração, tais como o número de conselheiros independentes/externos e o 
fato de o CEO ocupar cadeira no Conselho de Administração, mesmo que não seja o Chairman, além do uso de variáveis que estabeleçam uma relação não-linear entre as características do CA e o desempenho. 


\section{REFERÊNCIAS}

ANDRADE, L. P. de; SALAZAR, G. T.; CALEGÁRIO, C. L. L.; SILVA, S. S. Governança corporativa: uma análise da relação do Conselho de Administração com o valor de mercado e desempenho das empresas brasileiras. Revista de Administração Mackenzie, v. 10, n. 4, p. 431, 2009.

BALTAGI, B. H. Econometric analysis of panel data. $3^{\circ}$ Edição, Chichester: John Wiley \& Sons, 2005.

BARBOSA, N.; LOURI, H. Corporate performance: does ownership matter? A comparison of foreign- and domestic-owned firms in Greece and Portugal. Review of Industrial Organization, v. 27, n. 1, p. 73-102, 2005.

BAUM, C. F.; CAGLAYAN, M.; TALAVERA, O. Parliamentary election cycles and the Turkish banking sector. Journal of Banking and Finance, v. 34, n. 11, p. 2709-2719, 2010.

BEBCHUK, L. A.; FRIED, J. M. Executive compensation as an agency problem. The Journal of Economics Perspectives, v. 17, n. 3, p. 71-92, 2003.

BRASIL. Lei $\mathbf{n}^{\circ} \mathbf{6 . 4 0 4}$, de 15 de dezembro de 1976. Dispõe sobre as Sociedades por Ações. Diário Oficial [da] República Federativa do Brasil, Brasília, DF, 17 dez. 1976. Disponível em: <www.planalto.gov.br>. Acesso em: 11 out. 2014.

BRICK, I. E.; CHIDAMBARAN, N. K. Board meetings, committee structure, and firm value. Journal of Corporate Finance, v. 16, n. 4, p. 533-553, 2010.

BRICKLEY, J. A.; COLES, J. L.; JARRELL, G. Leadership structure: separating the CEO and the chairman of the board. Journal of Corporate Finance, v. 3, n. 3, p. 189-220, 1997.

BYRD, J. W.; HICKMAN, K. A. Do outside directors monitor managers? Evidence from tender offer bids. Journal of Financial Economics, v. 32, n. 2, p. 195-221, 1992.

CAMERON, A. C.; TRIVEDI, P. K. Microeconometrics: methods and applications. $1^{\circ}$ Edição, Cambridge: Cambridge University Press, 2005.

CHEN, P.; LIU, P. Bank ownership, performance, and the politics: evidence from Taiwan. Economic Modelling, v. 31, n. 1, p. 578-585, 2013.

CHENG, S. Board size and the variability of corporate performance. Journal of Financial Economics, v. 87, n. 1, p. 157-176, 2008.

CHOU, H.; CHUNG, H.; YIN, X. Attendance of board meetings and company performance: evidence from Taiwan. Journal of Banking and Finance, v. 37, n. 11, p. 4157-4171, 2013.

COHEN, J.; COHEN, P.; WEST, S. G.; AIKEN, L. S. Applied multiple regression/correlation analysis for the behavioral sciences. $3^{\circ}$ Edição, New Jersey: Lawrence Erlbaum Associates, 2003.

COLES, J. L.; DANIEL, N. D.; NAVEEN, L. Boards: does one size fit all? Journal of Financial Economics, v. 87, n. 2, p. 329-356, 2008.

COMISSÃO DE VALORES MOBILIÁRIOS. Recomendações da CVM sobre governança corporativa. 2002. Disponível em: <www.cvm.org.br>. Acesso em: 29 nov. 2014.

DIEZ, D. M.; BARR, C. D.; ÇETINKAYA-RUNDEL, M. OpenIntro Statistics. $2^{\circ}$ Edição, S.1.: CreateSpace Independent Publishing Platform, 2012. 
DONALDSON, L.; DAVIS, J. H. Stewardship theory or agency theory: CEO governance and shareholder returns. Australian Journal of Management, v. 16, n. 1, p. 49-65, 1991.

DOUMA, S.; GEORGE, R.; KABIR, R. Foreign and domestic ownership, business groups, and firm performance: evidence from a large emerging market. Strategic Management Journal, v. 27, n. 7, p. 637-657, 2006.

EISENBERG, T.; SUNDGREN, S.; WELLS, M. T. Larger board size and decreasing firm value in small firms. Journal of Financial Economics, v. 48, n. 1, p. 35-54, 1998.

FALEYE, O.; HOITASH, R.; HOITASH, U. The costs of intense board monitoring. Journal of Financial Economics, v. 101, n. 1, p. 160-181, 2011.

FAMA, E. F. Agency problems and the theory of the firm. The Journal of Political Economy, v. 88, n. 2, p. 288-307, 1980.

FAMA, E. F.; JENSEN, M. C. Separation of ownership and control. Journal of Law and Economics, v. 26, n. 2, p. 301-325, 1983.

GAMSON, W.; SCOTCH, N.; GAMSON, W. Scapegoating on baseball. American Journal of Sociology, v. 70, n. 1, p. 69-72, 1964.

GONDRIGE, E. O.; CLEMENTE, A.; ESPEJO, M. M. S. B. Estrutura do Conselho de Administração e valor das companhias brasileiras. Brazilian Business Review, v. 9, n. 3, p. 72-95, 2012.

GRASSENI, M. Domestic multinationals and foreign-owned firms in Italy: evidence from quantile regression. The European Journal of Comparative Economics, v. 7, n. 1, p. 61-86, 2010.

GREENE, W. H. Econometric analysis. $7^{\circ}$ Edição, Essex: Pearson Education, 2014.

GUJARATI, D. N.; PORTER, D. C. Econometria básica. 5 Edição, Porto Alegre: AMGH Editora Ltda., 2011.

HARRISON, J. R.; TORRES, D. L.; KUKALIS, S. The changing of the guard: turnover and structural change in the top-management positions. Administrative Science Quarterly, v. 33, n. 2, p. 211-232, 1988.

HAUSMAN, J. Specification tests in econometrics. Econometrica, v. 46, n. 6, p. 1251-1271, 1978.

HERMALIN, B. E.; WEISBACH, M. S. The determinants of board composition. RAND Journal of Economics, v. 19, n. 4, p. 589-606, 1988.

INSTITUTO BRASILEIRO DE GOVERNANÇA CORPORATIVA. Código das boas práticas para reuniões do Conselho de Administração. $1^{\text {a }}$ Edição, São Paulo: IBGC, 2010.

INSTITUTO BRASILEIRO DE GOVERNANÇA CORPORATIVA. Código das melhores práticas de governança corporativa. $4^{a}$ Edição, São Paulo: IBGC, 2009.

JENSEN, M. C. The modern industrial revolution, exit, and the failure of internal controlsystems. Journal of Finance, v. 48, n. 3, p. 831-880, 1993.

JENSEN, M. C.; MECKLING, W. H. Theory of the firm: managerial behaviour, agency costs and ownership structure. Journal of Financial Economics, v. 3, n. 4, p. 305-360, 1976.

KOENKER, R.; BASSETT JR., G. Regression quantiles. Econometrica, v. 46, n. 1, p. 33-50, 1978. 
LA PORTA, R.; LOPEZ-DE-SILANES, F.; SHLEIFER, A. Government ownership of banks. The Journal of Finance, v. 57, n. 1, 265-301, 2002.

LI, T.; SUN, L. X.; ZOU, L. State ownership and corporate performance: a quantile regression analysis of Chinese listed companies. China Economic Review, v. 20, n. 4, p. 703-716, 2009.

LIANG, Q.; XU, P.; JIRAPORN, P. Board characteristics and Chinese bank performance. Journal of Financial Economics, v. 37, n. 8, p. 2953-2968, 2013.

LIPTON, M.; LORSCH, J. W. A modest proposal for improved corporate governance. Business Lawyer, v. 48, n. 1, p. 59-77, 1992.

MAK, Y. T.; KUSNANDI, Y. Size really matters: further evidence on the negative relationship between board size and firm value. Pacific-Basin Finance Journal, v. 13, n. 3, p. 301-318, 2005.

MASULIS, R. W.; WANG, C.; XIE, F. Globalizing the boardroom - the effects of foreign directors on corporate governance and firm performance. Journal of Accounting and Economics, v. 53, n. 3, p. 527-554, 2012.

MATARAZZO, D. C. Análise financeira de balanços: abordagem gerencial. $7^{\circ}$ Edição, São Paulo: Editora Atlas, 2010.

MIAN, A. Foreign, private domestic, and government banks: new evidence from emerging markets. Mimeo, University of Chicago, 2003.

MICCO, A.; PANIZZA, U.; YAÑEZ, M. Bank ownership and performance: does politics matter? Journal of Banking and Finance, v. 31, n. 1, p. 219-241, 2007.

ROSENSTEIN, S.; WYATT, J. G. Outside directors, board independence and shareholder wealth. Journal of Financial Economics, v. 26, n. 2, p. 175-191, 1990.

SCHAFFER, M. E.; STILLMAN, S. xtoverid: Stata module to calculate tests of overidentifying restrictions after xtreg, xtivreg, xtivreg2, and xthtaylor. Disponível em: < https://ideas.repec.org/c/boc/bocode/s456779.html>. Acesso em: 5 fev. 2016.

SHLEIFER, A.; VISHNY, R. W. Politicians and firms. The Quarterly Journal of Economics, v. 109, n. 4, p. 995-1025, 1994.

SILVEIRA, A. D. M. da. Governança corporativa: no Brasil e no mundo. $1^{\circ}$ Edição, Rio de Janeiro: Elsevier, 2010.

UPTON, G.; COOK, I. Understainding statistics. $1^{\circ}$ Edição, New York: Oxford University Press, 1996.

VAFEAS, N. Board meeting frequency and firm performance. Journal of Financial Economics, v. 53, n. 1, p. 113-142, 1999.

VARCHOLOVA, T.; BESLEROVA, S. Ownership structure and company performance: research and literature review. Financial Internet Quarterly "e-Finanse", v. 9, n. 2, p. 24-33, 2013.

WEIDENBAUM, M. L. Updating the corporate board. Journal of Business Strategy, v. 7, n. 1, p. 77-83, 1986.

WEISBACH, M. S. Outside directors and CEO turnover. Journal of Financial Economics, v. 20, p. 431-460, 1988.

WHITE, H. A heteroskedasticity-consistent covariance matrix estimator and a direct test of heteroskedasticity. Econometrica, v. 48, n. 4, p. 817-838, 1980. 
WOOLDRIDGE, J. M. Econometric analysis of cross-sectional and panel data. $1^{\circ}$ Edição, London: The MIT Press, 2001.

YERMACK, D. Higher market valuation of companies with a small board of directors. Journal of Financial Economics, v. 40, n. 2, p. 185-211, 1996. 
Apêndice I - Resultado das estimações dos modelos de regressão quantílica (2010-2013)

Tabela 13 - Resultado das estimações dos modelos de regressão quantílica para a variável dependente ROA. 2013

\begin{tabular}{|c|c|c|c|c|c|c|}
\hline & Modelo 2 & Modelo 5 & Modelo 2 & Modelo 5 & Modelo 2 & Modelo 5 \\
\hline Variáveis & $\begin{array}{c}\text { Coef. } \\
\text { (Erro-P) }\end{array}$ & $\begin{array}{c}\text { Coef. } \\
\text { (Erro-P) }\end{array}$ & $\begin{array}{c}\text { Coef. } \\
\text { (Erro-P) }\end{array}$ & $\begin{array}{c}\text { Coef. } \\
\text { (Erro-P) }\end{array}$ & $\begin{array}{c}\text { Coef. } \\
\text { (Erro-P) }\end{array}$ & $\begin{array}{c}\text { Coef. } \\
\text { (Erro-P) }\end{array}$ \\
\hline & $\mathrm{Q}=0,25$ & $\mathrm{Q}=0,25$ & $\mathrm{Q}=0,50$ & $\mathrm{Q}=0,50$ & $\mathrm{Q}=0,75$ & $\mathrm{Q}=0,75$ \\
\hline TamanhoCA & $\begin{array}{c}0,0010 \\
(0,0025)\end{array}$ & $\begin{array}{c}0,0055 \\
(0,0032)\end{array}$ & $\begin{array}{c}0,0010 \\
(0,0030)\end{array}$ & $\begin{array}{c}0,0002 \\
(0,0032)\end{array}$ & $\begin{array}{l}-0,0005 \\
(0,0027)\end{array}$ & $\begin{array}{l}<0,0001 \\
(0,0030)\end{array}$ \\
\hline$\%$ Independentes & $\begin{array}{c}0,0352 \\
(0,0262)\end{array}$ & - & $\begin{array}{c}0,0181 \\
(0,0312)\end{array}$ & - & $\begin{array}{c}0,0169 \\
(0,0275)\end{array}$ & - \\
\hline$\%$ Externos & - & $\begin{array}{c}-0,1416^{* *} \\
(0,0576)\end{array}$ & - & $\begin{array}{c}0,0403 \\
(0,0579)\end{array}$ & - & $\begin{array}{c}0,0091 \\
(0,0537)\end{array}$ \\
\hline DualidadeCEO & $\begin{array}{c}0,0071 \\
(0,0139)\end{array}$ & $\begin{array}{l}-0,0107 \\
(0,0173)\end{array}$ & $\begin{array}{l}-0,0070 \\
(0,0166)\end{array}$ & $\begin{array}{l}-0,0068 \\
(0,0174)\end{array}$ & $\begin{array}{l}-0,0140 \\
(0,0146)\end{array}$ & $\begin{array}{l}-0,0122 \\
(0,0161)\end{array}$ \\
\hline LogAtivos & $\begin{array}{c}0,0109 \\
(0,0087)\end{array}$ & $\begin{array}{c}0,0134 \\
(0,0103)\end{array}$ & $\begin{array}{c}0,0018 \\
(0,0103)\end{array}$ & $\begin{array}{l}-0,0001 \\
(0,0103)\end{array}$ & $\begin{array}{l}-0,0016 \\
(0,0091)\end{array}$ & $\begin{array}{c}0,0023 \\
(0,0096)\end{array}$ \\
\hline Endividamento & $\begin{array}{c}-0,1092 * * * \\
(0,0261)\end{array}$ & $\begin{array}{c}-0,1124 * * * \\
(0,0308)\end{array}$ & $\begin{array}{c}-0,0999 * * * \\
(0,0311)\end{array}$ & $\begin{array}{c}-0,0976 * * * \\
(0,0310)\end{array}$ & $\begin{array}{c}-0,1684 * * * \\
(0,0274)\end{array}$ & $\begin{array}{c}-0,1528 * * * \\
(0,0287)\end{array}$ \\
\hline Estrangeiro & $\begin{array}{c}0,0334 \\
(0,0233)\end{array}$ & $\begin{array}{c}0,0151 \\
(0,0275)\end{array}$ & $\begin{array}{c}0,0365 \\
(0,0277)\end{array}$ & $\begin{array}{c}0,0355 \\
(0,0276)\end{array}$ & $\begin{array}{c}0,0737 * * * \\
(0,0244)\end{array}$ & $\begin{array}{c}0,0697 * * * \\
(0,0256)\end{array}$ \\
\hline Estatal & $\begin{array}{l}-0,0132 \\
(0,0229)\end{array}$ & $\begin{array}{l}-0,0167 \\
(0,0268)\end{array}$ & $\begin{array}{l}-0,0163 \\
(0,0272)\end{array}$ & $\begin{array}{l}-0,0126 \\
(0,0270)\end{array}$ & $\begin{array}{l}-0,0283 \\
(0,0239)\end{array}$ & $\begin{array}{l}-0,0341 \\
(0,0250)\end{array}$ \\
\hline Intercepto & $\begin{array}{l}-0,0179 \\
(0,0460)\end{array}$ & $\begin{array}{c}0,0614 \\
(0,0677)\end{array}$ & $\begin{array}{c}0,0742 \\
(0,0548)\end{array}$ & $\begin{array}{c}0,0623 \\
(0,0681)\end{array}$ & $\begin{array}{c}0,1831 * * * \\
(0,0482)\end{array}$ & $\begin{array}{c}0,1411 * * \\
(0,0631)\end{array}$ \\
\hline $\begin{array}{l}\text { Teste de Wald } \\
\text { Pseudo } \mathrm{R}^{2}\end{array}$ & $\begin{array}{l}0,0036 \\
0,0610\end{array}$ & $\begin{array}{l}0,0049 \\
0,0691\end{array}$ & $\begin{array}{l}0,0721 \\
0,0535\end{array}$ & $\begin{array}{l}0,0639 \\
0,0537\end{array}$ & $\begin{array}{l}0,0000 \\
0,1387\end{array}$ & $\begin{array}{l}0,0000 \\
0,1372\end{array}$ \\
\hline $\mathrm{N}^{\circ}$ Observações & 182 & 182 & 182 & 182 & 182 & 182 \\
\hline $\mathrm{N}^{\mathrm{o}}$ Empresas & 182 & 182 & 182 & 182 & 182 & 182 \\
\hline
\end{tabular}

Fonte: Formulário de Referência e Economatica®.

Notas: Significância estatística: $* * * 1 \%, * * 5 \%$ e *10\%.

Tabela 14 - Resultado das estimações dos modelos de regressão quantílica para a variável dependente ROA ajustado. 2013

\begin{tabular}{|c|c|c|c|c|c|c|}
\hline \multirow{3}{*}{ Variáveis } & Modelo 8 & Modelo 11 & Modelo 8 & Modelo 11 & Modelo 8 & Modelo 11 \\
\hline & $\begin{array}{c}\text { Coef. } \\
\text { (Erro-P) }\end{array}$ & $\begin{array}{c}\text { Coef. } \\
\text { (Erro-P) }\end{array}$ & $\begin{array}{c}\text { Coef. } \\
\text { (Erro-P) }\end{array}$ & $\begin{array}{c}\text { Coef. } \\
\text { (Erro-P) }\end{array}$ & $\begin{array}{c}\text { Coef. } \\
\text { (Erro-P) }\end{array}$ & $\begin{array}{c}\text { Coef. } \\
\text { (Erro-P) }\end{array}$ \\
\hline & $\mathrm{Q}=0,25$ & $\mathrm{Q}=0,25$ & $\mathrm{Q}=0,50$ & $\mathrm{Q}=0,50$ & $\mathrm{Q}=0,75$ & $\mathrm{Q}=0,75$ \\
\hline TamanhoCA & $\begin{array}{c}0,0016 \\
(0,0032)\end{array}$ & $\begin{array}{c}0,0032 \\
(0,0039)\end{array}$ & $\begin{array}{c}0,0016 \\
(0,0028)\end{array}$ & $\begin{array}{c}>-0,0001 \\
(0,0028)\end{array}$ & $\begin{array}{l}-0,0001 \\
(0,0035)\end{array}$ & $\begin{array}{c}0,0005 \\
(0,0037)\end{array}$ \\
\hline$\%$ Independentes & $\begin{array}{l}-0,0106 \\
(0,0329)\end{array}$ & - & $\begin{array}{l}-0,0072 \\
(0,0285)\end{array}$ & - & $\begin{array}{c}>-0,0001 \\
(0,0347)\end{array}$ & - \\
\hline$\%$ Externos & - & $\begin{array}{l}-0,0910 \\
(0,0701)\end{array}$ & - & $\begin{array}{c}0,0656 \\
(0,0520)\end{array}$ & - & $\begin{array}{c}0,0172 \\
(0,0669)\end{array}$ \\
\hline DualidadeCEO & $\begin{array}{l}-0,0014 \\
(0,0175)\end{array}$ & $\begin{array}{l}-0,0050 \\
(0,0211)\end{array}$ & $\begin{array}{l}-0,0040 \\
(0,0152)\end{array}$ & $\begin{array}{c}0,0030 \\
(0,0156)\end{array}$ & $\begin{array}{l}-0,0142 \\
(0,0190)\end{array}$ & $\begin{array}{l}-0,0122 \\
(0,0201)\end{array}$ \\
\hline LogAtivos & $\begin{array}{c}0,0138 \\
(0,0109)\end{array}$ & $\begin{array}{c}0,0167 \\
(0,0125)\end{array}$ & $\begin{array}{l}0,0177 * \\
(0,0094)\end{array}$ & $\begin{array}{c}0,0152 \\
(0,0093)\end{array}$ & $\begin{array}{c}0,0169 \\
(0,0118)\end{array}$ & $\begin{array}{c}0,0138 \\
(0,0119)\end{array}$ \\
\hline Endividamento & $\begin{array}{c}-0,1180 * * * \\
(0,0327)\end{array}$ & $\begin{array}{c}-0,1202^{* * * *} \\
(0,0375)\end{array}$ & $\begin{array}{c}-0,1340 * * \\
(0,0284)\end{array}$ & $\begin{array}{c}-0,1140 * * * \\
(0,0278)\end{array}$ & $\begin{array}{c}-0,2100 * * * \\
(0,0356)\end{array}$ & $\begin{array}{c}-0,1980 \text { **** } \\
(0,0358)\end{array}$ \\
\hline Estrangeiro & $\begin{array}{c}0,0012 \\
(0,0291)\end{array}$ & $\begin{array}{l}-0,0084 \\
(0,0335)\end{array}$ & $\begin{array}{c}0,0129 \\
(0,0253)\end{array}$ & $\begin{array}{c}0,0148 \\
(0,0248)\end{array}$ & $\begin{array}{c}0,0833 * * * \\
(0,0317)\end{array}$ & $\begin{array}{c}0,0888 * * * \\
(0,0319)\end{array}$ \\
\hline Estatal & $\begin{array}{l}-0,0312 \\
(0,0286)\end{array}$ & $\begin{array}{l}-0,0220 \\
(0,0327)\end{array}$ & $\begin{array}{l}-0,0156 \\
(0,0249)\end{array}$ & $\begin{array}{l}-0,0159 \\
(0,0242)\end{array}$ & $\begin{array}{l}-0,0254 \\
(0,0311)\end{array}$ & $\begin{array}{l}-0,0223 \\
(0,0312)\end{array}$ \\
\hline Intercepto & $\begin{array}{c}-0,0444 \\
(0,0577)\end{array}$ & $\begin{array}{c}-0,0001 \\
(0,0824)\end{array}$ & $\begin{array}{r}-0,0354 \\
(0,0501)\end{array}$ & $\begin{array}{r}-0,0777 \\
(0,0611)\end{array}$ & $\begin{array}{c}0,0637 \\
(0,0627)\end{array}$ & $\begin{array}{c}0,0562 \\
(0,0786)\end{array}$ \\
\hline Teste de Wald & 0,0444 & 0,0795 & 0,0015 & 0,0067 & 0,0000 & 0,0000 \\
\hline Pseudo R ${ }^{2}$ & 0,0758 & 0,0860 & 0,0634 & 0,0688 & 0,1161 & 0,1163 \\
\hline $\mathrm{N}^{\circ}$ Observações & 182 & 182 & 182 & 182 & 182 & 182 \\
\hline $\mathrm{N}^{\mathrm{o}}$ Empresas & 182 & 182 & 182 & 182 & 182 & 182 \\
\hline
\end{tabular}

Fonte: Formulário de Referência e Economatica ${ }^{\circledR}$.

Notas: Significância estatística: ***1\%,**5\% e *10\%. 
Tabela 15 - Resultado das estimações dos modelos de regressão quantílica para a variável dependente ROE. 2013

\begin{tabular}{|c|c|c|c|c|c|c|}
\hline \multirow{3}{*}{ Variáveis } & Modelo 14 & Modelo 17 & Modelo 14 & Modelo 17 & Modelo 14 & Modelo 17 \\
\hline & $\begin{array}{c}\text { Coef. } \\
\text { (Erro-P) }\end{array}$ & $\begin{array}{c}\text { Coef. } \\
\text { (Erro-P) }\end{array}$ & $\begin{array}{c}\text { Coef. } \\
\text { (Erro-P) }\end{array}$ & $\begin{array}{c}\text { Coef. } \\
\text { (Erro-P) }\end{array}$ & $\begin{array}{c}\text { Coef. } \\
\text { (Erro-P) }\end{array}$ & $\begin{array}{c}\text { Coef. } \\
\text { (Erro-P) }\end{array}$ \\
\hline & $\mathrm{Q}=0,25$ & $\mathrm{Q}=0,25$ & $\mathrm{Q}=0,50$ & $\mathrm{Q}=0,50$ & $\mathrm{Q}=0,75$ & $\mathrm{Q}=0,75$ \\
\hline TamanhoCA & $\begin{array}{c}0,0047 \\
(0,0115)\end{array}$ & $\begin{array}{c}0,0091 \\
(0,0107)\end{array}$ & $\begin{array}{c}-0,0013 \\
(0,0075)\end{array}$ & $\begin{array}{c}0,0044 \\
(0,0082)\end{array}$ & $\begin{array}{c}0,0017 \\
(0,0078)\end{array}$ & $\begin{array}{c}0,0047 \\
(0,0074)\end{array}$ \\
\hline$\%$ Independentes & $\begin{array}{c}0,1032 \\
(0,1192)\end{array}$ & ( & $\begin{array}{c}0,1028 \\
(0,0774)\end{array}$ & (2) & $\begin{array}{c}0,0282 \\
(0,0812)\end{array}$ & - \\
\hline$\%$ Externos & - & $\begin{array}{r}-0,3075 \\
(0,1936)\end{array}$ & - & $\begin{array}{l}-0,0292 \\
(0,1494)\end{array}$ & - & $\begin{array}{l}-0,0712 \\
(0,1348)\end{array}$ \\
\hline DualidadeCEO & $\begin{array}{c}0,0057 \\
(0,0633)\end{array}$ & $\begin{array}{l}-0,0328 \\
(0,0582)\end{array}$ & $\begin{array}{l}-0,0106 \\
(0,0411)\end{array}$ & $\begin{array}{l}-0,0353 \\
(0,0449)\end{array}$ & $\begin{array}{l}-0,0249 \\
(0,0431)\end{array}$ & $\begin{array}{l}-0,0388 \\
(0,0406)\end{array}$ \\
\hline LogAtivos & $\begin{array}{c}0,0275 \\
(0,0394)\end{array}$ & $\begin{array}{c}0,0275 \\
(0,0345)\end{array}$ & $\begin{array}{c}0,0167 \\
(0,0256)\end{array}$ & $\begin{array}{l}-0,0063 \\
(0,0266)\end{array}$ & $\begin{array}{c}0,0089 \\
(0,0268)\end{array}$ & $\begin{array}{c}0,0068 \\
(0,0240)\end{array}$ \\
\hline Endividamento & $\begin{array}{c}-0,2401 * * \\
(0,1187)\end{array}$ & $\begin{array}{c}-0,1897^{*} \\
(0,1035)\end{array}$ & $\begin{array}{c}-0,0173 * * \\
(0,0771)\end{array}$ & $\begin{array}{l}-0,0032 \\
(0,0799)\end{array}$ & $\begin{array}{c}-0,0279 * * * \\
(0,0808)\end{array}$ & $\begin{array}{l}-0,0200 \\
(0,0721)\end{array}$ \\
\hline Estrangeiro & $\begin{array}{c}0,1054 \\
(0,1057)\end{array}$ & $\begin{array}{c}0,0583 \\
(0,0924)\end{array}$ & $\begin{array}{c}0,1207 \\
(0,0686)\end{array}$ & $\begin{array}{c}0,0877 \\
(0,0713)\end{array}$ & $\begin{array}{c}0,2206 \\
(0,0719)\end{array}$ & $\begin{array}{c}0,2224 * * * \\
(0,0644)\end{array}$ \\
\hline Estatal & $\begin{array}{l}-0,0205 \\
(0,1038)\end{array}$ & $\begin{array}{l}-0,0115 \\
(0,0902)\end{array}$ & $\begin{array}{r}-0,0454 \\
(0,0674)\end{array}$ & $\begin{array}{l}-0,0271 \\
(0,0696)\end{array}$ & $\begin{array}{l}-0,0524 \\
(0,0707)\end{array}$ & $\begin{array}{c}-0,0556 \\
(0,0628)\end{array}$ \\
\hline Intercepto & $\begin{array}{c}-0,1031 \\
(0,2091)\end{array}$ & $\begin{array}{c}0,1214 \\
(0,2276)\end{array}$ & $\begin{array}{r}-0,0139 \\
(0,1358)\end{array}$ & $\begin{array}{c}0,1426 \\
(0,1756)\end{array}$ & $\begin{array}{c}0,1380 \\
(0,1424)\end{array}$ & $\begin{array}{c}0,2008 \\
(0,1585)\end{array}$ \\
\hline Teste de Wald & 0,5367 & 0,4823 & 0,4717 & 0,9032 & 0,1385 & 0,0460 \\
\hline Pseudo R ${ }^{2}$ & 0,0405 & 0,0472 & 0,0156 & 0,0125 & 0,0338 & 0,0340 \\
\hline $\mathrm{N}^{\circ}$ Observações & 182 & 182 & 182 & 182 & 182 & 182 \\
\hline $\mathrm{N}^{o}$ Empresas & 182 & 182 & 182 & 182 & 182 & 182 \\
\hline
\end{tabular}

Fonte: Formulário de Referência e Economatica®.

Notas: Significância estatística: $* * * 1 \%, * * 5 \%$ e *10\%.

Tabela 16 - Resultado das estimações dos modelos de regressão quantílica para a variável dependente ROE ajustado. 2013

\begin{tabular}{|c|c|c|c|c|c|c|}
\hline & Modelo 20 & Modelo 23 & Modelo 20 & Modelo 23 & Modelo 20 & Modelo 23 \\
\hline Variáveis & $\begin{array}{c}\text { Coef. } \\
\text { (Erro-P) }\end{array}$ & $\begin{array}{c}\text { Coef. } \\
\text { (Erro-P) }\end{array}$ & $\begin{array}{c}\text { Coef. } \\
\text { (Erro-P) }\end{array}$ & $\begin{array}{c}\text { Coef. } \\
\text { (Erro-P) }\end{array}$ & $\begin{array}{c}\text { Coef. } \\
\text { (Erro-P) }\end{array}$ & $\begin{array}{c}\text { Coef. } \\
\text { (Erro-P) }\end{array}$ \\
\hline & $\mathrm{Q}=0,25$ & $\mathrm{Q}=0,25$ & $\mathrm{Q}=0,50$ & $\mathrm{Q}=0,50$ & $\mathrm{Q}=0,75$ & $\mathrm{Q}=0,75$ \\
\hline TamanhoCA & $\begin{array}{c}0,0035 \\
(0,0103)\end{array}$ & $\begin{array}{c}0,0111 \\
(0,0112)\end{array}$ & $\begin{array}{c}0,0048 \\
(0,0068)\end{array}$ & $\begin{array}{c}0,0048 \\
(0,0073)\end{array}$ & $\begin{array}{l}-0,0023 \\
(0,0087)\end{array}$ & $\begin{array}{l}-0,0022 \\
(0,0096)\end{array}$ \\
\hline$\%$ Independentes & $\begin{array}{c}0,0564 \\
(0,1062)\end{array}$ & - & $\begin{array}{c}0,0295 \\
(0,0708)\end{array}$ & - & $\begin{array}{c}0,0044 \\
(0,0905)\end{array}$ & - \\
\hline$\%$ Externos & - & $\begin{array}{l}-0,2991 \\
(0,2024)\end{array}$ & - & $\begin{array}{c}0,0323 \\
(0,1333)\end{array}$ & - & $\begin{array}{c}0,0258 \\
(0,1745)\end{array}$ \\
\hline DualidadeCEO & $\begin{array}{l}-0,0076 \\
(0,0564)\end{array}$ & $\begin{array}{l}-0,0298 \\
(0,0609)\end{array}$ & $\begin{array}{l}-0,0150 \\
(0,0376)\end{array}$ & $\begin{array}{l}-0,0130 \\
(0,0401)\end{array}$ & $\begin{array}{l}-0,0792 \\
(0,0480)\end{array}$ & $\begin{array}{l}-0,0738 \\
(0,0525)\end{array}$ \\
\hline LogAtivos & $\begin{array}{c}0,0464 \\
(0,0351)\end{array}$ & $\begin{array}{c}0,0470 \\
(0,0361)\end{array}$ & $\begin{array}{c}0,0343 \\
(0,0234)\end{array}$ & $\begin{array}{c}0,0320 \\
(0,0237)\end{array}$ & $\begin{array}{c}0,0306 \\
(0,0299)\end{array}$ & $\begin{array}{c}0,0287 \\
(0,0311)\end{array}$ \\
\hline Endividamento & $\begin{array}{c}-0,2466 * * \\
(0,1058)\end{array}$ & $\begin{array}{c}-0,2168 * * \\
(0,1082)\end{array}$ & $\begin{array}{c}-0,1396 * * \\
(0,0705)\end{array}$ & $\begin{array}{c}-0,1343^{*} \\
(0,0713)\end{array}$ & $\begin{array}{l}-0,0503 \\
(0,0901)\end{array}$ & $\begin{array}{l}-0,0478 \\
(0,0933)\end{array}$ \\
\hline Estrangeiro & $\begin{array}{c}0,0515 \\
(0,0942)\end{array}$ & $\begin{array}{c}0,0056 \\
(0,0966)\end{array}$ & $\begin{array}{c}0,0566 \\
(0,0628)\end{array}$ & $\begin{array}{c}0,0484 \\
(0,0636)\end{array}$ & $\begin{array}{c}0,2401 * * * \\
(0,0802)\end{array}$ & $\begin{array}{c}0,2425 * * * \\
(0,0833)\end{array}$ \\
\hline Estatal & $\begin{array}{l}-0,0530 \\
(0,0925)\end{array}$ & $\begin{array}{l}-0,0594 \\
(0,0943)\end{array}$ & $\begin{array}{l}-0,0396 \\
(0,0617)\end{array}$ & $\begin{array}{l}-0,0296 \\
(0,0621)\end{array}$ & $\begin{array}{l}-0,0519 \\
(0,0788)\end{array}$ & $\begin{array}{l}-0,0472 \\
(0,0813)\end{array}$ \\
\hline Intercepto & $\begin{array}{l}-0,2595 \\
(0,1863)\end{array}$ & $\begin{array}{l}-0,0643 \\
(0,2380)\end{array}$ & $\begin{array}{l}-0,1613 \\
(0,1242)\end{array}$ & $\begin{array}{l}-0,1740 \\
(0,1467)\end{array}$ & $\begin{array}{l}-0,0160 \\
(0,1587)\end{array}$ & $\begin{array}{l}-0,0295 \\
(0,2052)\end{array}$ \\
\hline $\begin{array}{l}\text { Teste de Wald } \\
\text { Pseudo R }{ }^{2}\end{array}$ & $\begin{array}{l}0,4023 \\
0,0464\end{array}$ & $\begin{array}{l}0,3642 \\
0,0520\end{array}$ & $\begin{array}{l}0,2935 \\
0,0219\end{array}$ & $\begin{array}{l}0,3774 \\
0,0220\end{array}$ & $\begin{array}{l}0,0525 \\
0,0402\end{array}$ & $\begin{array}{l}0,0788 \\
0,0403\end{array}$ \\
\hline $\begin{array}{l}\mathrm{N}^{\circ} \text { Observações } \\
\mathrm{N}^{\mathrm{o}} \text { Empresas }\end{array}$ & $\begin{array}{l}182 \\
182\end{array}$ & $\begin{array}{l}182 \\
182\end{array}$ & $\begin{array}{l}182 \\
182\end{array}$ & $\begin{array}{l}182 \\
182\end{array}$ & $\begin{array}{l}182 \\
182\end{array}$ & $\begin{array}{l}182 \\
182\end{array}$ \\
\hline
\end{tabular}

Fonte: Formulário de Referência e Economatica®.

Notas: Significância estatística: $* * * 1 \%, * * 5 \%$ e *10\%. 
Tabela 17 - Resultado das estimações dos modelos de regressão quantílica para a variável dependente ROA. 2012

\begin{tabular}{|c|c|c|c|c|c|c|}
\hline & Modelo 2 & Modelo 5 & Modelo 2 & Modelo 5 & Modelo 2 & Modelo 5 \\
\hline Variáveis & $\begin{array}{c}\text { Coef. } \\
\text { (Erro-P) }\end{array}$ & $\begin{array}{c}\text { Coef. } \\
\text { (Erro-P) }\end{array}$ & $\begin{array}{c}\text { Coef. } \\
\text { (Erro-P) }\end{array}$ & $\begin{array}{c}\text { Coef. } \\
\text { (Erro-P) }\end{array}$ & $\begin{array}{c}\text { Coef. } \\
\text { (Erro-P) }\end{array}$ & $\begin{array}{c}\text { Coef. } \\
\text { (Erro-P) }\end{array}$ \\
\hline & $\mathrm{Q}=0,25$ & $\mathrm{Q}=0,25$ & $\mathrm{Q}=0,50$ & $\mathrm{Q}=0,50$ & $\mathrm{Q}=0,75$ & $\mathrm{Q}=0,75$ \\
\hline TamanhoCA & $\begin{array}{c}0,0012 \\
(0,0027)\end{array}$ & $\begin{array}{c}0,0024 \\
(0,0027)\end{array}$ & $\begin{array}{c}0,0003 \\
(0,0024)\end{array}$ & $\begin{array}{c}0,0015 \\
(0,0027)\end{array}$ & $\begin{array}{c}0,0007 \\
(0,0028)\end{array}$ & $\begin{array}{c}0,0009 \\
(0,0030)\end{array}$ \\
\hline$\%$ Independentes & $\begin{array}{l}-0,0169 \\
(0,0289)\end{array}$ & - & $\begin{array}{c}0,0002 \\
(0,0265)\end{array}$ & - & $\begin{array}{c}0,0451 \\
(0,0301)\end{array}$ & - \\
\hline$\%$ Externos & - & $\begin{array}{l}-0,0777 \\
(0,0544)\end{array}$ & - & $\begin{array}{l}-0,0481 \\
(0,0547)\end{array}$ & - & $\begin{array}{l}-0,0882 \\
(0,0608)\end{array}$ \\
\hline DualidadeCEO & $\begin{array}{c}0,0017 \\
(0,0146)\end{array}$ & $\begin{array}{l}-0,0039 \\
(0,0152)\end{array}$ & $\begin{array}{l}-0,0046 \\
(0,0134)\end{array}$ & $\begin{array}{l}-0,0130 \\
(0,0153)\end{array}$ & $\begin{array}{l}-0,0195 \\
(0,0152)\end{array}$ & $\begin{array}{c}-0,0339 * * \\
(0,0170)\end{array}$ \\
\hline LogAtivos & $\begin{array}{c}0,0033 \\
(0,0096)\end{array}$ & $\begin{array}{c}0,0076 \\
(0,0092)\end{array}$ & $\begin{array}{c}0,0010 \\
(0,0088)\end{array}$ & $\begin{array}{l}-0,0001 \\
(0,0092)\end{array}$ & $\begin{array}{l}-0,0112 \\
(0,0100)\end{array}$ & $\begin{array}{l}-0,0093 \\
(0,0103)\end{array}$ \\
\hline Endividamento & $\begin{array}{c}-0,0896 * * * \\
(0,0308)\end{array}$ & $\begin{array}{c}-0,0949 * * * \\
(0,0293)\end{array}$ & $\begin{array}{c}-0,0848 * * * \\
(0,0282)\end{array}$ & $\begin{array}{c}-0,0924 * * * \\
(0,0295)\end{array}$ & $\begin{array}{c}-0,1108 * * * \\
(0,0321)\end{array}$ & $\begin{array}{c}-0,1651 \text { *** } \\
(0,0328)\end{array}$ \\
\hline Estrangeiro & $\begin{array}{c}0,0342 \\
(0,0275)\end{array}$ & $\begin{array}{c}0,0331 \\
(0,0263)\end{array}$ & $\begin{array}{c}0,0384 \\
(0,0253)\end{array}$ & $\begin{array}{c}0,0540 * * \\
(0,0265)\end{array}$ & $\begin{array}{l}0,0478 * \\
(0,0287)\end{array}$ & $\begin{array}{c}0,0463 \\
(0,0294)\end{array}$ \\
\hline Estatal & $\begin{array}{l}-0,0133 \\
(0,0255)\end{array}$ & $\begin{array}{l}-0,0069 \\
(0,0241)\end{array}$ & $\begin{array}{c}0,0008 \\
(0,0234)\end{array}$ & $\begin{array}{l}-0,0050 \\
(0,0243)\end{array}$ & $\begin{array}{l}-0,0099 \\
(0,0266)\end{array}$ & $\begin{array}{l}-0,0081 \\
(0,0270)\end{array}$ \\
\hline Intercepto & $\begin{array}{c}0,0306 \\
(0,0504)\end{array}$ & $\begin{array}{c}0,0628 \\
(0,0604)\end{array}$ & $\begin{array}{l}0,0803 * \\
(0,0462)\end{array}$ & $\begin{array}{c}0,1297 * * \\
(0,0608)\end{array}$ & $\begin{array}{c}0,2005 * * * \\
(0,0526)\end{array}$ & $\begin{array}{c}0,3116^{* * * *} \\
(0,0675)\end{array}$ \\
\hline Teste de Wald & 0,0940 & 0,0426 & 0,0702 & 0,0202 & 0,0015 & 0,0000 \\
\hline Pseudo $\mathrm{R}^{2}$ & 0,0646 & 0,0761 & 0,0616 & 0,0625 & 0,0824 & 0,0884 \\
\hline $\mathrm{N}^{\circ}$ Observações & 182 & 182 & 182 & 182 & 182 & 182 \\
\hline $\mathrm{N}^{\mathrm{o}}$ Empresas & 182 & 182 & 182 & 182 & 182 & 182 \\
\hline
\end{tabular}

Fonte: Formulário de Referência e Economatica®.

Notas: Significância estatística: ***1\%,**5\% e *10\%.

Tabela 18 - Resultado das estimações dos modelos de regressão quantílica para a variável dependente ROA ajustado. 2012

\begin{tabular}{|c|c|c|c|c|c|c|}
\hline & Modelo 8 & Modelo 11 & Modelo 8 & Modelo 11 & Modelo 8 & Modelo 11 \\
\hline Variáveis & $\begin{array}{c}\text { Coef. } \\
\text { (Erro-P) }\end{array}$ & $\begin{array}{c}\text { Coef. } \\
\text { (Erro-P) }\end{array}$ & $\begin{array}{c}\text { Coef. } \\
\text { (Erro-P) }\end{array}$ & $\begin{array}{c}\text { Coef. } \\
\text { (Erro-P) }\end{array}$ & $\begin{array}{c}\text { Coef. } \\
\text { (Erro-P) }\end{array}$ & $\begin{array}{c}\text { Coef. } \\
\text { (Erro-P) }\end{array}$ \\
\hline & $\mathrm{Q}=0,25$ & $\mathrm{Q}=0,25$ & $\mathrm{Q}=0,50$ & $\mathrm{Q}=0,50$ & $\mathrm{Q}=0,75$ & $\mathrm{Q}=0,75$ \\
\hline TamanhoCA & $\begin{array}{l}-0,0005 \\
(0,0030)\end{array}$ & $\begin{array}{c}0,0015 \\
(0,0031)\end{array}$ & $\begin{array}{l}-0,0001 \\
(0,0024)\end{array}$ & $\begin{array}{c}0,0003 \\
(0,0025)\end{array}$ & $\begin{array}{c}>-0,0001 \\
(0,0025)\end{array}$ & $\begin{array}{c}0,0020 \\
(0,0030)\end{array}$ \\
\hline$\%$ Independentes & $\begin{array}{l}-0,0117 \\
(0,0329)\end{array}$ & - & $\begin{array}{c}0,0317 \\
(0,0261)\end{array}$ & - & $\begin{array}{l}0,0540^{*} \\
(0,0275)\end{array}$ & - \\
\hline$\%$ Externos & - & $\begin{array}{l}-0,0490 \\
(0,0615)\end{array}$ & - & $\begin{array}{c}0,0029 \\
(0,0501)\end{array}$ & - & $\begin{array}{l}-0,0150 \\
(0,0601)\end{array}$ \\
\hline DualidadeCEO & $\begin{array}{c}0,0047 \\
(0,0166)\end{array}$ & $\begin{array}{l}-0,0016 \\
(0,0172)\end{array}$ & $\begin{array}{l}-0,0069 \\
(0,0132)\end{array}$ & $\begin{array}{l}-0,0101 \\
(0,0140)\end{array}$ & $\begin{array}{c}-0,0086 \\
(0,0139)\end{array}$ & $\begin{array}{c}0,0038 \\
(0,0168)\end{array}$ \\
\hline LogAtivos & $\begin{array}{c}0,0116 \\
(0,0109)\end{array}$ & $\begin{array}{c}0,0073 \\
(0,0104)\end{array}$ & $\begin{array}{l}<0,0001 \\
(0,0086)\end{array}$ & $\begin{array}{l}-0,0016 \\
(0,0085)\end{array}$ & $\begin{array}{l}-0,0002 \\
(0,0091)\end{array}$ & $\begin{array}{l}-0,0034 \\
(0,0102)\end{array}$ \\
\hline Endividamento & $\begin{array}{c}-0,0908 * * * \\
(0,0351)\end{array}$ & $\begin{array}{c}-0,1004 * * * \\
(0,0331)\end{array}$ & $\begin{array}{c}-0,0677 * * \\
(0,0278)\end{array}$ & $\begin{array}{c}-0,0649 * * \\
(0,0270)\end{array}$ & $\begin{array}{c}-0,1575 * * * \\
(0,0293)\end{array}$ & $\begin{array}{c}-0,1453 \text { *** } \\
(0,0324)\end{array}$ \\
\hline Estrangeiro & $\begin{array}{c}0,0226 \\
(0,0314)\end{array}$ & $\begin{array}{c}0,0231 \\
(0,0297)\end{array}$ & $\begin{array}{c}0,0023 \\
(0,0248)\end{array}$ & $\begin{array}{c}0,0201 \\
(0,0242)\end{array}$ & $\begin{array}{c}0,0017 \\
(0,0262)\end{array}$ & $\begin{array}{c}0,0063 \\
(0,0291)\end{array}$ \\
\hline Estatal & $\begin{array}{l}-0,0196 \\
(0,0290)\end{array}$ & $\begin{array}{l}-0,0146 \\
(0,0273)\end{array}$ & $\begin{array}{l}-0,0221 \\
(0,0230)\end{array}$ & $\begin{array}{l}-0,0237 \\
(0,0222)\end{array}$ & $\begin{array}{c}-0,0123 \\
(0,0242)\end{array}$ & $\begin{array}{l}-0,0058 \\
(0,0267)\end{array}$ \\
\hline Intercepto & $\begin{array}{l}-0,0335 \\
(0,0574)\end{array}$ & $\begin{array}{c}0,0288 \\
(0,0683)\end{array}$ & $\begin{array}{c}0,0557 \\
(0,0455)\end{array}$ & $\begin{array}{c}0,0641 \\
(0,0556)\end{array}$ & $\begin{array}{c}0,1362 * * * \\
(0,0480)\end{array}$ & $\begin{array}{c}0,1546^{* * *} \\
(0,0667)\end{array}$ \\
\hline $\begin{array}{l}\text { Teste de Wald } \\
\text { Pseudo } R^{2}\end{array}$ & $\begin{array}{l}0,2820 \\
0,0590\end{array}$ & $\begin{array}{l}0,1295 \\
0,0601\end{array}$ & $\begin{array}{l}0,2487 \\
0,0637\end{array}$ & $\begin{array}{l}0,2095 \\
0,0595\end{array}$ & 0,0000 & $\begin{array}{l}0,0005 \\
0,0932\end{array}$ \\
\hline $\mathrm{N}^{\mathrm{o}}$ Observações & 182 & 182 & 182 & 182 & 182 & 182 \\
\hline $\mathrm{N}^{\circ}$ Empresas & 182 & 182 & 182 & 182 & 182 & 182 \\
\hline
\end{tabular}

Fonte: Formulário de Referência e Economatica®.

Notas: Significância estatística: $* * * 1 \%, * * 5 \%$ e *10\%. 
Tabela 19 - Resultado das estimações dos modelos de regressão quantílica para a variável dependente ROE. 2012

\begin{tabular}{|c|c|c|c|c|c|c|}
\hline & Modelo 14 & Modelo 17 & Modelo 14 & Modelo 17 & Modelo 14 & Modelo 17 \\
\hline Variáveis & $\begin{array}{c}\text { Coef. } \\
\text { (Erro-P) }\end{array}$ & $\begin{array}{c}\text { Coef. } \\
\text { (Erro-P) }\end{array}$ & $\begin{array}{c}\text { Coef. } \\
\text { (Erro-P) }\end{array}$ & $\begin{array}{c}\text { Coef. } \\
\text { (Erro-P) }\end{array}$ & $\begin{array}{c}\text { Coef. } \\
\text { (Erro-P) }\end{array}$ & $\begin{array}{c}\text { Coef. } \\
\text { (Erro-P) }\end{array}$ \\
\hline & $\mathrm{Q}=0,25$ & $\mathrm{Q}=0,25$ & $\mathrm{Q}=0,50$ & $\mathrm{Q}=0,50$ & $\mathrm{Q}=0,75$ & $\mathrm{Q}=0,75$ \\
\hline TamanhoCA & $\begin{array}{c}0,0004 \\
(0,0081)\end{array}$ & $\begin{array}{c}0,0071 \\
(0,0084)\end{array}$ & $\begin{array}{c}0,0007 \\
(0,0069)\end{array}$ & $\begin{array}{c}0,0019 \\
(0,0085)\end{array}$ & $\begin{array}{c}0,0056 \\
(0,0096)\end{array}$ & $\begin{array}{c}0,0049 \\
(0,0079)\end{array}$ \\
\hline$\%$ Independentes & $\begin{array}{l}-0,0550 \\
(0,0874)\end{array}$ & - & $\begin{array}{c}0,0268 \\
(0,0748)\end{array}$ & - & $\begin{array}{c}0,1173 \\
(0,1037)\end{array}$ & - \\
\hline$\%$ Externos & - & $\begin{array}{l}-0,2635 \\
(0,1685)\end{array}$ & - & $\begin{array}{l}-0,0390 \\
(0,1709)\end{array}$ & - & $\begin{array}{c}-0,3967 * * \\
(0,1598)\end{array}$ \\
\hline DualidadeCEO & $\begin{array}{l}-0,0341 \\
(0,0441)\end{array}$ & $\begin{array}{l}-0,0542 \\
(0,0471)\end{array}$ & $\begin{array}{l}-0,0208 \\
(0,0378)\end{array}$ & $\begin{array}{r}-0,0364 \\
(0,0477)\end{array}$ & $\begin{array}{l}-0,0407 \\
(0,0524)\end{array}$ & $\begin{array}{c}-0,1073^{*} * \\
(0,0446)\end{array}$ \\
\hline LogAtivos & $\begin{array}{c}0,0216 \\
(0,0290)\end{array}$ & $\begin{array}{c}0,0203 \\
(0,0285)\end{array}$ & $\begin{array}{c}0,0111 \\
(0,0248)\end{array}$ & $\begin{array}{c}0,0085 \\
(0,0289)\end{array}$ & $\begin{array}{l}-0,0381 \\
(0,0344)\end{array}$ & $\begin{array}{l}-0,0252 \\
(0,0270)\end{array}$ \\
\hline Endividamento & $\begin{array}{c}-0,1627 * * \\
(0,0931)\end{array}$ & $\begin{array}{c}-0,1596^{*} \\
(0,0908)\end{array}$ & $\begin{array}{c}0,0225 \\
(0,0797)\end{array}$ & $\begin{array}{c}0,0318 \\
(0,0921)\end{array}$ & $\begin{array}{c}0,1613 \\
(0,1105)\end{array}$ & $\begin{array}{l}0,1455^{*} \\
(0,0861)\end{array}$ \\
\hline Estrangeiro & $\begin{array}{c}0,1120 \\
(0,0833)\end{array}$ & $\begin{array}{c}0,1507 * * \\
(0,0815)\end{array}$ & $\begin{array}{c}0,0665 \\
(0,0713)\end{array}$ & $\begin{array}{c}0,0649 \\
(0,0826)\end{array}$ & $\begin{array}{c}0,1791 * * \\
(0,0989)\end{array}$ & $\begin{array}{l}0,1751 * * \\
(0,0773)\end{array}$ \\
\hline Estatal & $\begin{array}{l}-0,0143 \\
(0,0770)\end{array}$ & $\begin{array}{l}-0,0158 \\
(0,0748)\end{array}$ & $\begin{array}{c}0,0051 \\
(0,0659)\end{array}$ & $\begin{array}{c}0,0076 \\
(0,0758)\end{array}$ & $\begin{array}{l}-0,0283 \\
(0,0914)\end{array}$ & $\begin{array}{l}-0,0447 \\
(0,0709)\end{array}$ \\
\hline Intercepto & $\begin{array}{l}-0,0377 \\
(0,1524)\end{array}$ & $\begin{array}{c}0,1442 \\
(0,1872)\end{array}$ & $\begin{array}{c}0,0182 \\
(0,1304)\end{array}$ & $\begin{array}{c}0,0667 \\
(0,1898)\end{array}$ & $\begin{array}{c}0,2995 \\
(0,1809)\end{array}$ & $\begin{array}{c}0,6247 * * * \\
(0,1775)\end{array}$ \\
\hline Teste de Wald & 0,5152 & 0,2453 & 0,9255 & 0,9463 & 0,2510 & 0,0087 \\
\hline Pseudo R2 & 0,0474 & 0,0594 & 0,0234 & 0,0237 & 0,0451 & 0,0674 \\
\hline $\begin{array}{l}\mathrm{N}^{\circ} \text { Observações } \\
\mathrm{N}^{\mathrm{o}} \text { Empresas }\end{array}$ & $\begin{array}{l}182 \\
182\end{array}$ & $\begin{array}{l}182 \\
182\end{array}$ & $\begin{array}{l}182 \\
182\end{array}$ & $\begin{array}{l}182 \\
182\end{array}$ & $\begin{array}{l}182 \\
182\end{array}$ & $\begin{array}{l}182 \\
182\end{array}$ \\
\hline
\end{tabular}

Fonte: Formulário de Referência e Economatica®.

Notas: Significância estatística: $* * * 1 \%, * * 5 \%$ e $* 10 \%$.

Tabela 20 - Resultado das estimações dos modelos de regressão quantílica para a variável dependente ROE ajustado. 2012

\begin{tabular}{|c|c|c|c|c|c|c|}
\hline \multirow{3}{*}{ Variáveis } & Modelo 20 & Modelo 23 & Modelo 20 & Modelo 23 & Modelo 20 & Modelo 23 \\
\hline & $\begin{array}{c}\text { Coef. } \\
\text { (Erro-P) }\end{array}$ & $\begin{array}{c}\text { Coef. } \\
\text { (Erro-P) }\end{array}$ & $\begin{array}{c}\text { Coef. } \\
\text { (Erro-P) }\end{array}$ & $\begin{array}{c}\text { Coef. } \\
\text { (Erro-P) }\end{array}$ & $\begin{array}{c}\text { Coef. } \\
\text { (Erro-P) }\end{array}$ & $\begin{array}{c}\text { Coef. } \\
\text { (Erro-P) }\end{array}$ \\
\hline & $\mathrm{Q}=0,25$ & $\mathrm{Q}=0,25$ & $\mathrm{Q}=0,50$ & $\mathrm{Q}=0,50$ & $\mathrm{Q}=0,75$ & $\mathrm{Q}=0,75$ \\
\hline TamanhoCA & $\begin{array}{l}-0,0065 \\
(0,0061)\end{array}$ & $\begin{array}{l}-0,0029 \\
(0,0068)\end{array}$ & $\begin{array}{l}-0,0009 \\
(0,0067)\end{array}$ & $\begin{array}{c}0,0040 \\
(0,0070)\end{array}$ & $\begin{array}{c}0,0047 \\
(0,0079)\end{array}$ & $\begin{array}{c}0,0041 \\
(0,0081)\end{array}$ \\
\hline$\%$ Independentes & $\begin{array}{l}-0,0343 \\
(0,0660)\end{array}$ & - & $\begin{array}{c}0,0970 \\
(0,0724)\end{array}$ & - & $\begin{array}{c}0,0841 \\
(0,0860)\end{array}$ & - \\
\hline$\%$ Externos & - & $\begin{array}{l}-0,1111 \\
(0,1370)\end{array}$ & - & $\begin{array}{l}-0,1807 \\
(0,1414)\end{array}$ & - & $\begin{array}{c}-0,2949 * \\
(0,1627)\end{array}$ \\
\hline DualidadeCEO & $\begin{array}{c}-0,0561 * \\
(0,0333)\end{array}$ & $\begin{array}{l}-0,0562 \\
(0,0383)\end{array}$ & $\begin{array}{l}-0,0165 \\
(0,0365)\end{array}$ & $\begin{array}{l}-0,0635 \\
(0,0395)\end{array}$ & $\begin{array}{l}-0,0520 \\
(0,0434)\end{array}$ & $\begin{array}{c}-0,1117 * * \\
(0,0455)\end{array}$ \\
\hline LogAtivos & $\begin{array}{c}0,0297 \\
(0,0219)\end{array}$ & $\begin{array}{c}0,0320 \\
(0,0232)\end{array}$ & $\begin{array}{c}0,0144 \\
(0,0240)\end{array}$ & $\begin{array}{c}0,0112 \\
(0,0239)\end{array}$ & $\begin{array}{c}0,0002 \\
(0,0285)\end{array}$ & $\begin{array}{c}0,0193 \\
(0,0275)\end{array}$ \\
\hline Endividamento & $\begin{array}{l}-0,1021 \\
(0,0704)\end{array}$ & $\begin{array}{c}-0,1260^{*} \\
(0,0738)\end{array}$ & $\begin{array}{c}0,0132 \\
(0,0771)\end{array}$ & $\begin{array}{c}0,0268 \\
(0,0762)\end{array}$ & $\begin{array}{c}0,0296 \\
(0,0916)\end{array}$ & $\begin{array}{c}0,0328 \\
(0,0877)\end{array}$ \\
\hline Estrangeiro & $\begin{array}{l}-0,0110 \\
(0,0629)\end{array}$ & $\begin{array}{c}0,0434 \\
(0,0663)\end{array}$ & $\begin{array}{c}0,0991 \\
(0,0690)\end{array}$ & $\begin{array}{c}0,0763 \\
(0,0684)\end{array}$ & $\begin{array}{c}0,1717 * * \\
(0,0820)\end{array}$ & $\begin{array}{c}0,1638^{* *} \\
(0,0787)\end{array}$ \\
\hline Estatal & $\begin{array}{l}-0,0081 \\
(0,0582)\end{array}$ & $\begin{array}{l}-0,0078 \\
(0,0608)\end{array}$ & $\begin{array}{l}-0,0373 \\
(0,0638)\end{array}$ & $\begin{array}{l}-0,0247 \\
(0,0628)\end{array}$ & $\begin{array}{l}-0,0346 \\
(0,0758)\end{array}$ & $\begin{array}{l}-0,0465 \\
(0,0722)\end{array}$ \\
\hline Intercepto & $\begin{array}{l}-0,1266 \\
(0,1152)\end{array}$ & $\begin{array}{l}-0,0717 \\
(0,1522)\end{array}$ & $\begin{array}{l}-0,0751 \\
(0,1262)\end{array}$ & $\begin{array}{c}0,0929 \\
(0,1571)\end{array}$ & $\begin{array}{c}0,0633 \\
(0,1500)\end{array}$ & $\begin{array}{c}0,2360 \\
(0,1808)\end{array}$ \\
\hline $\begin{array}{l}\text { Teste de Wald } \\
\text { Pseudo } R^{2}\end{array}$ & $\begin{array}{l}0,5744 \\
0,0364\end{array}$ & $\begin{array}{l}0,5825 \\
0,0383\end{array}$ & $\begin{array}{l}0,5509 \\
0,0190\end{array}$ & $\begin{array}{l}0,5355 \\
0,0167\end{array}$ & $\begin{array}{l}0,2251 \\
0,0400\end{array}$ & $\begin{array}{l}0,0536 \\
0,0477\end{array}$ \\
\hline $\mathrm{N}^{\mathrm{o}}$ Observações & 182 & 182 & 182 & 182 & 182 & 182 \\
\hline $\mathrm{N}^{\circ}$ Empresas & 182 & 182 & 182 & 182 & 182 & 182 \\
\hline
\end{tabular}

Fonte: Formulário de Referência e Economatica®.

Notas: Significância estatística: $* * * 1 \%, * * 5 \%$ e *10\%. 
Tabela 21 - Resultado das estimações dos modelos de regressão quantílica para a variável dependente ROA. 2011

\begin{tabular}{|c|c|c|c|c|c|c|}
\hline & Modelo 2 & Modelo 5 & Modelo 2 & Modelo 5 & Modelo 2 & Modelo 5 \\
\hline Variáveis & $\begin{array}{c}\text { Coef. } \\
\text { (Erro-P) }\end{array}$ & $\begin{array}{c}\text { Coef. } \\
\text { (Erro-P) }\end{array}$ & $\begin{array}{c}\text { Coef. } \\
\text { (Erro-P) }\end{array}$ & $\begin{array}{c}\text { Coef. } \\
\text { (Erro-P) }\end{array}$ & $\begin{array}{c}\text { Coef. } \\
\text { (Erro-P) }\end{array}$ & $\begin{array}{c}\text { Coef. } \\
\text { (Erro-P) }\end{array}$ \\
\hline & $\mathrm{Q}=0,25$ & $\mathrm{Q}=0,25$ & $Q=0,50$ & $\mathrm{Q}=0,50$ & $\mathrm{Q}=0,75$ & $\mathrm{Q}=0,75$ \\
\hline TamanhoCA & $\begin{array}{l}-0,0027 \\
(0,0028)\end{array}$ & $\begin{array}{l}-0,0003 \\
(0,0029)\end{array}$ & $\begin{array}{l}-0,0015 \\
(0,0021)\end{array}$ & $\begin{array}{l}-0,0002 \\
(0,0023)\end{array}$ & $\begin{array}{c}0,0026 \\
(0,0030)\end{array}$ & $\begin{array}{c}0,0011 \\
(0,0035)\end{array}$ \\
\hline$\%$ Independentes & $\begin{array}{l}-0,0119 \\
(0,0283)\end{array}$ & - & $\begin{array}{l}-0,0166 \\
(0,0217)\end{array}$ & - & $\begin{array}{l}-0,0328 \\
(0,0309)\end{array}$ & - \\
\hline$\%$ Externos & - & $\begin{array}{l}-0,0686 \\
(0,0548)\end{array}$ & - & $\begin{array}{l}-0,0463 \\
(0,0440)\end{array}$ & - & $\begin{array}{l}-0,0824 \\
(0,0668)\end{array}$ \\
\hline DualidadeCEO & $\begin{array}{c}0,0002 \\
(0,0144)\end{array}$ & $\begin{array}{l}-0,0022 \\
(0,0154)\end{array}$ & $\begin{array}{l}-0,0022 \\
(0,0111)\end{array}$ & $\begin{array}{l}-0,0032 \\
(0,0124)\end{array}$ & $\begin{array}{c}0,0015 \\
(0,0157)\end{array}$ & $\begin{array}{l}-0,0249 \\
(0,0188)\end{array}$ \\
\hline LogAtivos & $\begin{array}{c}0,0111 \\
(0,0102)\end{array}$ & $\begin{array}{c}0,0110 \\
(0,0100)\end{array}$ & $\begin{array}{c}0,0043 \\
(0,0078)\end{array}$ & $\begin{array}{c}0,0019 \\
(0,0080)\end{array}$ & $\begin{array}{c}0,0017 \\
(0,0111)\end{array}$ & $\begin{array}{l}-0,0044 \\
(0,0122)\end{array}$ \\
\hline Endividamento & $\begin{array}{c}-0,0795^{* *} \\
(0,0323)\end{array}$ & $\begin{array}{c}-0,0804 * * \\
(0,0317)\end{array}$ & $\begin{array}{c}-0,0999 * * * \\
(0,0248)\end{array}$ & $\begin{array}{c}-0,0915 * * * \\
(0,0255)\end{array}$ & $\begin{array}{c}-0,1732 * * * \\
(0,0353)\end{array}$ & $\begin{array}{c}-0,1681 \text { *** } \\
(0,0387)\end{array}$ \\
\hline Estrangeiro & $\begin{array}{c}0,0367 \\
(0,0288)\end{array}$ & $\begin{array}{c}0,0378 \\
(0,0283)\end{array}$ & $\begin{array}{c}0,0196 \\
(0,0221)\end{array}$ & $\begin{array}{c}0,0368 \\
(0,0228)\end{array}$ & $\begin{array}{c}0,0139 \\
(0,0315)\end{array}$ & $\begin{array}{c}0,0147 \\
(0,0345)\end{array}$ \\
\hline Estatal & $\begin{array}{c}0,0079 \\
(0,0271)\end{array}$ & $\begin{array}{c}0,0044 \\
(0,0263)\end{array}$ & $\begin{array}{c}0,0013 \\
(0,0208)\end{array}$ & $\begin{array}{l}-0,0006 \\
(0,0211)\end{array}$ & $\begin{array}{l}-0,0429 \\
(0,0296)\end{array}$ & $\begin{array}{l}-0,0236 \\
(0,0321)\end{array}$ \\
\hline Intercepto & $\begin{array}{c}0,0125 \\
(0,0539)\end{array}$ & $\begin{array}{c}0,0544 \\
(0,0661)\end{array}$ & $\begin{array}{c}0,0925 * * \\
(0,0414)\end{array}$ & $\begin{array}{c}0,1279 * * \\
(0,0531)\end{array}$ & $\begin{array}{c}0,1603 * * * \\
(0,0589)\end{array}$ & $\begin{array}{c}0,2752 * * * \\
(0,0806)\end{array}$ \\
\hline Teste de Wald & 0,2142 & 0,1701 & 0,0040 & 0,0075 & 0,0001 & 0,0007 \\
\hline Pseudo R ${ }^{2}$ & 0,0331 & 0,0403 & 0,0638 & 0,0649 & 0,0859 & 0,0917 \\
\hline $\mathrm{N}^{\circ}$ Observações & 182 & 182 & 182 & 182 & 182 & 182 \\
\hline $\mathrm{N}^{\mathrm{o}}$ Empresas & 182 & 182 & 182 & 182 & 182 & 182 \\
\hline
\end{tabular}

Fonte: Formulário de Referência e Economatica®.

Notas: Significância estatística: $* * * 1 \%, * * 5 \%$ e $* 10 \%$.

Tabela 22 - Resultado das estimações dos modelos de regressão quantílica para a variável dependente ROA ajustado. 2011

\begin{tabular}{|c|c|c|c|c|c|c|}
\hline & Modelo 8 & Modelo 11 & Modelo 8 & Modelo 11 & Modelo 8 & Modelo 11 \\
\hline Variáveis & $\begin{array}{c}\text { Coef. } \\
\text { (Erro-P) }\end{array}$ & $\begin{array}{c}\text { Coef. } \\
\text { (Erro-P) }\end{array}$ & $\begin{array}{c}\text { Coef. } \\
\text { (Erro-P) }\end{array}$ & $\begin{array}{c}\text { Coef. } \\
\text { (Erro-P) }\end{array}$ & $\begin{array}{c}\text { Coef. } \\
\text { (Erro-P) }\end{array}$ & $\begin{array}{c}\text { Coef. } \\
\text { (Erro-P) }\end{array}$ \\
\hline & $\mathrm{Q}=0,25$ & $\mathrm{Q}=0,25$ & $\mathrm{Q}=0,50$ & $\mathrm{Q}=0,50$ & $\mathrm{Q}=0,75$ & $\mathrm{Q}=0,75$ \\
\hline TamanhoCA & $\begin{array}{l}-0,0042 \\
(0,0028)\end{array}$ & $\begin{array}{c}-0,0031 \\
(0,0028)\end{array}$ & $\begin{array}{c}0,0001 \\
(0,0018)\end{array}$ & $\begin{array}{c}0,0002 \\
(0,0021)\end{array}$ & $\begin{array}{l}-0,0014 \\
(0,0031)\end{array}$ & $\begin{array}{c}0,0012 \\
(0,0036)\end{array}$ \\
\hline$\%$ Independentes & $\begin{array}{l}-0,0143 \\
(0,0286)\end{array}$ & - & $\begin{array}{l}-0,0004 \\
(0,0182)\end{array}$ & - & $\begin{array}{c}0,0087 \\
(0,0312)\end{array}$ & - \\
\hline$\%$ Externos & - & $\begin{array}{l}-0,0148 \\
(0,0525)\end{array}$ & - & $\begin{array}{l}-0,0210 \\
(0,0397)\end{array}$ & - & $\begin{array}{l}-0,0722 \\
(0,0681)\end{array}$ \\
\hline DualidadeCEO & $\begin{array}{c}0,0038 \\
(0,0146)\end{array}$ & $\begin{array}{l}-0,0016 \\
(0,0148)\end{array}$ & $\begin{array}{c}0,0045 \\
(0,0093)\end{array}$ & $\begin{array}{c}0,0005 \\
(0,0112)\end{array}$ & $\begin{array}{c}-0,0065 \\
(0,0159)\end{array}$ & $\begin{array}{l}-0,0140 \\
(0,0191)\end{array}$ \\
\hline LogAtivos & $\begin{array}{c}0,0215^{* *} \\
(0,0103)\end{array}$ & $\begin{array}{c}0,0194 * * \\
(0,0096)\end{array}$ & $\begin{array}{c}0,0090 \\
(0,0066)\end{array}$ & $\begin{array}{c}0,0090 \\
(0,0072)\end{array}$ & $\begin{array}{c}0,0031 \\
(0,0112)\end{array}$ & $\begin{array}{c}0,0075 \\
(00124)\end{array}$ \\
\hline Endividamento & $\begin{array}{c}-0,1133 * * * \\
(0,0327)\end{array}$ & $\begin{array}{c}-0,1145^{* * * *} \\
(0,0304)\end{array}$ & $\begin{array}{c}-0,0946^{* * *} * \\
(0,0208)\end{array}$ & $\begin{array}{c}-0,1006 * * * \\
(0,0230)\end{array}$ & $\begin{array}{c}-0,1523 * * * \\
(0,0356)\end{array}$ & $\begin{array}{c}-0,1778 \text { *** } \\
(0,0394)\end{array}$ \\
\hline Estrangeiro & $\begin{array}{c}0,0333 \\
(0,0292)\end{array}$ & $\begin{array}{c}0,0389 \\
(0,0272)\end{array}$ & $\begin{array}{l}0,0331 * \\
(0,0186)\end{array}$ & $\begin{array}{c}0,0309 \\
(0,0205)\end{array}$ & $\begin{array}{c}0,0095 \\
(0,0318\end{array}$ & $\begin{array}{c}0,0085 \\
(0,0352)\end{array}$ \\
\hline Estatal & $\begin{array}{l}-0,0174 \\
(0,0275)\end{array}$ & $\begin{array}{l}-0,0169 \\
(0,0252)\end{array}$ & $\begin{array}{l}-0,0226 \\
(0,0175)\end{array}$ & $\begin{array}{l}-0,0247 \\
(0,0190)\end{array}$ & $\begin{array}{l}-0,0340 \\
(0,0299)\end{array}$ & $\begin{array}{l}-0,0428 \\
(0,0327)\end{array}$ \\
\hline Intercepto & $\begin{array}{l}-0,0571 \\
(0,0546)\end{array}$ & $\begin{array}{l}-0,0363 \\
(0,0634)\end{array}$ & $\begin{array}{c}0,0061 \\
(0,0347)\end{array}$ & $\begin{array}{c}0,0284 \\
(0,0479)\end{array}$ & $\begin{array}{c}0,1250 * * \\
(0,0594)\end{array}$ & $\begin{array}{l}0,1600^{*} \\
(0,0821)\end{array}$ \\
\hline Teste de Wald & 0,0179 & 0,0116 & 0,0007 & 0,0019 & 0,0023 & 0,0018 \\
\hline Pseudo R ${ }^{2}$ & 0,0516 & 0,0503 & 0,0632 & 0,0643 & 0,0791 & 0,0868 \\
\hline $\mathrm{N}^{\circ}$ Observações & 182 & 182 & 182 & 182 & 182 & 182 \\
\hline $\mathrm{N}^{\circ}$ Empresas & 182 & 182 & 182 & 182 & 182 & 182 \\
\hline
\end{tabular}

Fonte: Formulário de Referência e Economatica®.

Notas: Significância estatística: ***1\%,**5\% e *10\%. 
Tabela 23 - Resultado das estimações dos modelos de regressão quantílica para a variável dependente ROE. 2011

\begin{tabular}{|c|c|c|c|c|c|c|}
\hline \multirow{3}{*}{ Variáveis } & Modelo 14 & Modelo 17 & Modelo 14 & Modelo 17 & Modelo 14 & Modelo 17 \\
\hline & $\begin{array}{c}\text { Coef. } \\
\text { (Erro-P) }\end{array}$ & $\begin{array}{c}\text { Coef. } \\
\text { (Erro-P) }\end{array}$ & $\begin{array}{c}\text { Coef. } \\
\text { (Erro-P) }\end{array}$ & $\begin{array}{c}\text { Coef. } \\
\text { (Erro-P) }\end{array}$ & $\begin{array}{c}\text { Coef. } \\
\text { (Erro-P) }\end{array}$ & $\begin{array}{c}\text { Coef. } \\
\text { (Erro-P) }\end{array}$ \\
\hline & $\mathrm{Q}=0,25$ & $\mathrm{Q}=0,25$ & $Q=0,50$ & $\mathrm{Q}=0,50$ & $\mathrm{Q}=0,75$ & $Q=0,75$ \\
\hline TamanhoCA & $\begin{array}{l}-0,0047 \\
(0,0086)\end{array}$ & $\begin{array}{c}-0,0017 \\
(0,0087)\end{array}$ & $\begin{array}{l}-0,0028 \\
(0,0053)\end{array}$ & $\begin{array}{l}-0,0052 \\
(0,0058)\end{array}$ & $\begin{array}{c}0,0085 \\
(0,0090)\end{array}$ & $\begin{array}{c}0,0070 \\
(0,0093)\end{array}$ \\
\hline$\%$ Independentes & $\begin{array}{l}-0,0448 \\
(0,0876)\end{array}$ & - & $\begin{array}{l}-0,0540 \\
(0,0541)\end{array}$ & - & $\begin{array}{l}-0,0168 \\
(0,0913)\end{array}$ & - \\
\hline$\%$ Externos & - & $\begin{array}{l}-0,1122 \\
(0,1661)\end{array}$ & - & $\begin{array}{l}-0,0933 \\
(0,1108)\end{array}$ & - & $\begin{array}{l}-0,1045 \\
(0,1778)\end{array}$ \\
\hline DualidadeCEO & $\begin{array}{c}0,0101 \\
(0,0446)\end{array}$ & $\begin{array}{l}-0,0005 \\
(0,0467)\end{array}$ & $\begin{array}{l}-0,0016 \\
(0,0276)\end{array}$ & $\begin{array}{l}-0,0169 \\
(0,0311)\end{array}$ & $\begin{array}{c}0,0224 \\
(0,0465)\end{array}$ & $\begin{array}{l}-0,0077 \\
(0,0500)\end{array}$ \\
\hline LogAtivos & $\begin{array}{c}0,0492 \\
(0,0315)\end{array}$ & $\begin{array}{c}0,0435 \\
(0,0303)\end{array}$ & $\begin{array}{c}0,0289 \\
(0,0195)\end{array}$ & $\begin{array}{c}0,0160 \\
(0,0202)\end{array}$ & $\begin{array}{c}0,0096 \\
(0,0328)\end{array}$ & $\begin{array}{c}0,0106 \\
(0,0325)\end{array}$ \\
\hline Endividamento & $\begin{array}{l}-0,1180 \\
(0,1001)\end{array}$ & $\begin{array}{l}-0,0860 \\
(0,0961)\end{array}$ & $\begin{array}{c}0,0001 \\
(0,0618)\end{array}$ & $\begin{array}{c}0,0550 \\
(0,0641)\end{array}$ & $\begin{array}{c}0,1419 \\
(0,1042)\end{array}$ & $\begin{array}{c}0,1485 \\
(0,1029)\end{array}$ \\
\hline Estrangeiro & $\begin{array}{c}0,0913 \\
(0,0894)\end{array}$ & $\begin{array}{c}0,1171 \\
(0,0859)\end{array}$ & $\begin{array}{c}0,0456 \\
(0,0552)\end{array}$ & $\begin{array}{c}0,0722 \\
(0,0573)\end{array}$ & $\begin{array}{c}0,0745 \\
(0,0931)\end{array}$ & $\begin{array}{c}0,0778 \\
(0,0920)\end{array}$ \\
\hline Estatal & $\begin{array}{l}-0,0571 \\
(0,0840)\end{array}$ & $\begin{array}{l}-0,0448 \\
(0,0797)\end{array}$ & $\begin{array}{l}-0,0132 \\
(0,0519)\end{array}$ & $\begin{array}{c}0,0028 \\
(0,0532)\end{array}$ & $\begin{array}{l}-0,1266 \\
(0,0875)\end{array}$ & $\begin{array}{c}-0,1209 \\
(0,0853)\end{array}$ \\
\hline Intercepto & $\begin{array}{c}-0,1682 \\
(0,1671)\end{array}$ & $\begin{array}{l}-0,0733 \\
(0,2004)\end{array}$ & $\begin{array}{l}-0,0356 \\
(0,1032)\end{array}$ & $\begin{array}{c}0,1092 \\
(0,1337)\end{array}$ & $\begin{array}{c}0,0387 \\
(0,1741)\end{array}$ & $\begin{array}{c}0,1334 \\
(0,2145)\end{array}$ \\
\hline Teste de Wald & 0,6935 & 0,6755 & 0,7464 & 0,6240 & 0,4398 & 0,4137 \\
\hline Pseudo $\mathrm{R}^{2}$ & 0,0213 & 0,0227 & 0,0183 & 0,0184 & 0,0273 & 0,0285 \\
\hline $\mathrm{N}^{\circ}$ Observações & 182 & 182 & 182 & 182 & 182 & 182 \\
\hline $\mathrm{N}^{\mathrm{o}}$ Empresas & 182 & 182 & 182 & 182 & 182 & 182 \\
\hline
\end{tabular}

Fonte: Formulário de Referência e Economatica®.

Notas: Significância estatística: ***1\%,**5\% e *10\%.

Tabela 24 - Resultado das estimações dos modelos de regressão quantílica para a variável dependente ROE ajustado. 2011

\begin{tabular}{|c|c|c|c|c|c|c|}
\hline \multirow{3}{*}{ Variáveis } & Modelo 20 & Modelo 23 & Modelo 20 & Modelo 23 & Modelo 20 & Modelo 23 \\
\hline & $\begin{array}{c}\text { Coef. } \\
\text { (Erro-P) }\end{array}$ & $\begin{array}{c}\text { Coef. } \\
\text { (Erro-P) }\end{array}$ & $\begin{array}{c}\text { Coef. } \\
\text { (Erro-P) }\end{array}$ & $\begin{array}{c}\text { Coef. } \\
\text { (Erro-P) }\end{array}$ & $\begin{array}{c}\text { Coef. } \\
\text { (Erro-P) }\end{array}$ & $\begin{array}{c}\text { Coef. } \\
\text { (Erro-P) }\end{array}$ \\
\hline & $\mathrm{Q}=0,25$ & $\mathrm{Q}=0,25$ & $\mathrm{Q}=0,50$ & $\mathrm{Q}=0,50$ & $\mathrm{Q}=0,75$ & $\mathrm{Q}=0,75$ \\
\hline TamanhoCA & $\begin{array}{l}-0,0076 \\
(0,0082)\end{array}$ & $\begin{array}{l}-0,0067 \\
(0,0095)\end{array}$ & $\begin{array}{l}-0,0022 \\
(0,0050)\end{array}$ & $\begin{array}{l}-0,0014 \\
(0,0051)\end{array}$ & $\begin{array}{l}-0,0052 \\
(0,0074)\end{array}$ & $\begin{array}{l}-0,0002 \\
(0,0086)\end{array}$ \\
\hline$\%$ Independentes & $\begin{array}{l}-0,0826 \\
(0,0831)\end{array}$ & - & $\begin{array}{l}-0,0337 \\
(0,0511)\end{array}$ & - & $\begin{array}{l}-0,0153 \\
(0,0747)\end{array}$ & - \\
\hline$\%$ Externos & - & $\begin{array}{l}-0,0047 \\
(0,1812)\end{array}$ & - & $\begin{array}{l}-0,0346 \\
(0,0970)\end{array}$ & - & $\begin{array}{l}-0,1986 \\
(0,1636)\end{array}$ \\
\hline DualidadeCEO & $\begin{array}{l}-0,0351 \\
(0,0424)\end{array}$ & $\begin{array}{l}-0,0353 \\
(0,0509)\end{array}$ & $\begin{array}{l}-0,0200 \\
(0,0261)\end{array}$ & $\begin{array}{l}-0,0225 \\
(0,0273)\end{array}$ & $\begin{array}{c}0,0119 \\
(0,0381)\end{array}$ & $\begin{array}{l}-0,0197 \\
(0,0460)\end{array}$ \\
\hline LogAtivos & $\begin{array}{c}0,0348 \\
(0,0299)\end{array}$ & $\begin{array}{c}0,0370 \\
(0,0331)\end{array}$ & $\begin{array}{c}0,0399 * * \\
(0,0184)\end{array}$ & $\begin{array}{c}0,0390 * * \\
(0,0177)\end{array}$ & $\begin{array}{c}0,0386 \\
(0,0269)\end{array}$ & $\begin{array}{c}0,0255 \\
(0,0299)\end{array}$ \\
\hline Endividamento & $\begin{array}{l}-0,0666 \\
(0,0949)\end{array}$ & $\begin{array}{l}-0,1138 \\
(0,1048)\end{array}$ & $\begin{array}{l}-0,0116 \\
(0,0584)\end{array}$ & $\begin{array}{l}-0,0140 \\
(0,0561)\end{array}$ & $\begin{array}{c}0,1740 * * \\
(0,0853)\end{array}$ & $\begin{array}{c}0,1303 \\
(0,0947)\end{array}$ \\
\hline Estrangeiro & $\begin{array}{c}0,0090 \\
(0,0848)\end{array}$ & $\begin{array}{c}0,0101 \\
(0,0937)\end{array}$ & $\begin{array}{c}0,0311 \\
(0,0522)\end{array}$ & $\begin{array}{c}0,0467 \\
(0,0502)\end{array}$ & $\begin{array}{c}0,0516 \\
(0,0762)\end{array}$ & $\begin{array}{c}0,0323 \\
(0,0846)\end{array}$ \\
\hline Estatal & $\begin{array}{l}-0,0140 \\
(0,0797)\end{array}$ & $\begin{array}{c}0,0063 \\
(0,0869)\end{array}$ & $\begin{array}{l}-0,0238 \\
(0,0490)\end{array}$ & $\begin{array}{l}-0,0243 \\
(0,0466)\end{array}$ & $\begin{array}{l}-0,0707 \\
(0,0716)\end{array}$ & $\begin{array}{l}-0,0762 \\
(0,0785)\end{array}$ \\
\hline Intercepto & $\begin{array}{c}-0,1778 \\
(0,1586)\end{array}$ & $\begin{array}{l}-0,1837 \\
(0,2186)\end{array}$ & $\begin{array}{c}-0,2195^{* *} * \\
(0,0975)\end{array}$ & $\begin{array}{c}-0,1949^{*} \\
(0,1170)\end{array}$ & $\begin{array}{c}-0,2088 \\
(0,1424)\end{array}$ & $\begin{array}{c}0,0354 \\
(0,1974)\end{array}$ \\
\hline $\begin{array}{l}\text { Teste de Wald } \\
\text { Pseudo } R^{2}\end{array}$ & $\begin{array}{l}0,8244 \\
0,0332\end{array}$ & $\begin{array}{l}0,9383 \\
0,0247\end{array}$ & $\begin{array}{l}0,3635 \\
0,0167\end{array}$ & $\begin{array}{l}0,3106 \\
0,0158\end{array}$ & $\begin{array}{l}0,1458 \\
0.0364\end{array}$ & $\begin{array}{l}0,4473 \\
0,0437\end{array}$ \\
\hline $\mathrm{N}^{\mathrm{o}}$ Observações & 182 & 182 & 182 & 182 & 182 & 182 \\
\hline $\mathrm{N}^{\circ}$ Empresas & 182 & 182 & 182 & 182 & 182 & 182 \\
\hline
\end{tabular}

Fonte: Formulário de Referência e Economatica®.

Notas: Significância estatística: ***1\%,**5\% e *10\%. 
Tabela 25 - Resultado das estimações dos modelos de regressão quantílica para a variável dependente ROA. 2010

\begin{tabular}{|c|c|c|c|c|c|c|}
\hline & Modelo 2 & Modelo 5 & Modelo 2 & Modelo 5 & Modelo 2 & Modelo 5 \\
\hline Variáveis & $\begin{array}{c}\text { Coef. } \\
\text { (Erro-P) }\end{array}$ & $\begin{array}{c}\text { Coef. } \\
\text { (Erro-P) }\end{array}$ & $\begin{array}{c}\text { Coef. } \\
\text { (Erro-P) }\end{array}$ & $\begin{array}{c}\text { Coef. } \\
\text { (Erro-P) }\end{array}$ & $\begin{array}{c}\text { Coef. } \\
\text { (Erro-P) }\end{array}$ & $\begin{array}{c}\text { Coef. } \\
\text { (Erro-P) }\end{array}$ \\
\hline & $\mathrm{Q}=0,25$ & $\mathrm{Q}=0,25$ & $\mathrm{Q}=0,50$ & $\mathrm{Q}=0,50$ & $\mathrm{Q}=0,75$ & $\mathrm{Q}=0,75$ \\
\hline TamanhoCA & $\begin{array}{l}-0,0002 \\
(0,0020)\end{array}$ & $\begin{array}{l}-0,0012 \\
(0,0021)\end{array}$ & $\begin{array}{c}0,0023 \\
(0,0025)\end{array}$ & $\begin{array}{c}0,0011 \\
(0,0028)\end{array}$ & $\begin{array}{c}0,0014 \\
(0,0034)\end{array}$ & $\begin{array}{c}0,0028 \\
(0,0038)\end{array}$ \\
\hline$\%$ Independentes & $\begin{array}{c}0,0350 \\
(0,0213)\end{array}$ & - & $\begin{array}{c}0,0272 \\
(0,0268)\end{array}$ & - & $\begin{array}{c}0,0063 \\
(0,0356)\end{array}$ & - \\
\hline$\%$ Externos & - & $\begin{array}{c}0,0487 \\
(0,0402)\end{array}$ & - & $\begin{array}{c}0,0255 \\
(0,0524)\end{array}$ & - & $\begin{array}{l}-0,0865 \\
(0,0726)\end{array}$ \\
\hline DualidadeCEO & $\begin{array}{c}0,0043 \\
(0,0099)\end{array}$ & $\begin{array}{c}0,0029 \\
(0,0111)\end{array}$ & $\begin{array}{c}0,0058 \\
(0,0125)\end{array}$ & $\begin{array}{c}0,0031 \\
(0,0145)\end{array}$ & $\begin{array}{l}-0,0016 \\
(0,0166)\end{array}$ & $\begin{array}{l}-0,0148 \\
(0,0201)\end{array}$ \\
\hline LogAtivos & $\begin{array}{c}0,0053 \\
(0,0073)\end{array}$ & $\begin{array}{c}0,0037 \\
(0,0073)\end{array}$ & $\begin{array}{c}0,0047 \\
(0,0092)\end{array}$ & $\begin{array}{c}0,0007 \\
(0,0095)\end{array}$ & $\begin{array}{l}-0,0052 \\
(0,0122)\end{array}$ & $\begin{array}{l}-0,0065 \\
(0,0131)\end{array}$ \\
\hline Endividamento & $\begin{array}{c}-0,0575^{* *} \\
(0,0239)\end{array}$ & $\begin{array}{c}-0,0450^{*} \\
(0,0240)\end{array}$ & $\begin{array}{c}-0,0867 * * * \\
(0,0302)\end{array}$ & $\begin{array}{c}-0,0954 * * * \\
(0,0314)\end{array}$ & $\begin{array}{c}-0,1300 * * * \\
(0,0400)\end{array}$ & $\begin{array}{c}-0,1516^{* * * *} \\
(0,0434)\end{array}$ \\
\hline Estrangeiro & $\begin{array}{c}0,0460 * * \\
(0,0210)\end{array}$ & $\begin{array}{c}0,0519 * * \\
(0,0207)\end{array}$ & $\begin{array}{c}0,0239 \\
(0,0265)\end{array}$ & $\begin{array}{c}0,0153 \\
(0,0270)\end{array}$ & $\begin{array}{c}0,0553 \\
(0,0352)\end{array}$ & $\begin{array}{c}0,0691 \\
(0,0375)\end{array}$ \\
\hline Estatal & $\begin{array}{l}-0,0106 \\
(0,0195)\end{array}$ & $\begin{array}{l}-0,0147 \\
(0,0191)\end{array}$ & $\begin{array}{l}-0,0107 \\
(0,0246)\end{array}$ & $\begin{array}{l}-0,0089 \\
(0,0249)\end{array}$ & $\begin{array}{l}-0,0233 \\
(0,0327)\end{array}$ & $\begin{array}{l}-0,0329 \\
(0,0346)\end{array}$ \\
\hline Intercepto & $\begin{array}{c}0,0215 \\
(0,0389)\end{array}$ & $\begin{array}{l}-0,0049 \\
(0,0476)\end{array}$ & $\begin{array}{c}0,0537 \\
(0,0490)\end{array}$ & $\begin{array}{c}0,0779 \\
(0,0621)\end{array}$ & $\begin{array}{c}0,1909 * * * \\
(0,0651)\end{array}$ & $\begin{array}{c}0,2815^{* * * *} \\
(0,0860)\end{array}$ \\
\hline Teste de Wald & 0,0395 & 0,0541 & 0,0904 & 0,0894 & 0,0170 & 0,0037 \\
\hline Pseudo $\mathrm{R}^{2}$ & 0,0410 & 0,0350 & 0,0369 & 0,0335 & 0,0593 & 0,0633 \\
\hline $\mathrm{N}^{\circ}$ Observações & 182 & 182 & 182 & 182 & 182 & 182 \\
\hline $\mathrm{N}^{\mathrm{o}}$ Empresas & 182 & 182 & 182 & 182 & 182 & 182 \\
\hline
\end{tabular}

Fonte: Formulário de Referência e Economatica ${ }^{\circledR}$.

Notas: Significância estatística: ***1\%,**5\% e *10\%.

Tabela 26 - Resultado das estimações dos modelos de regressão quantílica para a variável dependente ROA ajustado. 2010

\begin{tabular}{|c|c|c|c|c|c|c|}
\hline & Modelo 8 & Modelo 11 & Modelo 8 & Modelo 11 & Modelo 8 & Modelo 11 \\
\hline Variáveis & $\begin{array}{c}\text { Coef. } \\
\text { (Erro-P) }\end{array}$ & $\begin{array}{c}\text { Coef. } \\
\text { (Erro-P) }\end{array}$ & $\begin{array}{c}\text { Coef. } \\
\text { (Erro-P) }\end{array}$ & $\begin{array}{c}\text { Coef. } \\
\text { (Erro-P) }\end{array}$ & $\begin{array}{c}\text { Coef. } \\
\text { (Erro-P) }\end{array}$ & $\begin{array}{c}\text { Coef. } \\
\text { (Erro-P) }\end{array}$ \\
\hline & $\mathrm{Q}=0,25$ & $\mathrm{Q}=0,25$ & $\mathrm{Q}=0,50$ & $\mathrm{Q}=0,50$ & $\mathrm{Q}=0,75$ & $\mathrm{Q}=0,75$ \\
\hline TamanhoCA & $\begin{array}{l}-0,0004 \\
(0,0021)\end{array}$ & $\begin{array}{l}-0,0007 \\
(0,0024)\end{array}$ & $\begin{array}{l}-0,0017 \\
(0,0019)\end{array}$ & $\begin{array}{l}-0,0022 \\
(0,0021)\end{array}$ & $\begin{array}{l}<0,0001 \\
(0,0033)\end{array}$ & $\begin{array}{c}0,0030 \\
(0,0040)\end{array}$ \\
\hline$\%$ Independentes & $\begin{array}{c}0,0245 \\
(0,0226)\end{array}$ & - & $\begin{array}{c}0,0189 \\
(0,0204)\end{array}$ & - & $\begin{array}{l}0,0599 * \\
(0,0351)\end{array}$ & - \\
\hline$\%$ Externos & - & $\begin{array}{c}0,0029 \\
(0,0452)\end{array}$ & - & $\begin{array}{c}0,0335 \\
(0,0393)\end{array}$ & - & $\begin{array}{l}-0,0213 \\
(0,0766)\end{array}$ \\
\hline DualidadeCEO & $\begin{array}{c}0,0109 \\
(0,0106)\end{array}$ & $\begin{array}{c}0,0151 \\
(0,0125)\end{array}$ & $\begin{array}{l}-0,0060 \\
(0,0095)\end{array}$ & $\begin{array}{c}0,0019 \\
(0,0109)\end{array}$ & $\begin{array}{l}<0,0001 \\
(0,0164)\end{array}$ & $\begin{array}{l}-0,0058 \\
(0,0212)\end{array}$ \\
\hline LogAtivos & $\begin{array}{c}0,0161^{* * *} \\
(0,0078)\end{array}$ & $\begin{array}{c}0,0185^{* * *} \\
(0,0082)\end{array}$ & $\begin{array}{c}0,0068 \\
(0,0070)\end{array}$ & $\begin{array}{l}0,0126^{*} \\
(0,0071)\end{array}$ & $\begin{array}{c}0,0043 \\
(0,0121)\end{array}$ & $\begin{array}{c}0,0042 \\
(0,0138)\end{array}$ \\
\hline Endividamento & $\begin{array}{c}-0,0752 * * * \\
(0,0254)\end{array}$ & $\begin{array}{c}-0,0808 * * * \\
(0,0271)\end{array}$ & $\begin{array}{c}-0,1004 * * * \\
(0,0230)\end{array}$ & $\begin{array}{c}-0,1224 * * * \\
(0,0235)\end{array}$ & $\begin{array}{c}-0,1435 * * * \\
(0,0395)\end{array}$ & $\begin{array}{c}-0,1321 * * * \\
(0,0458)\end{array}$ \\
\hline Estrangeiro & $\begin{array}{c}0,0346 \\
(0,0223)\end{array}$ & $\begin{array}{l}0,0400^{*} \\
(0,0233)\end{array}$ & $\begin{array}{c}0,0131 \\
(0,0202)\end{array}$ & $\begin{array}{c}0,0219 \\
(0,0203)\end{array}$ & $\begin{array}{c}0,0467 \\
(0,0347)\end{array}$ & $\begin{array}{c}0,0510 \\
(0,0395)\end{array}$ \\
\hline Estatal & $\begin{array}{l}-0,0313 \\
(0,0208)\end{array}$ & $\begin{array}{c}-0,0364^{*} \\
(0,0215)\end{array}$ & $\begin{array}{l}-0,0152 \\
(0,0187)\end{array}$ & $\begin{array}{l}-0,0245 \\
(0,0187)\end{array}$ & $\begin{array}{l}-0,0383 \\
(0,0322)\end{array}$ & $\begin{array}{l}-0,0512 \\
(0,0364)\end{array}$ \\
\hline Intercepto & $\begin{array}{c}-0,0781 * \\
(0,0414)\end{array}$ & $\begin{array}{l}-0,0892 \\
(0,0536)\end{array}$ & $\begin{array}{c}0,0382 \\
(0,0373)\end{array}$ & $\begin{array}{l}-0,0108 \\
(0,0465)\end{array}$ & $\begin{array}{c}0,0936 \\
(0,0642)\end{array}$ & $\begin{array}{c}0,0952 \\
(0,0907)\end{array}$ \\
\hline $\begin{array}{l}\text { Teste de Wald } \\
\text { Pseudo } R^{2}\end{array}$ & $\begin{array}{l}0,0202 \\
0,0495\end{array}$ & $\begin{array}{l}0,0166 \\
0,0428\end{array}$ & $\begin{array}{l}0,0022 \\
0,0577\end{array}$ & $\begin{array}{l}0,0000 \\
0,0569\end{array}$ & $\begin{array}{l}0,0034 \\
0,0677\end{array}$ & $\begin{array}{l}0,0696 \\
0,0637\end{array}$ \\
\hline $\mathrm{N}^{\mathrm{o}}$ Observações & 182 & 182 & 182 & 182 & 182 & 182 \\
\hline $\mathrm{N}^{\circ}$ Empresas & 182 & 182 & 182 & 182 & 182 & 182 \\
\hline
\end{tabular}

Fonte: Formulário de Referência e Economatica ${ }^{\circledR}$.

Notas: Significância estatística: ***1\%,**5\% e *10\%. 
Tabela 27 - Resultado das estimações dos modelos de regressão quantílica para a variável dependente ROE. 2010

\begin{tabular}{|c|c|c|c|c|c|c|}
\hline \multirow{3}{*}{ Variáveis } & Modelo 14 & Modelo 17 & Modelo 14 & Modelo 17 & Modelo 14 & Modelo 17 \\
\hline & $\begin{array}{c}\text { Coef. } \\
\text { (Erro-P) }\end{array}$ & $\begin{array}{c}\text { Coef. } \\
\text { (Erro-P) }\end{array}$ & $\begin{array}{c}\text { Coef. } \\
\text { (Erro-P) }\end{array}$ & $\begin{array}{c}\text { Coef. } \\
\text { (Erro-P) }\end{array}$ & $\begin{array}{c}\text { Coef. } \\
\text { (Erro-P) }\end{array}$ & $\begin{array}{c}\text { Coef. } \\
\text { (Erro-P) }\end{array}$ \\
\hline & $\mathrm{Q}=0,25$ & $\mathrm{Q}=0,25$ & $Q=0,50$ & $\mathrm{Q}=0,50$ & $\mathrm{Q}=0,75$ & $Q=0,75$ \\
\hline TamanhoCA & $\begin{array}{l}-0,0006 \\
(0,0060)\end{array}$ & $\begin{array}{l}-0,0010 \\
(0,0063)\end{array}$ & $\begin{array}{l}<0,0001 \\
(0,0064)\end{array}$ & $\begin{array}{l}-0,0020 \\
(0,0080)\end{array}$ & $\begin{array}{l}-0,0023 \\
(0,0138)\end{array}$ & $\begin{array}{c}0,0081 \\
(0,0158)\end{array}$ \\
\hline$\%$ Independentes & $\begin{array}{c}0,0864 \\
(0,0636)\end{array}$ & - & $\begin{array}{c}0,0732 \\
(0,0673)\end{array}$ & - & $\begin{array}{c}0,0021 \\
(0,1461)\end{array}$ & - \\
\hline$\%$ Externos & - & $\begin{array}{c}0,0338 \\
(0,1193)\end{array}$ & - & $\begin{array}{c}0,0408 \\
(0,1531)\end{array}$ & - & $\begin{array}{c}-0,5162^{*} \\
(0,3010)\end{array}$ \\
\hline DualidadeCEO & $\begin{array}{c}0,0111 \\
(0,0297)\end{array}$ & $\begin{array}{c}0,0067 \\
(0,0330)\end{array}$ & $\begin{array}{c}0,0511 \\
(0,0314)\end{array}$ & $\begin{array}{c}0,0424 \\
(0,0423)\end{array}$ & $\begin{array}{c}0,0515 \\
(0,0682)\end{array}$ & $\begin{array}{l}-0,0376 \\
(0,0832)\end{array}$ \\
\hline LogAtivos & $\begin{array}{c}0,0061 \\
(0,0219)\end{array}$ & $\begin{array}{c}0,0107 \\
(0,0216)\end{array}$ & $\begin{array}{c}0,0263 \\
(0,0232)\end{array}$ & $\begin{array}{c}0,0119 \\
(0,0277)\end{array}$ & $\begin{array}{l}-0,0342 \\
(0,0503)\end{array}$ & $\begin{array}{c}-0,0474 \\
(0,544)\end{array}$ \\
\hline Endividamento & $\begin{array}{c}0,0052 \\
(0,0716)\end{array}$ & $\begin{array}{l}-0,0117 \\
(0,0714)\end{array}$ & $\begin{array}{l}-0,0259 \\
(0,0757)\end{array}$ & $\begin{array}{l}-0,0075 \\
(0,0915)\end{array}$ & $\begin{array}{c}0,3466^{* *} * \\
(0,1644)\end{array}$ & $\begin{array}{c}0,2665 \\
(0,1800)\end{array}$ \\
\hline Estrangeiro & $\begin{array}{c}0,0868 \\
(0,0629)\end{array}$ & $\begin{array}{c}0,0919 \\
(0,0615)\end{array}$ & $\begin{array}{c}0,1971 * * * \\
(0,0665)\end{array}$ & $\begin{array}{c}0,1772 * * \\
(0,0790)\end{array}$ & $\begin{array}{c}0,2216 \\
(0,1443)\end{array}$ & $\begin{array}{c}0,2567 \\
(0,1552)\end{array}$ \\
\hline Estatal & $\begin{array}{l}-0,0429 \\
(0,0584)\end{array}$ & $\begin{array}{l}-0,0487 \\
(0,0568)\end{array}$ & $\begin{array}{l}-0,0244 \\
(0,0618)\end{array}$ & $\begin{array}{l}-0,0121 \\
(0,0729)\end{array}$ & $\begin{array}{l}-0,0482 \\
(0,1340)\end{array}$ & $\begin{array}{l}-0,0819 \\
(0,1432)\end{array}$ \\
\hline Intercepto & $\begin{array}{c}0,0238 \\
(0,1164)\end{array}$ & $\begin{array}{l}-0,0100 \\
(0,1413)\end{array}$ & $\begin{array}{l}-0,0024 \\
(0,1231)\end{array}$ & $\begin{array}{c}0,0673 \\
(0,1812)\end{array}$ & $\begin{array}{c}0,3316 \\
(0,2671)\end{array}$ & $\begin{array}{c}0,8602 * * \\
(0,3564)\end{array}$ \\
\hline Teste de Wald & 0,6676 & 0,8392 & 0,0616 & 0,5230 & 0,3567 & 0,1789 \\
\hline Pseudo $\mathrm{R}^{2}$ & 0,0116 & 0,0079 & 0,0132 & 0,0112 & 0,0216 & 0,0263 \\
\hline $\mathrm{N}^{\circ}$ Observações & 182 & 182 & 182 & 182 & 182 & 182 \\
\hline $\mathrm{N}^{\mathrm{o}}$ Empresas & 182 & 182 & 182 & 182 & 182 & 182 \\
\hline
\end{tabular}

Fonte: Formulário de Referência e Economatica®.

Notas: Significância estatística: $* * * 1 \%, * * 5 \%$ e $* 10 \%$.

Tabela 28 - Resultado das estimações dos modelos de regressão quantílica para a variável dependente ROE ajustado. 2010

\begin{tabular}{|c|c|c|c|c|c|c|}
\hline & Modelo 20 & Modelo 23 & Modelo 20 & Modelo 23 & Modelo 20 & Modelo 23 \\
\hline Variáveis & $\begin{array}{c}\text { Coef. } \\
\text { (Erro-P) }\end{array}$ & $\begin{array}{c}\text { Coef. } \\
\text { (Erro-P) }\end{array}$ & $\begin{array}{c}\text { Coef. } \\
\text { (Erro-P) }\end{array}$ & $\begin{array}{c}\text { Coef. } \\
\text { (Erro-P) }\end{array}$ & $\begin{array}{c}\text { Coef. } \\
\text { (Erro-P) }\end{array}$ & $\begin{array}{c}\text { Coef. } \\
\text { (Erro-P) }\end{array}$ \\
\hline & $\mathrm{Q}=0,25$ & $\mathrm{Q}=0,25$ & $Q=0,50$ & $\mathrm{Q}=0,50$ & $\mathrm{Q}=0,75$ & $\mathrm{Q}=0,75$ \\
\hline TamanhoCA & $\begin{array}{l}-0,0069 \\
(0,0066)\end{array}$ & $\begin{array}{l}-0,0068 \\
(0,0075)\end{array}$ & $\begin{array}{l}-0,0061 \\
(0,0060)\end{array}$ & $\begin{array}{l}-0,0059 \\
(0,0061)\end{array}$ & $\begin{array}{c}0,0038 \\
(0,0154)\end{array}$ & $\begin{array}{c}0,0063 \\
(0,0162)\end{array}$ \\
\hline$\%$ Independentes & $\begin{array}{c}0,0047 \\
(0,0701)\end{array}$ & - & $\begin{array}{c}0,0347 \\
(0,0630)\end{array}$ & - & $\begin{array}{c}0,0817 \\
(0,1627)\end{array}$ & - \\
\hline$\%$ Externos & - & $\begin{array}{l}-0,0235 \\
(0,1438)\end{array}$ & - & $\begin{array}{l}-0,0550 \\
(0,1169)\end{array}$ & - & $\begin{array}{l}-0,2223 \\
(0,3095)\end{array}$ \\
\hline DualidadeCEO & $\begin{array}{c}0,0171 \\
(0,0327)\end{array}$ & $\begin{array}{c}0,0156 \\
(0,0397)\end{array}$ & $\begin{array}{l}-0,0080 \\
(0,0294)\end{array}$ & $\begin{array}{l}-0,0209 \\
(0,0323)\end{array}$ & $\begin{array}{c}0,0484 \\
(0,0760)\end{array}$ & $\begin{array}{c}0,0140 \\
(0,0856)\end{array}$ \\
\hline LogAtivos & $\begin{array}{c}0,0512 * * \\
(0,0241)\end{array}$ & $\begin{array}{l}0,0506^{*} \\
(0,0260)\end{array}$ & $\begin{array}{c}0,0107 \\
(0,0217)\end{array}$ & $\begin{array}{c}0,0102 \\
(0,0211)\end{array}$ & $\begin{array}{l}-0,0063 \\
(0,0560)\end{array}$ & $\begin{array}{l}-0,0115 \\
(0,0559)\end{array}$ \\
\hline Endividamento & $\begin{array}{l}-0,0419 \\
(0,0788)\end{array}$ & $\begin{array}{l}-0,0424 \\
(0,0860)\end{array}$ & $\begin{array}{l}-0,0229 \\
(0,0709)\end{array}$ & $\begin{array}{l}-0,0414 \\
(0,0699)\end{array}$ & $\begin{array}{c}0,2216 \\
(0,1831)\end{array}$ & $\begin{array}{c}0,2387 \\
(0,1851)\end{array}$ \\
\hline Estrangeiro & $\begin{array}{c}0,0605 \\
(0,0692)\end{array}$ & $\begin{array}{c}0,0635 \\
(0,0742)\end{array}$ & $\begin{array}{c}0,1854 * * * \\
(0,0623)\end{array}$ & $\begin{array}{c}0,1745^{* * *} \\
(0,0603)\end{array}$ & $\begin{array}{c}0,2517 \\
(0,1608)\end{array}$ & $\begin{array}{l}0,2655^{*} \\
(0,1596)\end{array}$ \\
\hline Estatal & $\begin{array}{l}-0,0480 \\
(0,0643)\end{array}$ & $\begin{array}{l}-0,0494 \\
(0,0684)\end{array}$ & $\begin{array}{l}-0,0314 \\
(0,0578)\end{array}$ & $\begin{array}{l}-0,0410 \\
(0,0556)\end{array}$ & $\begin{array}{l}-0,0721 \\
(0,1493)\end{array}$ & $\begin{array}{l}-0,0903 \\
(0,1473)\end{array}$ \\
\hline Intercepto & $\begin{array}{c}-0,3190 * * \\
(0,1281)\end{array}$ & $\begin{array}{c}-0,2931 * \\
(0,1702)\end{array}$ & $\begin{array}{c}0,0024 \\
(0,1153)\end{array}$ & $\begin{array}{c}0,0705 \\
(0,1384)\end{array}$ & $\begin{array}{c}0,0034 \\
(0,2976)\end{array}$ & $\begin{array}{c}0,2346 \\
(0,3665)\end{array}$ \\
\hline $\begin{array}{l}\text { Teste de Wald } \\
\text { Pseudo R }\end{array}$ & $\begin{array}{l}0,5326 \\
0,0125\end{array}$ & $\begin{array}{l}0,6179 \\
0,0126\end{array}$ & $\begin{array}{l}0,1197 \\
0,0073\end{array}$ & $\begin{array}{l}0,0975 \\
0,0065\end{array}$ & $\begin{array}{l}0,6870 \\
0,0273\end{array}$ & $\begin{array}{l}0,5480 \\
0,0285\end{array}$ \\
\hline $\begin{array}{l}\mathrm{N}^{\circ} \text { Observações } \\
\mathrm{N}^{\mathrm{o}} \text { Empresas }\end{array}$ & $\begin{array}{l}182 \\
182\end{array}$ & $\begin{array}{l}182 \\
182\end{array}$ & $\begin{array}{l}182 \\
182\end{array}$ & $\begin{array}{l}182 \\
182\end{array}$ & $\begin{array}{l}182 \\
182\end{array}$ & $\begin{array}{l}182 \\
182\end{array}$ \\
\hline
\end{tabular}

Fonte: Formulário de Referência e Economatica®.

Notas: Significância estatística: $* * * 1 \%, * * 5 \%$ e *10\%. 